\title{
GESTEINSKLÜFTE UND RUNDHÖCKER
}

\author{
UNTERSUCHUNGEN IM AARE- UND GOTTHARDMASSIV
}

OSKAR Bär

\section{A. Überblick und Problemstellung}

\section{EINLEITUNG}

Während verschiedener Exkursionen des Geographischen Instituts unserer Universität, sei es in die Alpen oder in den Schwarzwald, wurden zerklüftete Felswände oder zersplitterte Rundhöcker oft Objekte der Beobachtung, und sie lenkten die Blicke aufwärts zu ähnlich geformten Gipfeln, Gräten und Gendarmen.

Die vorliegende Arbeit greift aus der Fülle solcher Erscheinungen nur eine Kleinform heraus. Sie untersucht mit eigens zu diesem $Z_{w}$ ecke geschaffenen Methoden ein fast klassisches Objekt morphologischer Spekulation, den Rundhöcker. Die Untersuchung trägt den Charakter einer ausgesprochenen Detailstudie im Rahmen der kluftbedingten Morphologie.

\section{ORIENTIERUNG}

Wir bewegen uns mit dieser Arbeit, besonders im Abschnitt über die Klüfte, auf einem Gebiet der Geomorphologie, das selbst dem Geographen etwas ungewohnt ist. Ich werde deshalb in den folgenden Zeilen die wichtigsten Begriffe und Theorien kurz erläutern und gleichzeitig auf bestehende Arbeiten und schon entwickelte Arbeitsmethoden hinweisen.

\section{Die Klïfte}

Choos (13) definiert die Klüfte wie folgt:

«Als Klüftung bezeichnen wir jede Art von Fugenbildung, soweit sich an der Fuge keine meßbare Verschiebung vollzog. Meßbare Verschiebung macht die Kluft zur Verschiebungsfläche, meßbares Auseinanderweichen der Wände macht sie zum Spalt.»

Er fügt noch bei:

«Doch ist die Grenze nicht scharf. Flächen mit sehr kleinen Bewegungen wird man noch zu den Klüften rechnen dürfen.»

Unter den andern, in den Lehrbüchern für die Klüfte angegebenen Definitionen [vgl. z. B. Cadisch (9), Billings (4), Stiny (50)] ist vor allem die letztere von STINy interessant, da sie die allgemeinste Auffassung von der Kluft zum Ausdruck bringt. Stiny (50) definiert die Klüfte als:

Abb. 1: Längs einer Kluftschar zerfallener Rundhöcker W Grimselpaß. Die schrägliegenden Steinplatten standen ursprünglich mehr rechts, außerhalb des Bildausschnittes. Als Größenvergleich mag der Rucksack (hinten links) dienen.

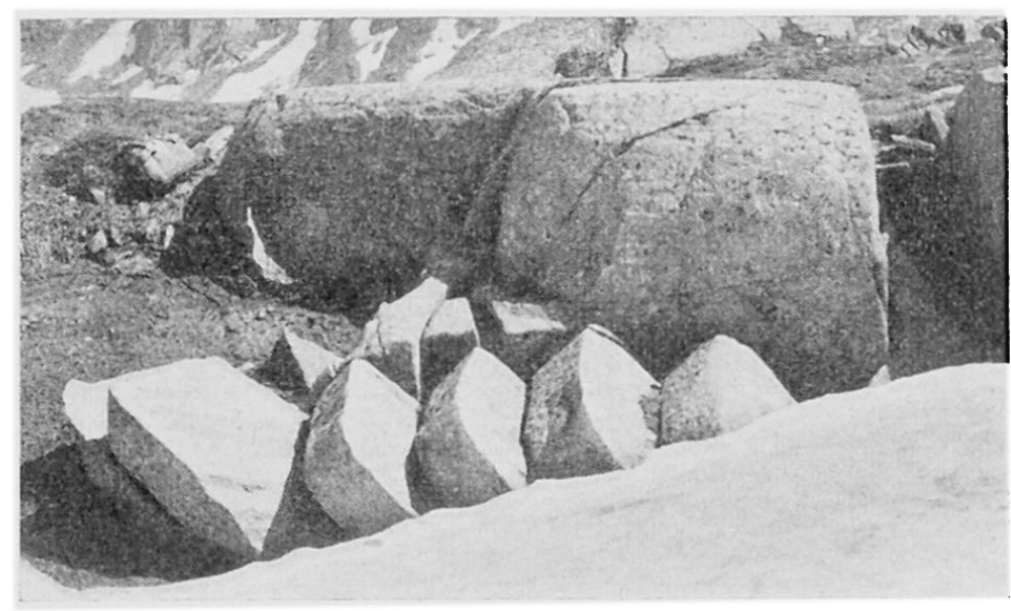




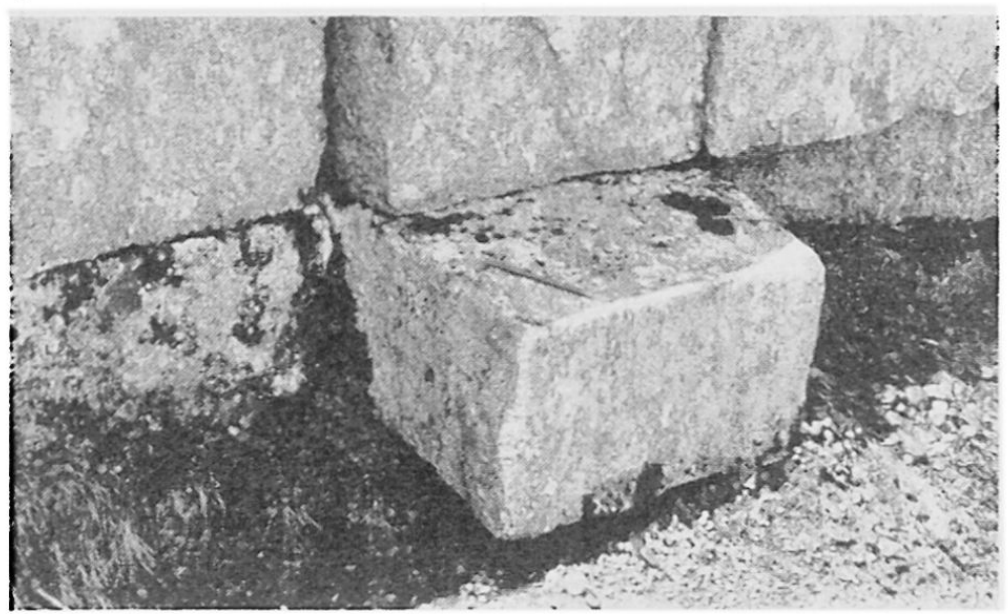

$A b b .2$ : Drei annähernd orthogonal stehende Klüfte begrenzen einen Gesteinsquader.

Größenvergleich: Bleistift vorn links. Aufnahme W Grimselpaß.

«alle (klaffenden oder nicht klaffenden, verheilten oder nicht verheilten, weit durchgreifenden oder nur klein angelegten) wie immer auch entstandenen Trennflächen im Gestein.»

Für meine Arbeit darf ich wohl diese Definition in ihrer weitesten Fassung verwenden, da ich nicht auf die Deutung der Kluftentstehung hinziele und zudem kein tektonisches Problem zur Diskussion steht ${ }^{1}$.

Klüfte treten meist scharenweise auf, so daß man von Kluftscharen oder Kluftsystemen (vgl. Abb. 1) reden kann. Klüfte des gleichen Systems verlaufen annähernd parallel und zeigen auch durchwegs gleiche Ausbildung der Flächen.

Meistens werden 2 steile Hauptsysteme und mehrere diffuse Nebensysteme gemessen. Die Hauptsysteme stehen in der Regel annähernd senkrecht und werden von einem flachen dritten System geschnitten (vgl. Abb. 2).

Während sich die genetische Deutung ${ }^{2}$ der steilen Klüfte allgemein auf tektonische Erklärungen stützt, gehen die Ansichten über die Entstehung der flachen Systeme weit auseinander ${ }^{3}$. Groß ist deshalb die Zahl der Namen und Einteilungsversuche, denen die Klüfte unterzogen wurden. Dies liegt daran, daß vielfach nicht zwischen erklärender und beschreibender Bezeichnungsweise unterschieden wurde ${ }^{4}$.

Für die vorliegende Arbeit, die wohl eines Bezeichnungssystems, nicht aber einer genetischen Deutung bedarf, erscheint mir die in kristallinen Massiven aufgestellte Einteilung nach CLoos (13) am zweckmäßigsten. In seiner Schule (Arbeiten in Granittektonik) werden die Klüfte nach Merkmalen des innern Baus orientiert und entsprechend bezeichnet.

Längs- oder S-Klüfte liegen bei Parallelbau der Gesteine im Hauptbruch, in den Flächen bester Spaltbarkeit.

Quer-oder $Q$-Klüfte stehen senkrecht zu den linearen Merkmalen (Striemung, Streckung, Gewölbefasern).

Scher-oder D-Klüfte verlaufen diagonal zu den beiden ersten Scharen. Diese 3 Systeme stehen mehr oder weniger senkrecht.

1 Meine Auffassung fand ich in diesem Punkt bestätigt in Нӧявом (23), wo auch die Genese der Klüftung als für die morphologischen Formen nicht relevant betrachtet wird.

2 Vgl. dazu: Salomon (44), Bucher (8), v. Bubnoff (6 und 7), Múllerried (37), Stiny (50), Swanson (55), Schmid (47), Thiele (58 und 59), Niggli (38) u. a. m. Verschiedene Theorien sind sogar durch Experimente nachgewiesen worden: Lueders, DaubreE (14), MEAD (33). Letztere nach LJUNGNER (33).

${ }^{3}$ LJUNGNER (33) ordnet diese Erklärung in 7 Gruppen: Kontraktion durch Abkühlung / Orogenetischer Druck / Belastungsdruck / Dirigierender Einfluß einer gegebenen Struktur auf spätere Vorgänge / Atmosphärische Temperaturschwankungen und Insolation / Chemische Verwitterung / Dehnung der Erdbaumassen, nachdem die Erosion die belastenden Massen entfernt hat.

+ Eine ausgezeichnete Darstellung der mannigfaltigen Einteilungsversuche gibt MülLLER (36) in seiner Arbeit über "Statistische Kluftmessungen". 
Abb. 3: Kluftflächen einer Sprengstelle an der Grimselstraße. Streichen und Fallen der Flächen wurden mit Kreide aufgezeichnet.

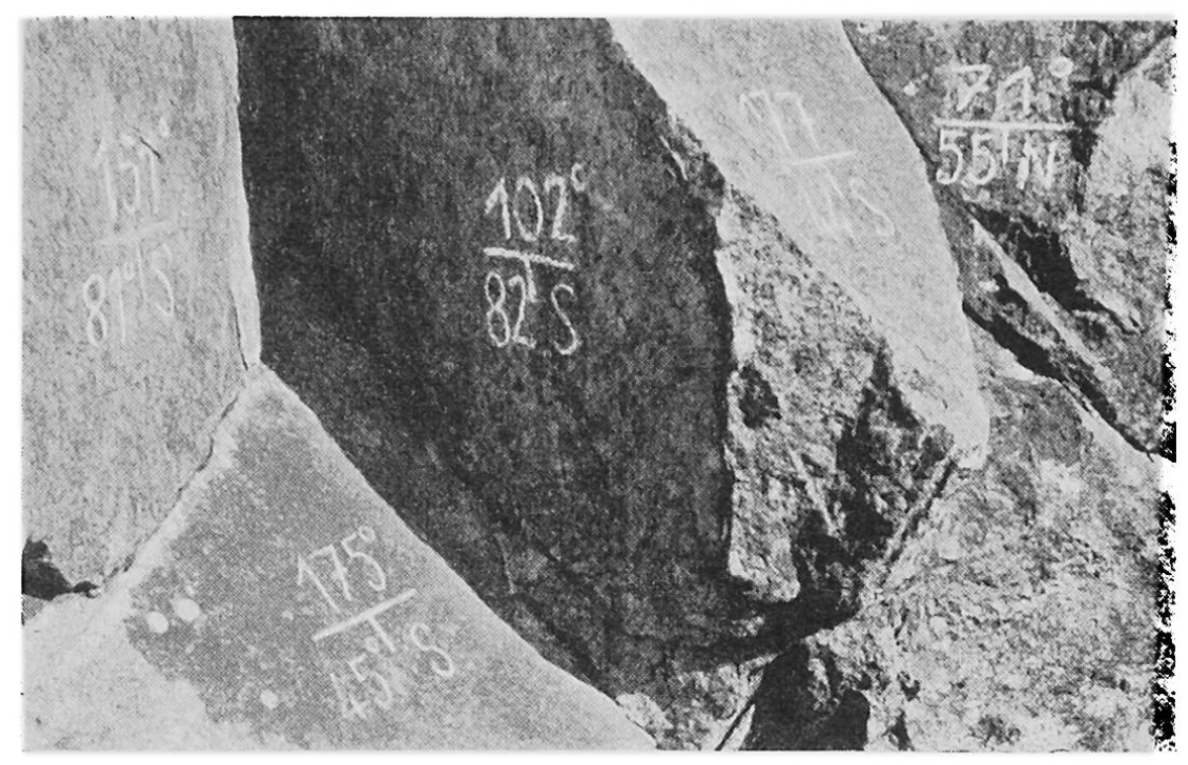

Lager- oder L-Klüfte (Bankung, sheeting) liegen schließlich schwach geneigt bis horizontal.

Bei der Kluftmessung werden - wie bei der Messung geologischer Schichten Streichen und Fallen festgestellt (vgl. Abb. 3).

Mit dem wachsenden Interesse, das den Gesteinsklüften geschenkt wurde, begannen sich auch die Methoden der Darstellung zu entwickeln. Statistische Messungen ersetzten die Einzelwerte. Von der tabellenmäßigen Zusammenstellung der Messungen [LehmanN (30), Teichert (56) ${ }^{5}$ ] schritt man weiter zur Darstellung der Streichrichtungen in Polarkoordinaten ${ }^{6}$ in sogenannten Kluftrosen oder Kluftsternen [Ljungner (33), v. Bubnoff (7), Müllerried (37), Liechti (31), MinDER $\left.(35)^{5}\right]$.

Obschon diese Darstellungsart gut erfaßbar Streichrichtung und Häufigkeit verknüpft, ist sie mit dem gleichen Mangel behaftet wie die vorher beschriebene Methode: Sie zeigt nur eine von 2 Variabeln, nur eine Richtung, statt eine Stellung im Raum.

Allen Ansprüchen gerecht wird indessen nur die Darstellungsart, die sich die Abbildung einer «Lagekugel» zunutze macht ${ }^{\text {? }}$. Sie wurde durch W. Schmid in der Mineralogie eingeführt. Verschiebt man eine Kluftfläche unter Beibehaltung ihrer Richtung in den Mittelpunkt einer Kugel (Lagekugel), so durchstößt ein in ihrem Zentrum errichtetes Lot die Kugeloberfläche in 2 Punkten und bestimmt dadurch die Lage der Kluftfläche eindeutig ${ }^{8}$.

Fig. 1: Verteilung der Klüfte im Grimselgranit. - Darstellung der Kluftanlagen als Lot-Bild. Süden liegt am untern Rand (Marke). Die Punkthäufung am Rand des SW-Quadranten stellt steile, NW/SE-streichende Klüfte dar. Die Häufung wenig über dem Zentrum zeigt flache, fast $\mathrm{E} / \mathrm{W}$-streichende Klüfte.

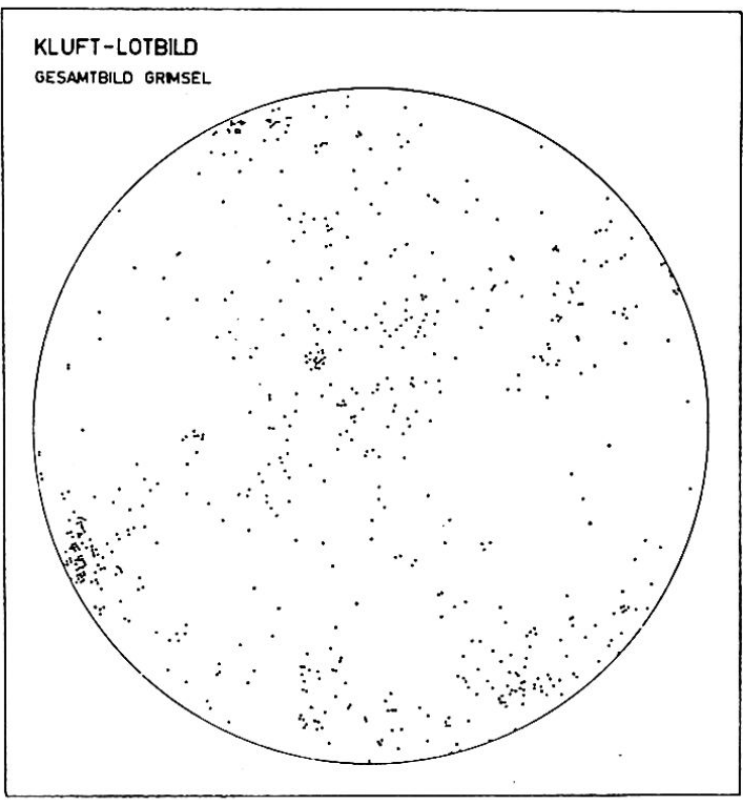

5 Die Angabe der Bearbeiter ist nicht vollständig.

6 Vgl. Fig. 2, 4 und 6.

7 Das Gradnetz der Lagekugel wurde für diese Arbeit in einer äquatorständigen, flächentreuen Azimutalprojektion abgebildet.

8 Eine praktische Anleitung zu dieser Darstellungsmethode gibt RüGER (43). 
Im Hinblick auf das Untersuchungsobjekt, den Rundhöcker, der ein konvexes Gebilde darstellt, wurden nur die Lotdurchstoßpunkte der obern Halbkugel dargestellt (Kluft-Lotbilder; vgl. dazu Fig. 1).

Die Punktzahl pro Flächeneinheit wird in den Kluftdiagrammen zum Ausdruck gebracht ${ }^{9}$. Entsprechendes Diagramm zu Fig. 1 ist Fig. ${ }^{10}$.

Mit diesen Zeilen können wir die Betrachtungen über Kluftgenese, Nomenklatur und Darstellungsmethoden abschließen und uns in einem folgenden Kapitel über die Verwendung der Kluftmessungen orientieren.

\section{Die Kluftmessungen in der Morphologie 11}

Wohl das allgemeinste, in diesem Zusammenhang immer wieder aufgegriffene Problem, ist das der Kluftbestimmtheit von Talrichtungen. Schon Salomon (44) und eine ganze Reihe seiner Schüler untersuchten mittels statistischer Kluftmessungen den Rheintalgraben und seine angrenzenden Gebiete. Lehmann (30) und Teichert (56) fanden Übereinstimmungen zwischen Klüften und Talrichtungen. Panzer (39) wollte diese Abhängigkeit nur in kleinen Nebentälern erkennen. Nach Liechti (31) und Minder (35) bestimmen Klüfte im Zusammenwirken mit Mylonitzonen auch in den alpinen Massiven Talrichtung und Couloirbildung. STINy (51) vergleicht schon 1926 in den Ostalpen Streichen von «Geländeformenlinien» und Gesteinsklüften.

Es ist fast selbstverständlich, daß die Beziehungen zwischen Klüften und Erdoberfläche das Interesse der Nordländer wecken mußte, treten doch in den alten, vom Eis bearbeiteten Schichttafeln und kristallinen Massen die Klüfte in wunderbarer Weise zu Tage.

Sederholm (48) stellt fest, daß die Tiefenrinnen in Seen den Bruchspalten folgen, da $\beta$ die Seen selber an den dichtesten Stellen des Kluftnetzes liegen, und daß die Inselgröße mit der Kluftdichte in direktem Zusammenhang steht. Er deutet die Arbeit des Eises als eine Funktion der Klüftung. Auch Tuominen (60) spricht der glazialen Bearbeitung nur modifizierende Wirkung an präglazialen Anlagen zu. Die Beziehungen zwischen Klüften und Morphologie zeigen sich am ehesten in den Kleinformen. Hӧввом (23) schätzte an einer glazial bearbeiteten Kuppe den Anteil der Kluftflächen an der Gesamtoberfläche $a b$ und beschäftigte sich mit dem Problem des Abschleifens und Ausreißens.

Wohl das umfassendste Werk zu diesen Fragen stellt LJUnGNers «Spaltentektonik und Morphologie der schwedischen Skagerrak-Küste» (33) dar. Der Verfasser beschäftigt sich vorerst eingehend mit den verschiedenen Gesteinen und Klüften, um dann den Zusammenhang mit glazialen, subglazialen und marinen Erosionsformen aufs trefflichste darzustellen.

Neuere Arbeiten der Universität Lund verknüpfen Klüfte und Gefügedaten der Gesteine 12. BeHRENs (2) ordnet solche Merkmalkombinationen bestimmten Küstentypen zu. LARSSON (29) erklärt auf dieser Grundlage Strukturelemente der Landschaft.

Im alpinen Bereich, speziell in meinem Arbeitsgebiet, haben die Bearbeiter der petrographischen Verhältnisse, Minder (35) und Liechti (31), ihre Beobachtungen zur kluftbedingten Morphologie der Talgehänge, zu Gratrichtungen und Gratformen, zu Gendarmen und Aiguilles dargestellt.

Die hier aufgeführten Arbeiten bergen ausgezeichnete Beobachtungen. Sie erfassen meist lineare morphologische Elemente (oder Schnittlinien höherdimensionaler

9 Vgl. dazu: RüGer (43), Mülleer (36), BILLings (4).

10 Die links angefügten \%-Zahlen geben die Dichte in \% (Punkte) pro \% (Fläche) an. Für eine gleichmäßige Verteilung müßte dieser Wert also immer 1 betragen.

11 Wertvolle Dienste leistet die Kluftmessung den Ingenieur-Geologen für Stollenbauten, Verankerung und Abdichtung von Staumauern, Projektion großer Hallen u. a.m.

12 Gefüge: Vgl. dazu Sander (45). 


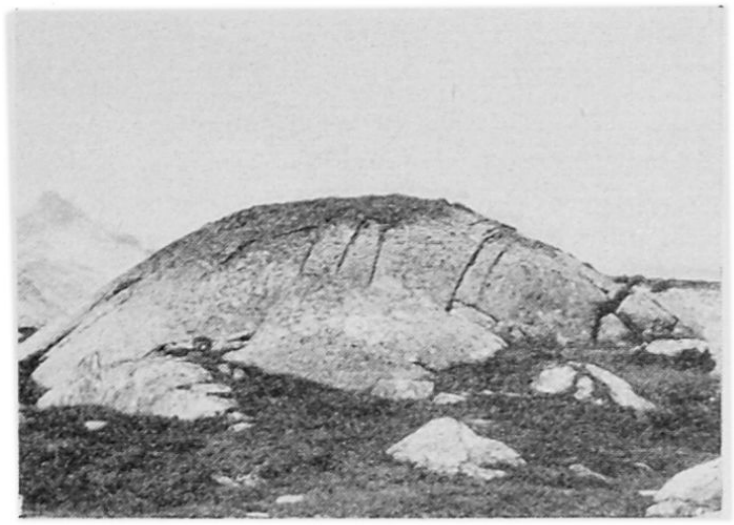

$A b b .4$ : Rundhöcker auf Nägelisgrätli, ca. $200 \mathrm{~m}$ N Pt. 2395. Aufnahme gegen NW' Eis von rechts.

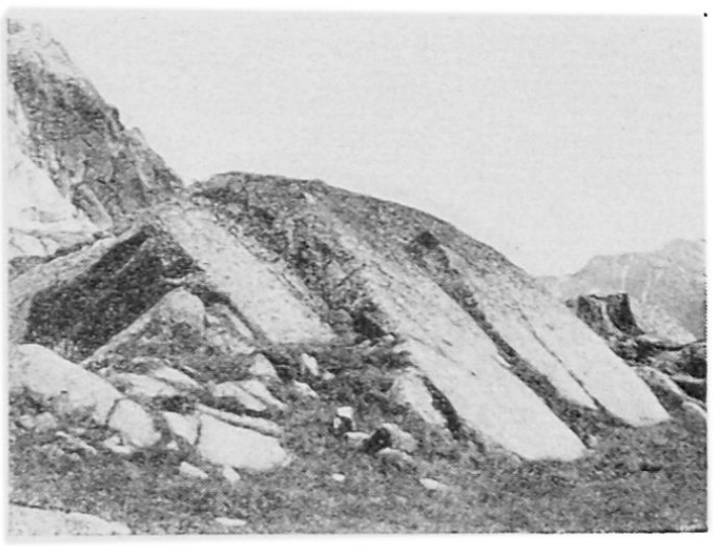

Abb.5: Rundhöcker wie in Abb. 4. Aufnahme gegen E. Eis gegen den Betrachter.

Objekte mit der Erdoberfläche), die dann einer qualitativ abschätzenden Beurteilung unterzogen werden. Klüfte, im Gegensatz dazu, erfahren stets eine quantitativ - statistische Behandlung.

\section{Die Rundhöcker}

Rundhöcker sind durch Gletscherschliff gerundete, das nahe Umgelände überragrende Kuppen im anstehenden Fels ${ }^{13}$.

Rundhöcker, auch etwa Rundbuckel genannt, benennt man im französischen und englischen Sprachgebrauch mit dem Fachausdruck «roches moutonnées». Die Bezeichnung geht auf Horace-Benedict de SAussures «Voyages dans les Alpes» zurück ${ }^{14}$.

Die Rundhöcker treten besonders auf Transfluenzstellen des Eises und auf Mündungsschwellen meist gesellig auf und können deshalb mühelos mit einer Herde weidender Schafe oder nach Herm (20) mit dem «welligen Vließ» eines Schafes verglichen werden. FlüCKIGER (18) prägte für ihre Gesamtheit den Begriff der Rundhöckerflur (vgl. Abb. 6).

Die Rundhöcker werden in den meisten morphologischen, sicher aber in allen glazialmorphologischen Arbeiten erwähnt, obschon ihnen unter den Erosionsformen niemals die gleiche Bedeutung zuerkannt wird wie glazialen Großformen.

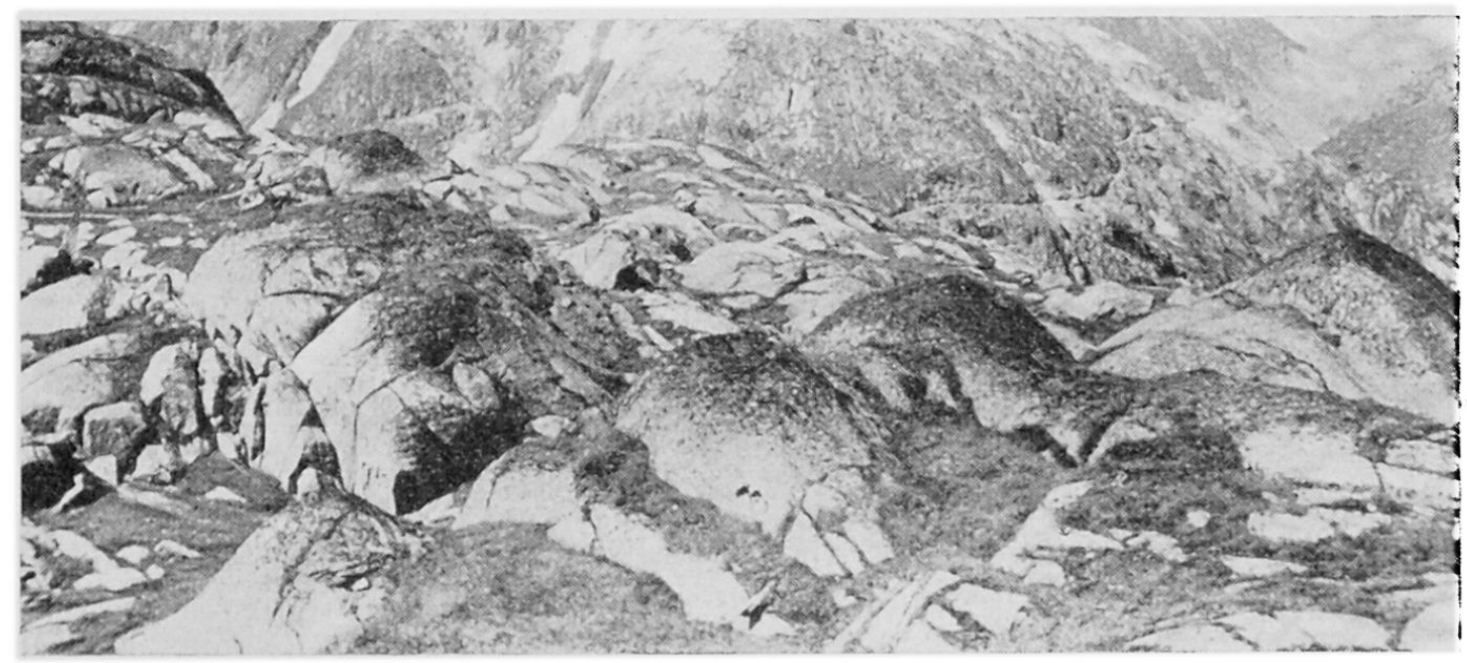

Abb.6: Rundhöckerflur auf Nägelisgrätli, N Pt. 2395 (links im Bild). Eis von links nach rechts.

13 Vgl. dazu auch die Definition von Beringer (3) und meine Präzisierung der Abgrenzung Seite 15.

14 Nach Boesch (5). 
Nun will ich die vielzitierten, charakteristischen Merkmale ihrer Form stichwortartig zusammenstellen. Die meisten Autoren ${ }^{15}$ erwähnen die folgenden:

elliptisch, spindelförmig/Länge und Breite wechselnd/Längsachse meist größer als Querachse/manchmal rundum gleichmäßig geneigt und geschliffen/oft schiefstehend/mehrere Meter große bis gewaltige Rundhöckerberge/flache Schildrücken bis kräftige, steilwandige Kuppen/Luv-Seiten (StoB-Seiten) flach und glatt geschliffen, Lee-Seiten steiler und zersplittert/asymmetrisch/Richtung: die der Eisbewegung.

In den meisten Beschreibungen fehlen irgendwelche quantitativen Angaben. Einzig Hess (22) stellt für die Terrasse von Salvan (Wallis) Längen, Breiten und Höhen einiger Rundhöcker aus Sedimentgestein und Gneis in einer Tabelle zusammen. Sein Längen-Breitenindex beträgt für das Sedimentgestein (Karbon) im Mittel 4,9, für Gneis16 . . . . im Mittel 2,o.

Über die Entstehung der Rundhöcker ist wohl schon viel diskutiert und geschrieben worden ${ }^{17}$ :

HUGI sah in ihnen spezielle Verwitterungsformen des Granits, sog. «Bauchgranit».

Alle folgenden Deutungsversuche stützen sich auf die Glazialtheorie:

LAPPARENT schreibt der Entstehung der Rundhöcker härteren, widerstandsfähigeren Stellen (《protubérances dures») im Gestein zu.

PENCK (wie auch STINY) erklärt sich ihre Bildung auf Grund eines polyedrischen Kluftnetzes, denkt aber, besonders bei der Beschreibung der dazwischenliegenden Wannen, auch an die unterschiedliche $\mathrm{Härte}$ der Gesteine.

DAvis, ähnlich auch HeIM und GeRLACH, sehen in den Rundhöckern Reste größerer präglazialer Unebenheiten, die durch das Eis nicht ganz niedergeschliffen werden konnten. FLÜCKIGER mißt den obgenannten Theorien nur nebensächliche Bedeutung zu. Er erklärt den Rundhöcker als «Ausdruck und Abbild der besondern Bewegungsformen des Gletschers». (Gesetz der Wellenbildung zweier strömender Medien nach Helmholtz).

STREIFF-BeCKER ( 53 und 54) will eine solche Wellenbildung nur in den Großformen beobachtet haben. Er weist auf die Arbeit subglazialer Gewässer hin, die ein ganzes Netz von Kanälen mit dazwischenliegenden, abgerundeten Buckeln schaffen können.

Hess erklärt das Vorhandensein der Rundhöcker durch folgende Sequenz: Schutt bedeckt bestimmte Stellen des Untergrundes und schützt sie vor Erosion. Eis und subglaziale Gewässer vertiefen die Umgebung. Die dynamische Glazialerosion nach FLÜCKIGER stellt dann einen Gleichgewichtszustand zwischen fluviatiler Erosion in den Rinnen und Eiserosion auf den Buckeln dar.

CAROL (10) untersuchte in Gletscherrandklüften die Kontaktzone zwischen Eis und Fels. Er führte Rundhöckerbildung auf ein Herausarbeiten bestehender Unebenheiten durch differenzierte Erosion am Rundhöcker zurück. (Plastisches und sprödes Verhalten des Eises auf der Stoß- bzw. Lee-Seite eines Rundhöckers und damit Abschleifen (Detersion) bzw. Absprengen und Ausreißen (Detraktion) an den entsprechenden Stellen.

Die Schwierigkeiten in der Erklärung liegen wohl darin, daß die Gletscher während der Hauptphase ihrer Arbeit nicht belauscht werden können. Versuche, dieser Unzulänglichkeit zu begegnen, hat meines Wissens nur CAROL unternommen, so daß seine Ansichten besondere Beachtung verdienen.

\section{PROBLEMSTELLUNG}

Nach diesem kurzen Überblick über die bestehenden Arbeiten zur kluftbedingten Morphologie und den beiden Anschlußgebieten, der Kluftmessung und der Rundhökkermorphologie, will ich das Problem, das meiner Arbeit zu Grunde gelegt wurde, genau umreißen.

Es läßt sich am besten durch eine Auflösung in die 4 folgenden Fragen darstellen:

1. Beeinflußt die gegebene Klüftung die Form der Rundhöcker?

1a. Wenn ja: Ist auch eine Beeinflussung festzustellen, wenn dies nicht offensichtlich in Erscheinung tritt?

15 Flückiger (18), Woldstedt (62), Klebelsberg (28), Carol (10, 11), Hess (22), Penck (40) Bd. II.

16 Vergleiche p. 15 für das Gebiet der Grimsel.

17 Ich folge hier BoEsCH (5), FlÜCKIGER (18), Hess (22), wo nicht gesondert auf die Literatur verwiesen wird. 
2. Sind bei gleichbleibender Kluftgesamtheit demnach auch gleiche Züge an Rundhöckern festzustellen?

2a. Wenn ja: Ist dies auch der Fall, wenn die Fließrichtung des Eises stark variierte?

Wir fragen also nicht nach der Entstehung, sondern einzig nach der Form der Rundhöcker. Es läßt sich jedoch wegen der Verwandtschaft formaler und genetischer Aspekte nicht vermeiden, daß Probleme der Genese immer wieder gestreift werden.

Die Art der Fragestellung (vor allem in 1a) verlangt ein Vorgehen, das sich von der herkömmlichen direkten Beobachtung und Schlußführung löst, die anschauliche Betrachtungsweise weitgehend verläßt und mittels abstrakter Darstellungen die $\mathrm{Zu}$ sammenhänge sucht. Es soll deshalb in dieser Arbeit erstmals versucht werden, ein derartiges morphologisches Problem auf statistischem Wege unter Verwendung mathematischer und graphischer Korrelationsmethoden zu lösen. Daß dabei die Grenzen der quantitativen Untersuchungsmöglichkeiten für diesen Abschnitt der Naturwissenschaften z. T. erreicht, oft vielleicht überschritten werden, möge bei der Deutung der quantitativen Ergebnisse berücksichtigt werden (vgl. p. 30/31).

\section{B. Felduntersuchung und analytische Behandlung der Beobachtungen}

Der nun folgende Arbeitsteil soll mein Vorgehen während der Untersuchung darstellen.

Ich unterteile diesen Hauptabschnitt in zwei Hälften (B und C), die in ihrem Inhalt und ihrer Grundhaltung dem wirklichen Gang der Untersuchung entsprechen mögen.

Den ersten Abschnitt (B), der vorwiegend die Feldarbeit beschreibt, bezeichne ich sinngemäß als analytischen Teil. Die Resultate dieser Analyse sollen, um später ein umständliches Nachschlagen zu vermeiden, sofort dargestellt und diskutiert werden.

Im zweiten Abschnitt (C) wird die graphische und mathematische Behandlung der Beobachtungsergebnisse dargestellt. Da diese Arbeitsweise eine Verknüpfung (Korrelation) der Beobachtungen und Messungen aus dem ersten, analytischen Teil darstellt, darf dieses Kapitel als Synthese aufgefaßt werden. Der Übersichtlichkeit halber werden auch hier die Ergebnisse anschließend an die Erklärung der Arbeitsmethode dargestellt und diskutiert.

\section{DAS UNTERSUCHUNGSGEBIET}

Die ganze Untersuchung wurde im Kristallin der Alpen durchgeführt, denn gerade hier und besonders in den Massiven sind die Klüfte auffallend schön und gleichmäßig ausgebildet. Sie sind in Richtung und Dichte über weite Strecken konstant. Störende Schichtfugen treten nicht auf. Die petrographische Einheitlichkeit ist mit Ausnahme der gut unterscheidbaren Gänge auf weite Strecken gewährleistet. Dazu tritt die außerordentlich günstige Tatsache, daß die Rundhöcker im kristallinen Gestein bedeutend besser erhalten sind als in Sedimentgesteinen, ja da $\beta$ vielfach die glaziale Politur bis auf den heutigen Tag vollkommen frisch geblieben ist ${ }^{18}$.

Aus den erwähnten Gründen und durch das Wegfallen anderer störender Faktoren läßt sich in diesen Gebieten ein Schlußverfahren (wie z. B. die Differentialdiagnose) zur Bestimmung der Wirkungsweise erosiv tätiger Agentien mit höherer Sicherheit anwenden als anderswo.

Das Hauptgewicht wurde auf das Studium der Verhältnisse im Aarmassiv gelegt. Zwei Rundhöckerfluren wurden im Gebiet des Grimsel-Passes studiert, eine weitere auf der Göschener Alp. Anschließend bearbeitete ich zum Vergleich noch einige Formen im Gotthardmassiv, direkt auf der Gotthard-Paßhöhe. Ein Beispiel aus dem Kristallin der Bernina-Decke, SE der Bernina-Paßhöhe wurde ebenfalls untersucht.

${ }^{18}$ Die guterhaltene Glazialpolitur auf den Alpenpässen ist vielleicht weitgehend die Folge einer langwährenden Konservierung unter Erosionsschutt an Stellen geringer fluviatiler Erosion. 
a) Grimselgebiet

\section{Die Klüfte}

Nach Minder (35) «bildet der zentrale Aaregranit im ganzen Aarmassiv eine große petrographische Einheit mit relativ geringen Abweichungen». Er trennt jedoch für das Gebiet des Haslitales aus Gründen der Lagerung resp. der Struktur die nördliche und südliche Randzone als selbständige Facies ab. Meine Untersuchungen im Gebiet der Grimsel fallen in den Bereich dieser südlichen Randfacies, des sog. Grimselgranits, der nach der spindelförmigen lentikularen Gestalt der Feldspateinsprenglinge auch als Augengneis bezeichnet wird und sich überdies wegen seines höheren Biotitgehaltes durch dunklere Färbung vom normalen Granit unterscheidet. In dieser Zone wurden von mir zwischen Rätrichsboden und Totensee, auf einem Gebiet von ca. $5 \mathrm{~km}^{2}$ an 7 engbegrenzten Stellen mit gut sichtbarer Klüftung (im Durchschnitt etwa 2 Aren) insgesamt 602 Klüfte gemessen.

Besonders gut eigneten sich für die Kluftmessungen künstliche, durch Sprengung geschaffene Aufschlüsse längs Straßen, weil darin in der Regel alle Systeme gefunden werden konnten. In einem solchen Aufschluß wurden stets alle sichtbaren Klüfte eingemessen, auf weitlaufenden Kluftflächen in Abständen von ca. $1 \mathrm{~m}$ sogar weitere Messungen mit besonderem Vermerk ins Protokoll aufgenommen.

Die ganze Arbeit wurde mittels einer Geologen-Bussole durchgeführt und die Deklination nach Angabe der Landeskarte 1:50000 (Blatt 265) mit $5^{\circ}$ (genau $4^{\circ} 45^{\prime}$ ) für das Jahr 1955 in Abzug gebracht. Zur Einmessung überhängender oder sehr kleiner Kluftflächen verwendete ich nach dem Vorschlag MüLlers (36) verschiedene Messingbleche, die später auch bei der Messung der Oberfläche von Rundhöckern wertvolle Dienste leisten sollten.

Die Ergebnisse der Kluftmessung sind in Tabelle 1 und in Fig. 2 und 3 dargestellt ${ }^{19}$ :

\section{Tabelle 1 - Klüfte im Grimselgranit}

$\begin{array}{lcccccc}\text { Streichen : } & 1-5 & 6-10 & 11-15 & 16-20 & 21-25 & 26-30 \\ \text { Anzahl : } & 3 & 3 & 6 & 4 & 5 & 7 \\ \text { Streichen : } & 31-35 & 36-40 & 41-45 & 46-50 & 51-55 & 56-60 \\ \text { Anzahl : } & 8 & 10 & 17 & 16 & 21 & 25 \\ \text { Streichen : } & 61-65 & 66-70 & 71-75 & 76-80 & 81-85 & 86-90 \\ \text { Anzahl : } & 41 & 23 & 30 & 21 & 6 & 23 \\ \text { Streichen : } & 91-95 & 96-100 & 101-105 & 106-110 & 111-115 & 116-120 \\ \text { Anzahl : } & 10 & 26 & 20 & 11 & 9 & 14 \\ \text { Streichen : } & 121-125 & 126-130 & 131-135 & 136-140 & 141-145 & 146-150 \\ \text { Anzahl : } & 10 & 10 & 12 & 14 & 19 & 28 \\ \text { Streichen : } & 151-155 & 156-160 & 161-165 & 166-170 & 171-175 & 176-180 \\ \text { Anzahl: } & 41 & 52 & 24 & 12 & 6 & 15\end{array}$

Um eine leichtere Vergleichbarkeit zwischen Kluftrosen und Diagrammen zu erzielen, was vor allem in Bezug auf die Bildung der Maxima unter Berücksichtigung des Fallens interessieren dürfte, wurden die Kluftrosen um $90^{\circ}$ gedreht und neben die Diagramme gestellt. Kluftrosen und Diagramme sind somit direkt vergleichbar. Bei der Gegenüberstellung mit Kluftrosen anderer Arbeiten müssen meine Darstellungen nach der N/S Orientierung interpretiert, das heißt in Gedanken um $90^{\circ} \mathrm{im} \mathrm{Uhr-}$ zeigersinn ged reht werden.

19 Fig. 2 ist mit der Darstellung von Minder (35; p. 380) vergleichbar. Jene Messungen sind für meine Arbeit jedoch weiter nicht verwendbar, da die Werte für das Fallen nicht dargestellt werden. 


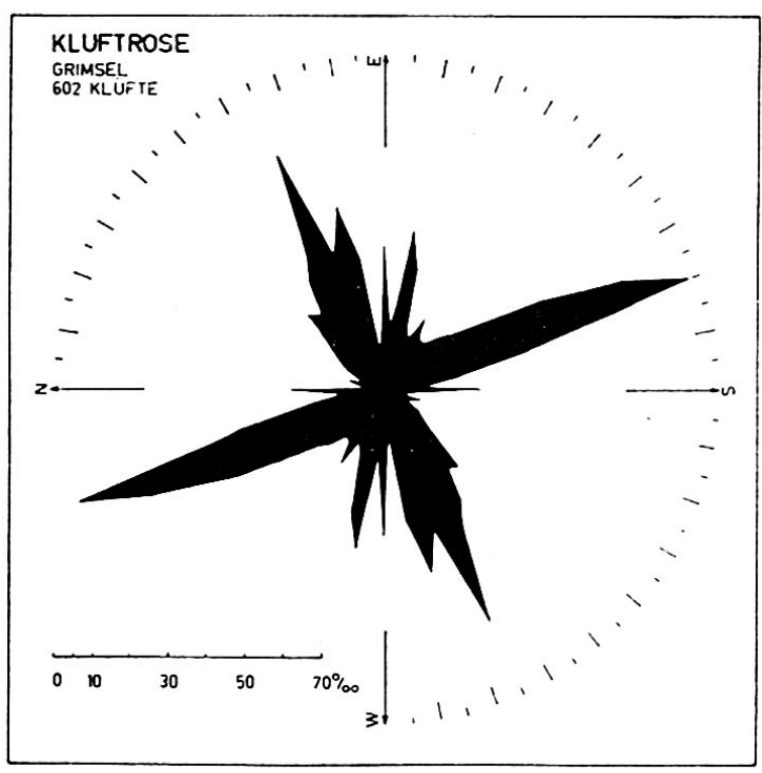

Fig. 2: Verteilung der Klüfte im Grimselgranit. - Darstellung der Streichrichtungen in Polarkoordinaten (Kluftrose).

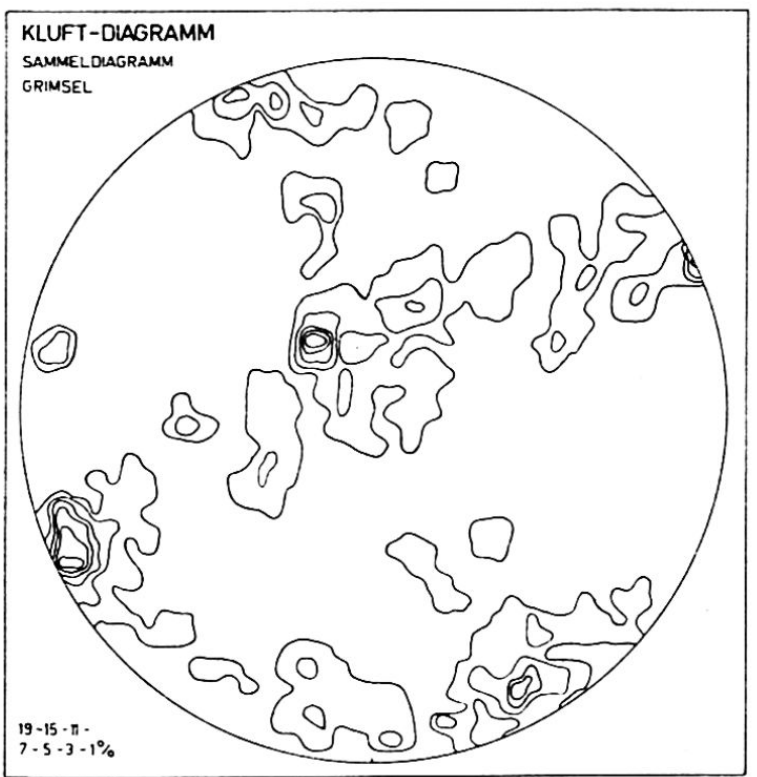

Fig. 3: Verteilung der Klüfte im Grimselgranit. - Darstellung der Kluftlagen als Diagramm. Die Prozentwerte bezeichnen die Besetzungsdichten der verschiedenen Flächen.

Die Darstellung von Fig. 2 zeigt das Vorherrschen eines fast orthogonalen Doppelsystems mit den Maxima bei $65^{\circ}$ und $160^{\circ}$, von denen das erstere deutlich von einem Mohr'schen Scherflächensystem eingeschlossen ist.

Es wäre verlockend, aus der Darstellung noch ein zweites Doppelsystem mit den Maxima bei $10^{\circ}$ bzw. $100^{\circ}$ und Scherflächen bei $90^{\circ}$ und $115^{\circ}$ herauszugreifen. Auf Grund meiner Beobachtungen während der Messungen und besonders während der Auswertung von Teil-Diagrammen glaube ich aber, eine derart feingliederige Interpretation ablehnen zu müssen. Innerhalb einer Meßreihe von nur 400-700 Messungen spielt nämlich die Vorherrschaft eines einzigen Kluftsystems in irgend einem Aufschluß bereits eine Rolle bei der Bildung kleinster Häufungen. Nebenmaxima flacher Kluftscharen, die mit den steilstehenden Hauptsystemen nichts zu tun haben, könnten sowohl die Darstellung als auch eine zu detaillierte Interpretation von Kluftrosen empfindlich verfälschen.

Ein Vergleich mit der Darstellung im Projektionsnetz der Lagekugel ist deshalb unumgänglich. Fig. 3 zeigt, daß die Klüfte, was das Streichen betrifft, recht konstant verlaufen. Die kreuzförmige Anordnung der Pole verrät aber eine bedeutend weniger große Einheitlichkeit der Fallbeträge.

Etwas anschaulicher ausgedrückt: Wir erhalten das Bild zweier rotierender Kluftscharen mit den Rotationsachsen $65^{\circ}$ bzw. $160^{\circ}$, wobei die überwiegende Mehrheit der Klüfte steil bis senkrecht steht.

Der Vergleich meiner Kluftrose mit der von Minder (35; p. 380) zeigt fast vollständige Übereinstimmung in den Abschnitten zwischen $150^{\circ}$ und $180^{\circ}$ (bzw. $90^{\circ}$ und $\left.110^{\circ}\right)$. Das Maximum bei $65^{\circ}$ tritt bei ihm nur als Nebenmaximum $\left(70^{\circ}\right)$ in Erscheinung, während seine größte Häufung bei $50^{\circ}$ (die zwar nirgends untergebracht werden kann) in meiner Darstellung kaum auftritt.

b) Göschener Alp

Meine Kluftmessungen auf der Göschener Alp fallen gänzlich in den Bereich des Zentralgranits. Minder (35) beschreibt ihn wie folgt:

«Der normale Zentralgranit ist ein hypidiomorphes-körniges saures Gestein mit weißem Alkalifeldspat, grünlichem Plagioklas, grauem bis bläulichem Quarz und we- 
nig Biotit. Seine Hauptfarbe ist hellgrau, auf Kluftflächen durch die mehr oder weniger fortgeschrittene Chloritisierung der Glimmer oft grünlich.»

Über das ganze Gebiet der Göschener Alp verteilt wurden auf 6 Meß-Stellen innerhalb $8 \mathrm{~km}^{2}$ und an zwei außerhalb liegenden Punkten insgesamt 629 Klüfte gemessen.

Tabelle 2, sowie Fig. 4 und 5 stellen die Ergebnisse dar:

Tabelle 2 - Klüfte im Zentralgranit der Göschener Alp

$\begin{array}{lcccccc}\text { Streichen : } & 1-5 & 6-10 & 11-15 & 16-20 & 21-25 & 26-30 \\ \text { Anzahl : } & 2 & 5 & 6 & 8 & 10 & 18 \\ \text { Streichen : } & 31-35 & 36-40 & 41-45 & 46-50 & 51-55 & 56-60 \\ \text { Anzahl : } & 14 & 42 & 12 & 41 & 34 & 28 \\ \text { Streichen : } & 61-65 & 66-70 & 71-75 & 76-80 & 81-85 & 86-90 \\ \text { Anzahl : } & 15 & 15 & 18 & 14 & 13 & 22 \\ \text { Streichen : } & 91-95 & 96-100 & 101-105 & 106-110 & 111-115 & 116-120 \\ \text { Anzahl : } & 24 & 23 & 14 & 25 & 4 & 15 \\ \text { Streichen : } & 121-125 & 126-130 & 131-135 & 136-140 & 141-145 & 146-150 \\ \text { Anzahl : } & 6 & 10 & 8 & 17 & 27 & 56 \\ \text { Streichen: } & 151-155 & 156-160 & 161-165 & 166-170 & 171-175 & 176-180 \\ \text { Anzahl : } & 38 & 20 & 8 & 4 & 9 & 4\end{array}$

Die Darstellung (Fig. 4) zeigt ein Doppelsystem mit den Streichrichtungen $50^{\circ} / 60^{\circ}$ und $150^{\circ}$, von dem dasjenige bei $150^{\circ}$ besonders scharf ausgebildet ist. Der Sektor zwischen $40^{\circ}$ und $110^{\circ}$ ist im übrigen durch eine große Zahl kleinerer Häufungen besetzt. Diese stammen z. T. von flachen Kluftsystemen in Superposition mit steilen Klüften (vgl. Fig. 5).

Fig. 5 zeigt hier noch deutlicher als im Grimselgranit das leichte Südfallen der Kluftflächen und ihrer Schnittachsen.

Der Vergleich der Messungen mit denen Liechtis (31) zeigt große Übereinstimmung in der Lage der Hauptmaxima, der breiten Verteilung zwischen $40^{\circ}$ und $110^{\circ}$ und der fast vollständigen Kluftfreiheit zwischen $160^{\circ}$ und $30^{\circ}$.

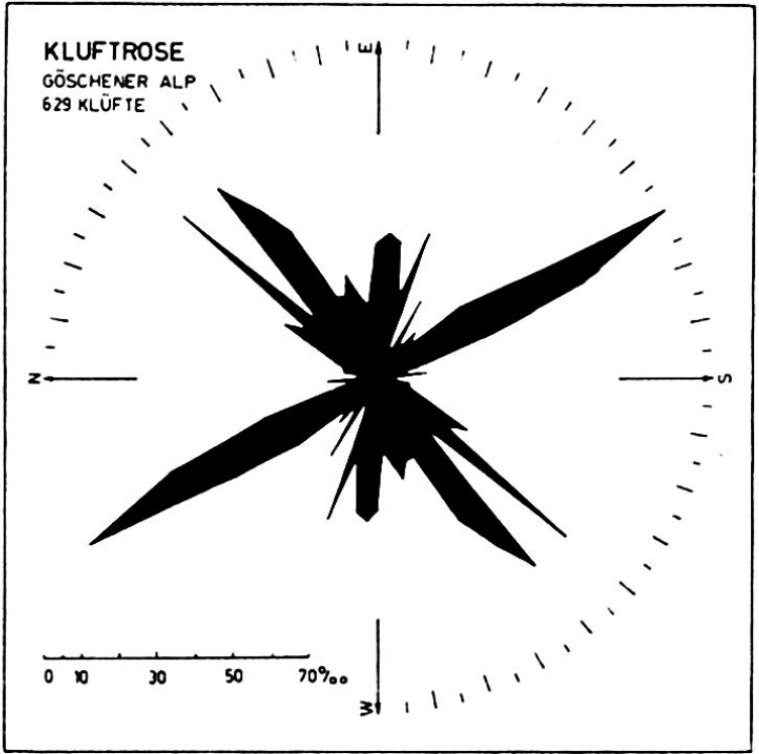

Fig. 4: Verteilung der Klüfte im Zentralgranit der Göschener Alp. - Darstellung der Streichrichtungen in Polarkoordinaten.

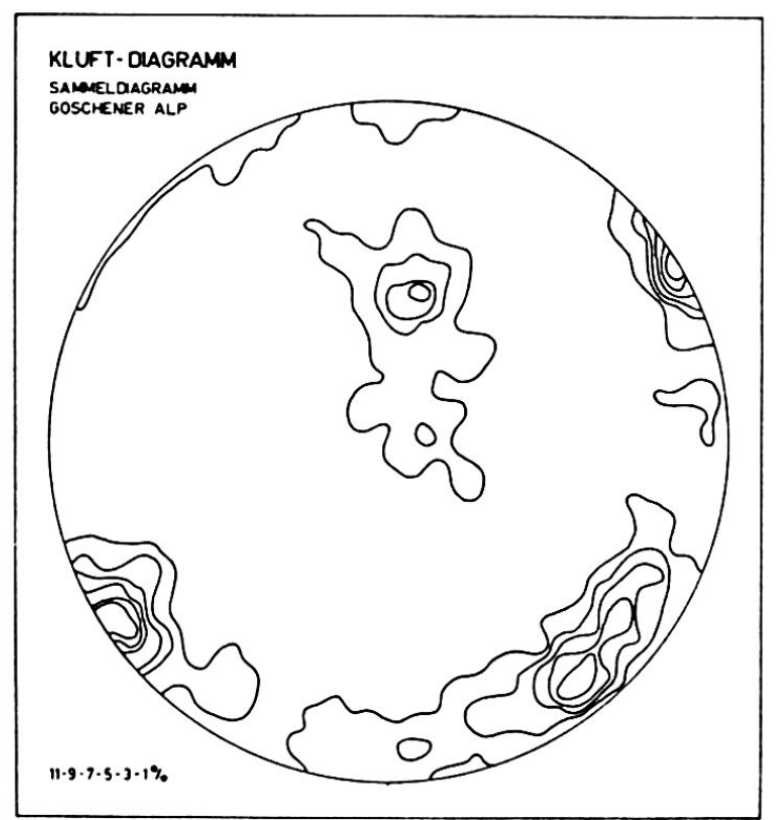

Fig. 5: Verteilung der Klüfte im Zentralgranit der Göschener Alp. - Darstellung der Kluftlagen als Diagramm. Die Prozentwerte bezeichnen die Besetzungsdichten der verschiedenen Flächen. 
c) Gotthard

Alle 137 Kluftmessungen für das Gotthardmassiv entstammen einem Gebiet von ca. einem halben $\mathrm{km}^{2}$ SW der Paß-Straße zwischen Pt. 2108,5 (Paßhöhe) und dem Hospiz.

Nach der von E. Амвӥнl (1) zusammengestellten und kurz kommentierten geologischen Karte fällt dieses Untersuchungsgebiet in die Zone des Fibbiagneises oder -granites. Dieses hellgraue Eruptivgestein zeigt noch besser als der Grimselgranit große, linear orientierte Feldspateinsprenglinge. Der Biotit, deutlich flächig angeordnet, läßt die Schieferungsebenen im Vergleich zu den andern Flächen etwas dunkler erscheinen. Der Quarz wurde während der alpinen Faltung zu «Sandquarz» zertrümmert. Seine chemische Zusammensetzung gleicht nach CADISCH (9) der des zentralen Aaregranits.

Tabelle 3 und Fig. 6 und 7 veranschaulichen die Ergebnisse der Kluftmessung:

Tabelle 3 - Klüfte in Fibbia-Granit des Gotthard-Passes

Streichen :

Anzahl :

Streichen :

Anzahl :

Streichen :

Anzahl :

Streichen :

Anzahl :

Streichen :

Anzahl :

Streichen :

Anzahl :

$$
1-5
$$$$
31-35
$$$$
61-65
$$$$
91-95
$$$$
10
$$

$$
121-125
$$$$
3
$$$$
151-155
$$

4

$$
6-10
$$$$
36-40
$$$$
66-70
$$$$
96-100
$$

26-130

$$
5
$$$$
156-160
$$

8

$$
11-15
$$$$
41-45
$$$$
71-75
$$$$
101-105
$$$$
131-135
$$$$
161-165
$$

2

$$
16-20
$$$$
46-50
$$$$
76-80
$$$$
106-110
$$$$
136-140
$$$$
166-170
$$

$$
21-25
$$$$
26-30
$$

$$
51-55 \quad 56-60
$$

$$
81-85 \quad 86-90
$$

$$
111-115
$$

$$
141-145 \quad 146-150
$$$$
171-175
$$

Die Deutung der Darstellungen 6 und 7 ist nicht so leicht wie in den vorangehenden Beispielen aus dem Aarmassiv. Dies mag z. T. an der weit geringeren Zahl von

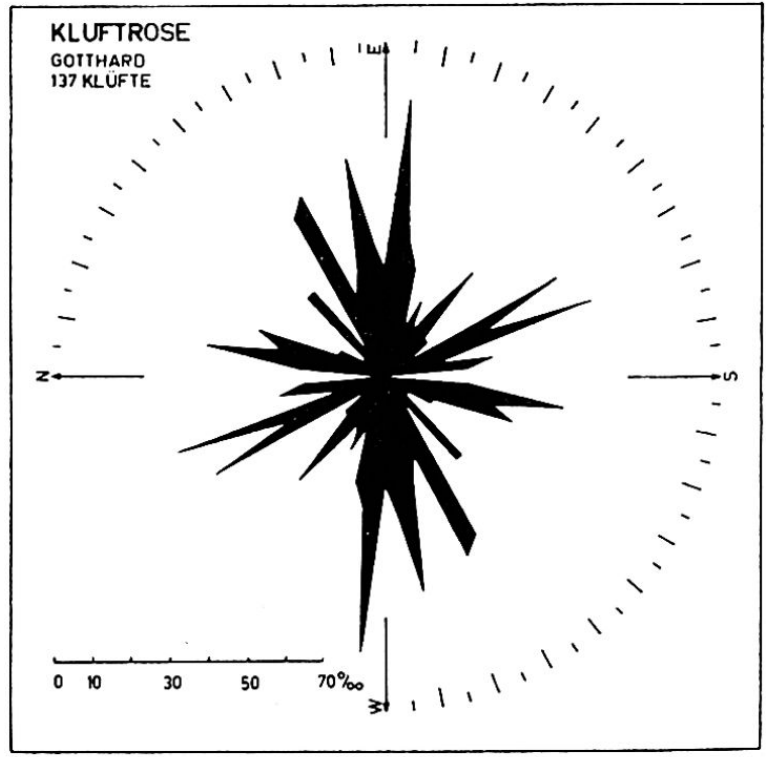

Fig. 6: Verteilung der Klüfte im Fibbia-Granit der Gotthardpaßhöhe. - Darstellung der Streichrichtungen in Polarkoordinaten.

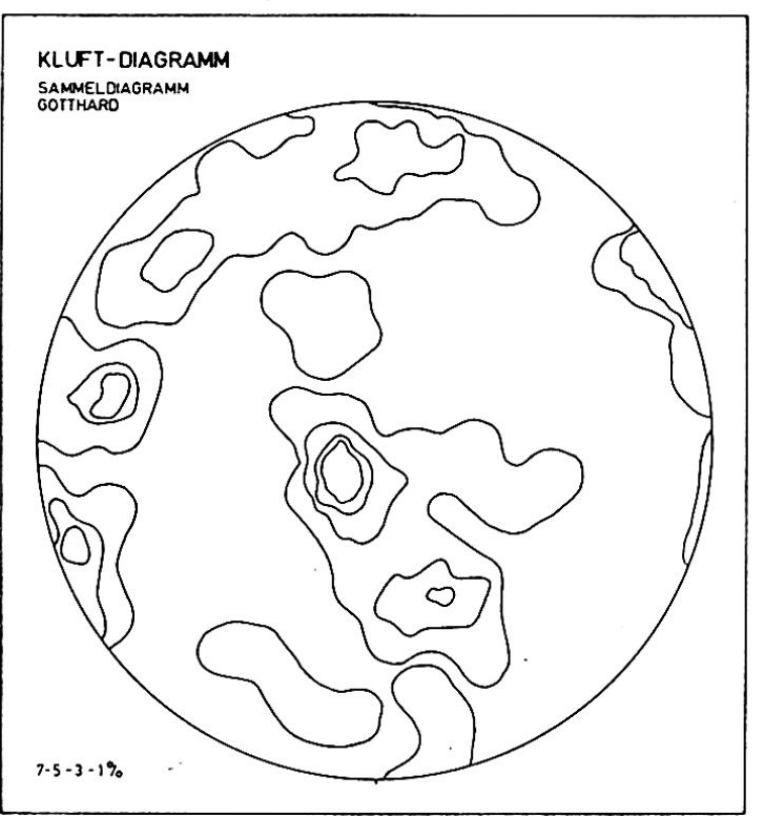

Fig. 7: Verteilung der Klüfte im Fibbia-Granit der Gotthardpaßhöhe. - Darstellung der Kluftlagen als Diagramm. Die Prozentwerte bezeichnen die Besetzungsdichten der verschiedenen Flächen. 
Messungen liegen (vgl. dazu Abschnitt a). Wenn jedoch beide Figuren zugezogen werden, läßt sich mit Sicherheit ein steilstehendes, leicht nach W einfallendes Doppelsystem bei $10^{\circ}$ und $95^{\circ}$ feststellen. Ein anderes erkennt man bei $70 \% / 75^{\circ}$ und $160^{\circ}$. Das zweite dieser beiden Systeme steht wiederum annähernd senkrecht, während das erste sehr ungleiche Fallwinkel aufweist und fast über die ganze Lagekugel streut. Auffallend ist die vollständige Kluftfreiheit zwischen $0^{\circ}$ und $5^{\circ}$.

Trotz der niedrigen $Z$ ahl von Messungen zeigt das Diagramm deutlich Häufungen und kluftfreie Stellen. Das entsprechende Lotbild war für die Korrelationsmethoden gut verwendbar.

d) Bernina-Paß

Um die erwähnten Kontrollen außerhalb des eigentlichen Arbeitsgebietes durchführen zu können, wurden auch auf der Bernina-Paßhöhe ca. 50 Klüfte gemessen. Die Resultate dieser Arbeit sind jedoch für eine andere Untersuchung der Kluftsysteme dieses Gebietes ohne Bedeutung, so daß auf eine Darstellung dieser Messungen verzichtet werden kann.

e) Schwankung der Kluftflächen

Klüfte sind nie im geometrischen Sinne eben, selbst dann nicht, wenn sie im Kluftprotokoll die Bezeichnung «eben» oder gar «sehr eben»vollauf verdienen. Die Variationsmöglichkeiten zwischen sehr ebenen und stark gekrümmten Kluftflächen sind aber groß. Ich habe diese Frage im Hinblick auf die im nächsten Abschnitt angewendeten Korrelationsmethoden untersucht.

Während der Kluftuntersuchungen im Gebiet der Grimsel wurden auf weitlaufenden Flächen von mindestens $2 \mathrm{~m}^{2}$ Ausmaß, die sich dem Auge des Beobachters als «eben»darboten, jeweils mehr als eine einzige Kluftmessung gemacht. Die Abstände zwischen den Meßpunkten betrugen in der Regel $1 \mathrm{~m} .42$ große Kluftflächen wurden so mit 2- und 3-fachen Messungen und besonderem Vermerk ins Protokoll aufgenommen. Im Arbeitsnetz konnte ich nachher den Schwerpunkt der Pole zweier zusammengehörender Messungen bestimmen. Der Winkel zwischen den so bestimmten Flächen (Winkeldifferenz zwischen den Lotstellungen) konnte ebenfalls dem Arbeitsnetz entnommen werden. (Verwendung der Großkreise des Netzes.)

In Fig. 8 wurde die Steilheit dieser Flächen mit ihrer Ebenheit (Winkeldifferenz der Lote) in Beziehung gesetzt:

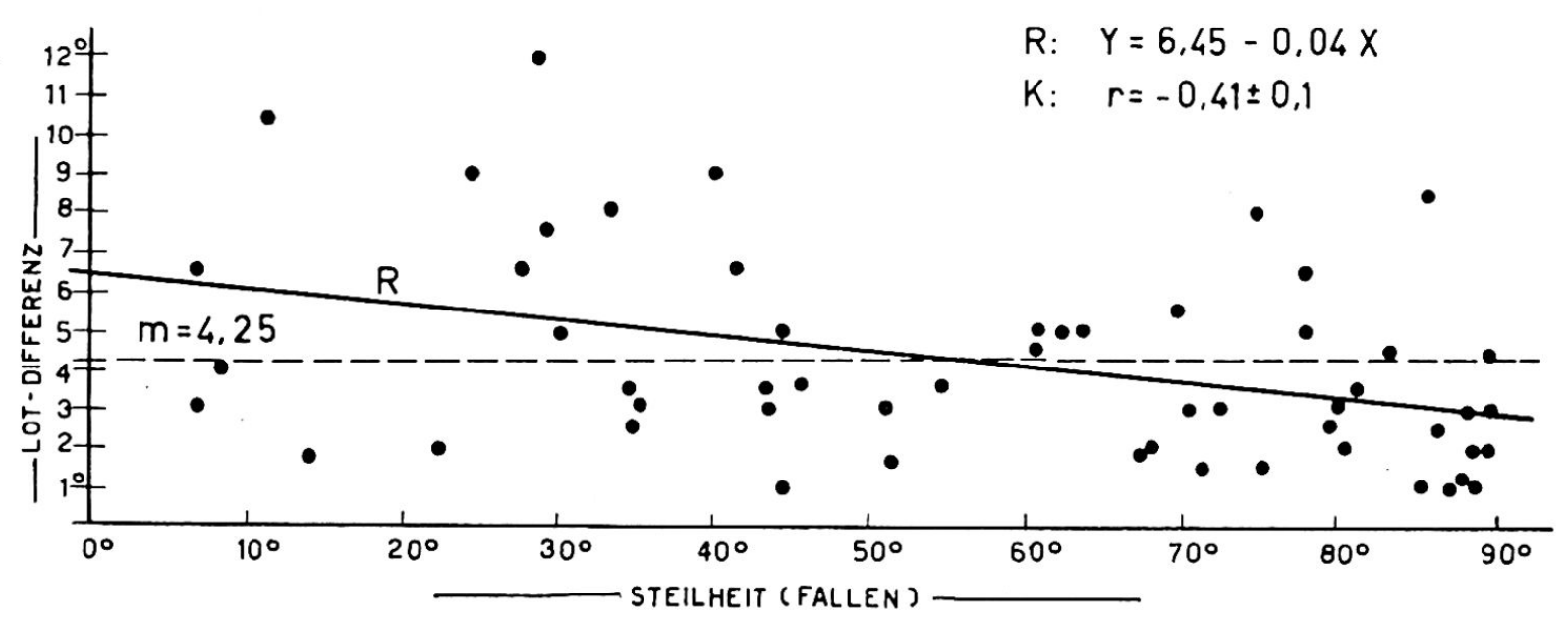

Fig. 8: Vergleich von Steilheit und Ebenheit großer Kluftflächen. $\mathrm{R}=$ Regressionsgerade für kleinste Ordinatenquadrate. $\mathrm{K}=$ Korrelation. $\mathrm{r}=$ Korrelationskœffizient. $\mathrm{m}=$ Arithmetisches Mittel der Lotdifferenzen in Grad. Der Ordinatenmaßstab ist 2,5 mal größer als der auf der Abszisse. 
Abb. 7: Rundhöckerflur SW Totensee (Grimsel), gegen E. In der Mitte des Bildes, direkt vor dem See, erkennt man die mit «Pfeilstein» bezeichnete Kuppe. - Aufnahme Juli 1955.

Der Maßstab wurde auf der Ordinate 2,5 mal gröBer gewählt als auf der Abszisse, was die Zeichengenauigkeit ein wenig erhöhte, die Scharung um die Regressionsgerade aber leider

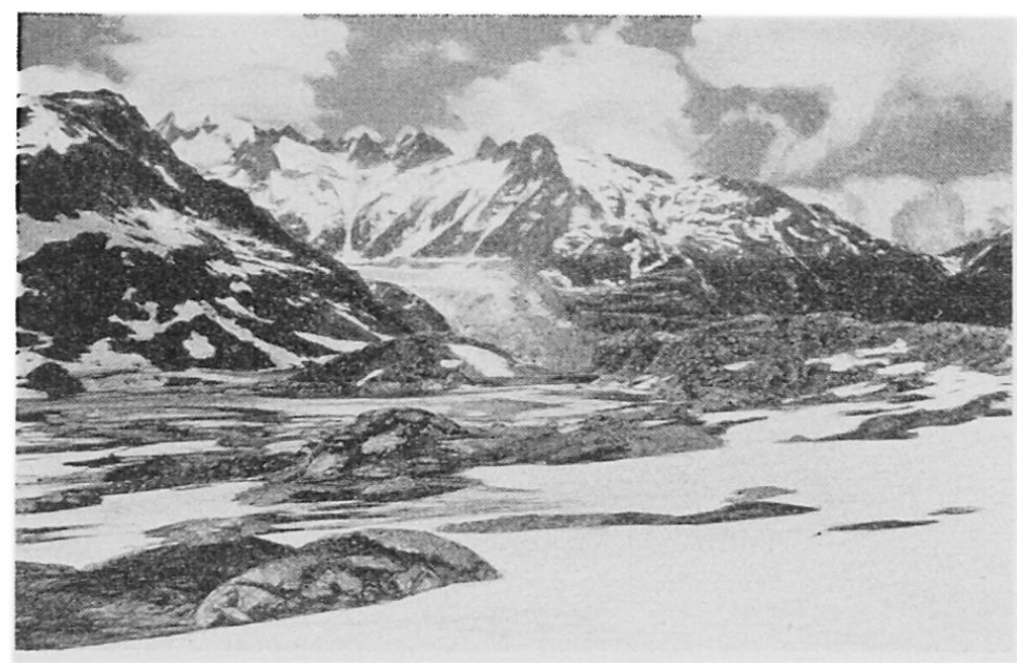
etwas verwischte ${ }^{20}$.

Die Darstellung beweist, daß flache Klüfte im allgemeinen weniger eben sind als steile. Sie zeigt aber zudem, daß die Punkte im Abschnitt zwischen $0^{\circ}$ und $40^{\circ}$ gleichmäßig verstreut sind, während im Abschnitt über $65^{\circ}$ nur einzelne Punkte aus der großen Konzentration um die Regressionsgerade austreten.
a) Grimsel
2. Die Rundhöcker

In diesem Hauptarbeitsgebiet wurden aus der Rundhöckerflur SW des Totensees 8 Rundhöcker bearbeitet. Die Auswahl der Objekte erfolgte nicht auf Grund vorgefaßter Meinungen über glaziale Erosion. Auch die glazialbedingte Großform beeinflußte das Auswahlverfahren nicht.

Ausschlaggebend waren die für mein Meßverfahren sich negativ auswirkenden Erscheinungsmerkmale:

Größe (Horizontalausdehnung und Höhe, die einen Teil der Flächen der Messung unzugänglich machten).

Postglazialer Zerfall [Deterration im Sinne Ljungners (33; p. 40t)].

Plattenform (Grenzfälle zwischen Rundhöcker und Felsplatten; siehe Definition p. 15).

Gelände (stark von der Horizontalen abweichendes Umgelände).

Vegetation um den Rundhöcker (kräftiger, ringsum stark an den Rundhöcker hinaufgreifender Vegetations- oder Schuttkragen).

Vegetation am Rundhöcker (wie oben, aber nur einseitig ausgebildet).

Vegetation auf dem Rundhöcker (Schutt bzw. Vegetationspolster auf dem Rundhöcker; wurde jeweils nach Möglichkeit entfernt).

Schneebedeckung (zur Zeit der Auswahl waren z. T. die Fußzonen verdeckt). Anthropogene Veränderungen (Sprengungen für Wege, Masten und Markierungen). flïchen :

20 Die auf Grund der Statistik errechneten Größen ergeben für die 56 Wertepaare auf 42 Kluft-

$$
\begin{aligned}
& \text { Korrelationskoeffizient: } \mathrm{r}=-0,41 \text { [Nach FISHER (17) mit } \mathrm{P}=0,01 \text { gesichert] } \\
& \text { Regressionsgerade : } \quad \mathrm{Y}=\mathrm{a}+\mathrm{bx}=6,45-0,04 \mathrm{x} \\
& \text { da nach LiNDER (32): } \quad Y=\bar{y}-b(x-\bar{x}) \\
& \text { wobei } \quad \mathrm{b}=\mathrm{r} \frac{\mathrm{S}_{\mathrm{y}}}{\mathrm{S}_{\mathrm{x}}}=0,042 \\
& \text { und } \quad \bar{y}=\text { arithmetisches Mittel aus } y_{1}, y_{2}, \ldots, y_{i}=4,07 \\
& \overline{\mathrm{x}}=\cdots, \cdots \mathrm{x}_{1}, \mathrm{x}_{2}, \ldots, \mathrm{x}_{\mathrm{i}}=56,87 \\
& \mathrm{~S}_{\mathrm{y}}=\text { mittlere quadrat. Abweichung der } \quad \mathrm{yi}_{\mathrm{i}}=25,9 \\
& \mathrm{~S}_{\mathrm{x}}=\cdots, \quad, \quad \mathrm{x}_{\mathrm{i}}=2,66
\end{aligned}
$$


Im Umkreis von ca. $100 \mathrm{~m}$ um Pt. 268 900/156 600 wurden alle anstehenden Gesteinspartien einer Beurteilung nach den Kriterien der obigen Aufstellung unterzogen. Die Ergebnisse sind in Tabelle 4 zusammengestellt worden.

\begin{tabular}{|c|c|c|c|c|c|c|c|c|c|c|c|c|c|}
\hline \multicolumn{4}{|c|}{$\begin{array}{l}\text { Tabelle } 4 \text { - Meßbarkeit } \\
\text { von Rundhöckern } \\
\text { (Gebiet SW Totensee) }\end{array}$} & \multirow[b]{2}{*}{$\begin{array}{l}\mathscr{2} \\
: 0 \\
:\end{array}$} & \multirow{2}{*}{ 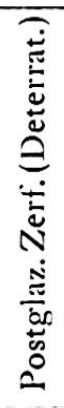 } & \multirow{2}{*}{ 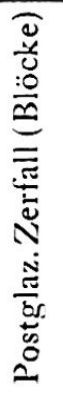 } & \multirow[b]{2}{*}{ 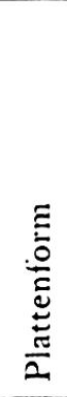 } & \multirow{2}{*}{ 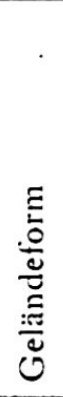 } & \multirow{2}{*}{ 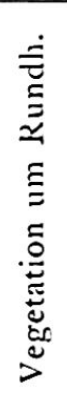 } & \multirow{2}{*}{ 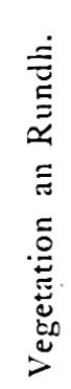 } & \multirow{2}{*}{ 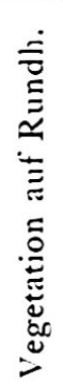 } & \multirow{2}{*}{ 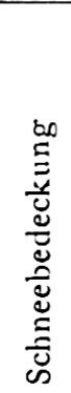 } & \multirow{2}{*}{ 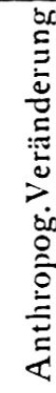 } \\
\hline \multicolumn{4}{|c|}{ Ausmaße in $\mathrm{m}$} & & & & & & & & & & \\
\hline 1 & 30 & 10 & 7 & 1 & & 1 & & & & $1 / 2$ & 1 & & \\
\hline 2 & 5 & 3 & 1.5 & & & 1 & & 1 & & 1 & & & \\
\hline 3 & 10 & $?$ & 2 & & 1 & & & 1 & & 1 & 1 & & i \\
\hline 4 & 15 & 7 & 2,5 & & & & & 1 & & 1 & $i$ & 1 & \\
\hline 5 & 6 & 5 & 1 & & & & & $i$ & 1 & & 1 & & \\
\hline 6 & 5 & 4 & 1 & & 1 & & 1 & 1 & 1 & & 1 & & \\
\hline 7 & 35 & 7 & 5 & 1 & 1 & 1 & & 1 & & & 1 & & \\
\hline 8 & 20 & 10 & 3 & $i$ & 1 & $1 / 2$ & & 1 & & 1 & 1 & & \\
\hline 9 & 15 & 6 & 1 & & 1 & & & & 1 & 1 & 1 & & 1 \\
\hline 10 & 10 & 10 & 0,5 & & $1 / 2$ & & 1 & & 1 & & 1 & & \\
\hline $11^{*}$ & 15 & 10 & 4 & & & & & $1 / 2$ & & $1 / 2$ & $/ \mathrm{e}$ & & \\
\hline 12 & 3 & 2 & 1,5 & & & $1 / 2$ & & $1 / 2$ & & $i$ & & & \\
\hline 13 & 8 & 6 & 1,5 & & $1 / 2$ & $1_{i 2}$ & & & & & 1 & & \\
\hline $14^{*}$ & 13 & 8 & 2 & & $1 / 2$ & & & $1 / 2$ & & 1 & & & \\
\hline 15 & 11 & 7 & 1 & & 1 & & 1 & & 1 & & $1 / 2$ & & $1 / 2$ \\
\hline 16 & 10 & 10 & 1 & & $1 / 2$ & & 1 & & 1 & & $i$ & & \\
\hline 17 & 13 & 5 & 1 & & $1 / 2$ & & 1 & & 1 & & $1 / 2$ & & \\
\hline 18 & 8 & 3 & 1 & & & & & & & 1 & 1 & & \\
\hline 19 & 12 & 10 & 2 & & 1 & & 1 & & 1 & & 1 & & \\
\hline 20 & 10 & 6 & $?$ & & & & & & 1 & & 11 & & \\
\hline 21 & 15 & 7 & 2 & & & & ${ }_{12}^{1}$ & & & $1 / 2$ & & $1 / 2$ & \\
\hline $22 *$ & 10 & 6 & 1 & & & & & & $1 / 2$ & & & $1 / 2$ & \\
\hline 23 & 7 & 4 & 1 & & 11 & & & & & 1 & & & \\
\hline 24 & 15 & 10 & 2 & & & & $1 / 2$ & & 1 & & 1 & & \\
\hline 25 & 8 & 4 & 1,5 & & $1 / 2$ & $1 / 2$ & $1 / 2$ & & & 1 & & 1 & \\
\hline
\end{tabular}

$/=$ ungünstig $;{ }^{1 / 2}=\mathrm{z}$. T. ungünstig $;{ }^{*}=$ vermessener Rundhöcker $; \mathrm{e}=$ vor der Messung entfernte Vegetationspolster.

Aus der Reihe der eben betrachteten, negativ in Erscheinung tretenden Faktoren möchte ich zwei noch besonders herausgreifen. Es sind der «Oberflächenzerfall»

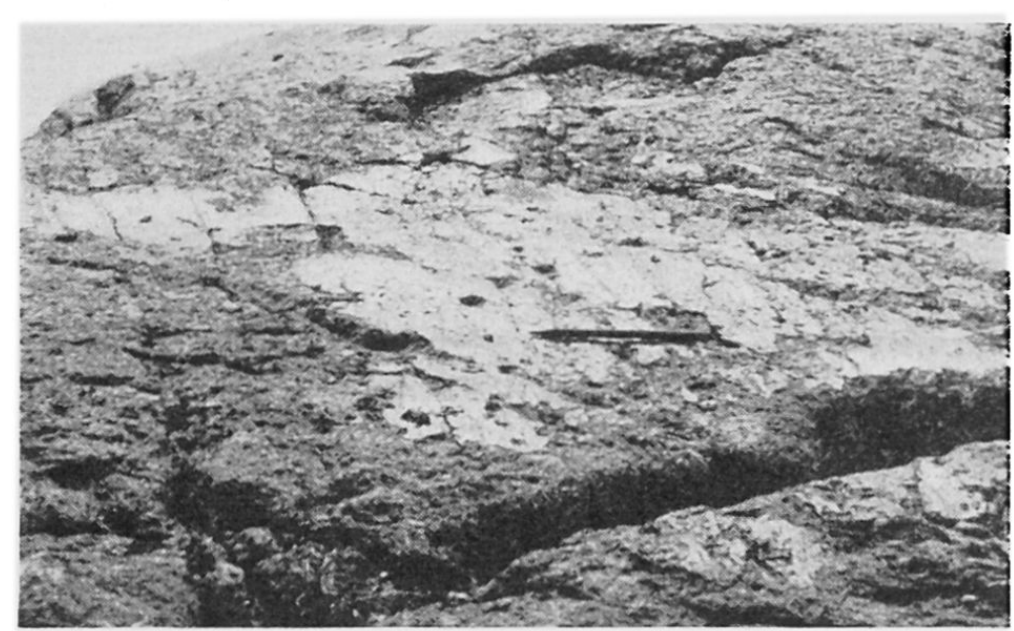
und die ganze Gruppe *Vegetation, Schuttbedeckung, Gelände . Während der Zerfall die Messungen überhaupt verunmöglichte, da dadurch das Objekt der Messung,

Abb. 8: Rundhöckeroberfläche mit einem Rest glazialer Politur. Daneben Zerfall durch Verwitterung und Ausbrechen längs Kluftrissen. 
die Oberfläche, nicht mehr im definitorischen Sinne mit der nötigen Genauigkeit existierte, konnte gegen die einschränkende Wirkung der andern Faktoren eine befriedigende Lösung gefunden werden ${ }^{21}$.

Vorerst wurden bei den ausgewählten 8 Rundhöckern Länge, Breite und Höhe gemessen, dann das Achsenverhältnis von Länge zu Breite gebildet. Wir wollen es fortan mit c bezeichnen. Schließlich wurden die Werte von c gemittelt ${ }^{22}$.

\section{Tabelle 5-Achsenverhältnisse}

\begin{tabular}{|c|c|c|c|c|c|c|}
\hline Rundhöcker & & in $n$ & 1 & $\mathrm{~b}$ & $\mathrm{~h}$ & c \\
\hline $\begin{array}{ll}\text { Pfeilstein } & 11 \\
\text { Pfeilstein } & 14 \\
\text { Pfeilstein } & 22\end{array}$ & . & $\begin{array}{l}. \\
. \\
.\end{array}$ & $\begin{array}{l}16 \\
12,5 \\
5\end{array}$ & $\begin{array}{r}10 \\
6 \\
9\end{array}$ & $\begin{array}{l}3,5 \\
2 \\
1\end{array}$ & $\begin{array}{l}1,6 \\
2,1 \\
0,5 *\end{array}$ \\
\hline $\begin{array}{l}\text { Am Bach } 1 \\
\text { Am Bach } 2 \\
\text { Am Bach } 3\end{array}$ & . &.$\quad$. & $\begin{array}{l}4,6 \\
9 \\
7,5\end{array}$ & $\begin{array}{l}2,7 \\
5,5 \\
5\end{array}$ & $\begin{array}{l}1,4 \\
2 \\
2\end{array}$ & $\begin{array}{l}1,7 \\
1,6 \\
1,5\end{array}$ \\
\hline $\begin{array}{l}\text { Kamel . } \\
\text { Dach . }\end{array}$ & &. & $\begin{array}{l}6 \\
8\end{array}$ & $\begin{array}{l}4,5 \\
6\end{array}$ & $\begin{array}{l}1,5 \\
2,5\end{array}$ & $\begin{array}{l}1,3 \\
1,3\end{array}$ \\
\hline
\end{tabular}

A rithmetisches Mittel $\mathrm{m}=1,58$ (prakt. Wert 1,6).

(* Wurde als ganz abseitsliegend nicht zur Mittelbildung verwendet.)

Im Zusammenhang mit der Mittelwertbildung mußte einer andern, ganz grundlegenden Frage ebenfalls genügend Aufmerksamkeit geschenkt werden.

Alle bearbeiteten Rundhöcker waren von vegetationsbedecktem Glazialschutt umgeben, ja sie wuchsen gewissermaßen aus diesem Material heraus. Wie weit besaßen nun diese gemessenen Achsenverhältnisse überhaupt Gültigkeit, wenn nur der Vegetationsrand und nicht die anstehende Fußzone des Rundhöckers vermessen werden konnte? ${ }^{23}$ Die Untersuchung dieser Frage ergab aber, daß unter gewissen Voraussetzungen das grundlegende Achsenverhältnis c erhalten bleibt.

Unter diesen einschränkenden Bedingungen scheint es mir angepaßt, die eingangs aufgestellte Definition des Rundhöckers für die praktische Arbeit durch einen Nachsatz zu ergänzen. Wir würden dann den Rundhöcker folgendermaßen umschreiben:

«Eine das Umgelände überragende, glazial gerundete Gesteinspartie, deren randliche Begrenzung durch die Zone größter Konkavität oder durch Vegetations- und Schuttbedeckung gebildet wird.»

Mit dem Ziel, die Ergebnisse dieser analytischen Untersuchung in einer späteren Synthese verknüpfen zu können, wurde die quantitative Betrachtung der Rundhöcker, also deren Messung, nach dieser allgemein üblichen Protokollaufnahme noch weitergetrieben.

21 Siehe später (mathematische Partialkorrelation).

22 Bei der Bearbeitung stellte sich die Frage, ob das arithmetische Mittel gewählt werden dürfe, oder ob ein den geometrischen Beziehungen näherstehendes Verfahren herangezogen werden sollte. Die Rechnung ergab:

$$
\begin{array}{ll}
\mathrm{m}_{\mathrm{a}}=\text { Arithmet. Mittel }: \frac{\mathrm{c}_{1}+\ldots \ldots+\mathrm{c}_{i}}{7}= & 1,58 \\
\mathrm{~m}_{\mathrm{g}}=\text { Geometr. Mittel }: \sqrt[7]{\mathrm{c}_{1} \cdot \ldots \ldots \cdot \mathrm{c}_{i}} & =1,57 \\
\mathrm{~m}_{\mathrm{w}}=\text { Mittel der Winkel }: \operatorname{tg} \frac{\sum_{\mathrm{i}=1}^{7} \operatorname{arctg} \mathrm{c}_{\mathrm{i}}}{7}= & 1,56
\end{array}
$$

Die Belanglosigkeit der Differenzen und die Wahl von 1,6 als praktischer Wert erübrigten eine weitere Diskussion dieser Frage.

23 Wenn wir die Objekte der Untersuchung für einen Moment zu Ellipsoiden idealisieren wollen (siehe spätere Begründung), so ist leicht einzusehen, da $\beta$ bei einem beliebigen achsenparallelen Schnitt (= Oberfläche der Umgebung) die Achsenverhältnisse auf Grund der Affinitätsgesetze erhalten bleiben. 


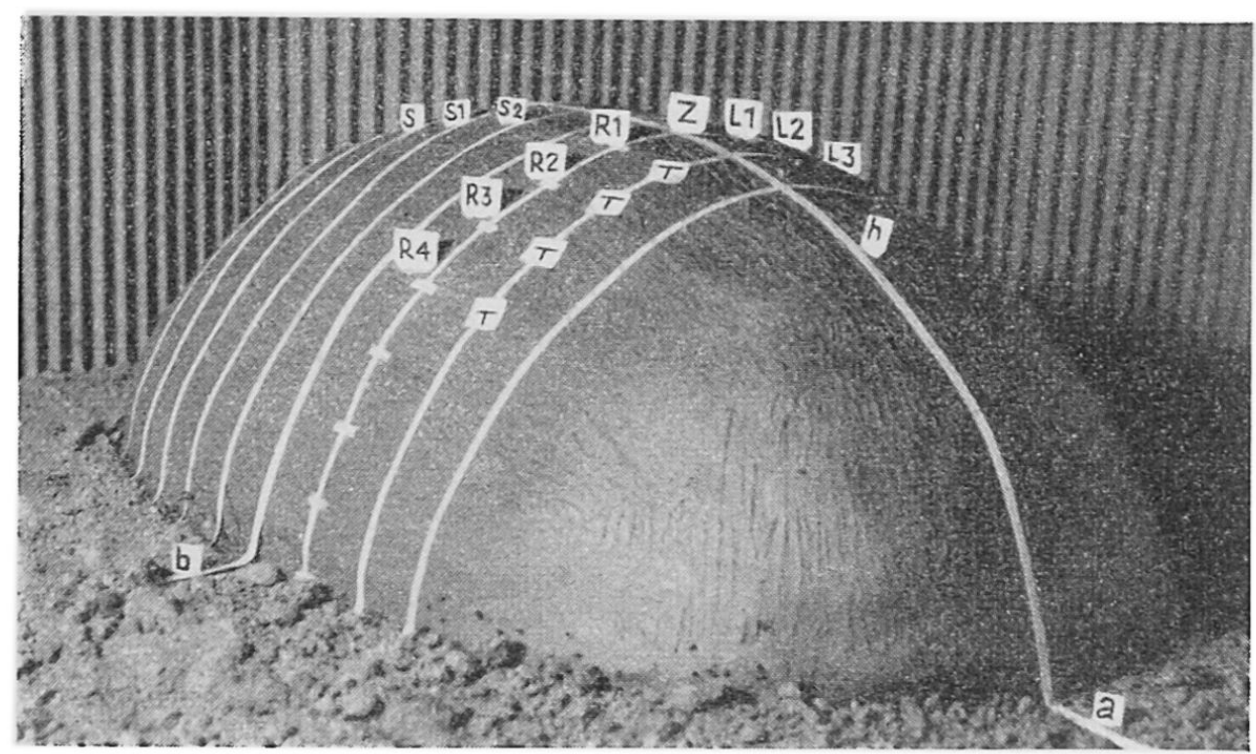

Abb.9: Modell des Ideal-Rundhöckers (E). - Achsenverhältnis, nach Tabelle 5, beträgt $1: 1,6$.

Die Anlage des Rundhöcker-Netzes und die Verteilung der Meßpunkte sind angedeutet.

$\mathrm{a}=$ Große Rundhöcker-Achse; $\mathrm{b}=$ Kleine Rundhöcker-Achse ; $\mathrm{h}=$ Hauptspant $; \mathrm{s}, \mathrm{s}_{1}, \mathrm{~s}_{2}, \ldots=$ Spanten; $Z=$ Meßpunkt auf dem Hauptspant $; L_{1}, L_{2}, L_{2}, \ldots=$ Meßpunkte vom Hauptspant nach links; $R_{1}, R_{2}, R_{3}, \ldots=$ Meßpunkt vom Hauptspant nach rechts.

Es galt vorerst einmal, die Form der Rundhöckeroberfläche, oder sagen wir besser die Stellung der Flächengesamtheit der Rundhöcker, in eine ähnliche oder gar gleiche Darstellungsform zu bringen wie die Klüfte.

An vielen Stellen des Rundhöckers die Tangentialfläche $z u$ bestimmen und diese wie Kluftflächen auszuwerten, war naheliegend. Es stellte sich deshalb das Problem, die zu vermessenden Punkte auf dem Rundhöcker möglichst gut, d. h. gleichmäßig zu verteilen.

Diese Punkte, fortan als Meßpunkte benannt, wurden durch das Rundhöckernetz fixiert.

Wir vergleichen dazu am besten Abb. 9, die das Modell eines Rundhöckers mit Teilen eines Rundhöckernetzes darstellt.

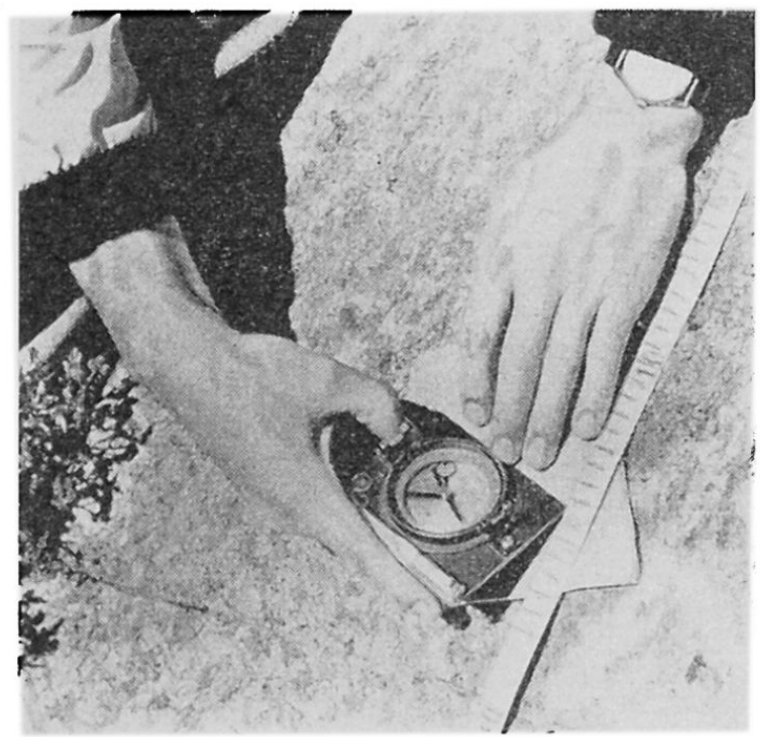

$A b b$.10: Oberflächenmessung an Rundhöckern. - Ablesen der Streichrichtung in einem Meßpunkt.

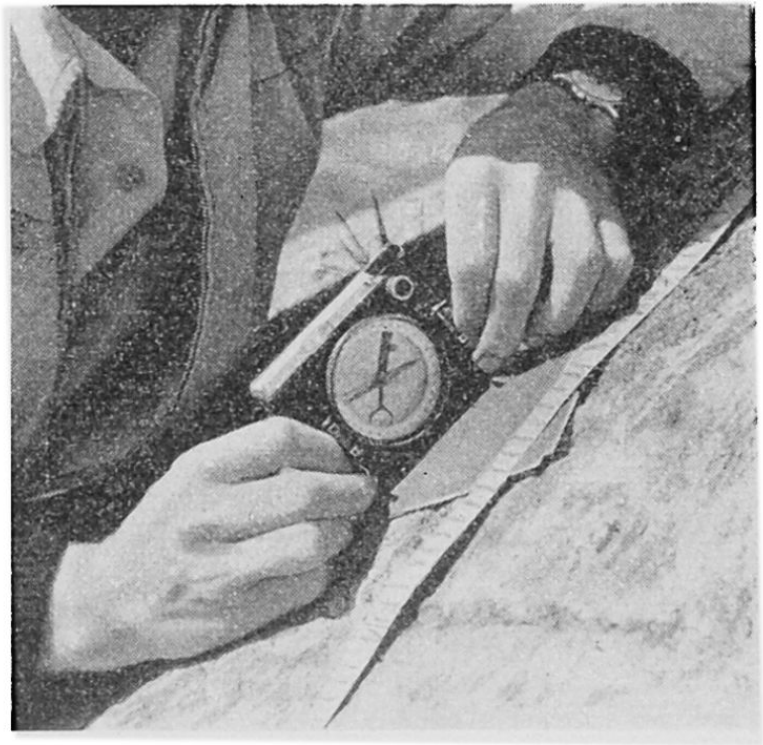

Abb. 11: Oberflächenmessung an Rundhöckern. - Ablesen des Fallens im gleichen Meßpunkt wie in Abb. 10. 
Auf dem Hauptspant (h) wurden, von den Stoßseiten ausgehend, Strecken von $50 \mathrm{~cm}^{24}$ abgetragen. Durch die so festgelegten Punkte, in der Vertikalebene normal zur großen Hauptachse (a), verlaufen dann die Spanten ( $s_{1} s_{1}, \ldots$ ) über den Rundhöcker. Auf diesen wiederum, in Abständen von $50 \mathrm{~cm}$ konnten dann vom Zenith $(Z)$ aus nach links und rechts fortschreitend die Meßpunkte $L_{1}, L_{2}, L_{3}, \ldots$ bzw. $R_{1}$, $\mathrm{R}_{2}, \mathrm{R}_{3}, \ldots$ festgelegt werden.

Die Stellung der Tangentialflächen in diesen Meßpunkten konnte gleichermaßen ermittelt werden wie die der Kluftflächen. Ein kleines Messingblech leistete auch hier große Dienste, einmal zum Anlegen der Bussole, dann aber auch zum Wegkratzen störender Flechten.

Den gemessenen Werten für Streichen und Fallen wurde noch eine Beschreibung über Zustand und Form der Bezugsfläche $\left(0,25 \mathrm{~m}^{2}\right)$ beigefügt. Diese sog. Flächencharakteristik war viergliederig mit stufenweise sich ausweitendem Geltungsbereich ${ }^{25}$.

Die gefundenen Zahlenwerte wurden ins Arbeitsnetz übertragen und wie Klüfte (Abschnitt A, II, 1) weiterbehandelt.

Fig. 9 zeigt eine solche Darstellung als Lotbild am Beispiel des Rundhöckers «Am Bach $1 »$, der gleich nachher in den Abb. 12 und 13 dargestellt ist.

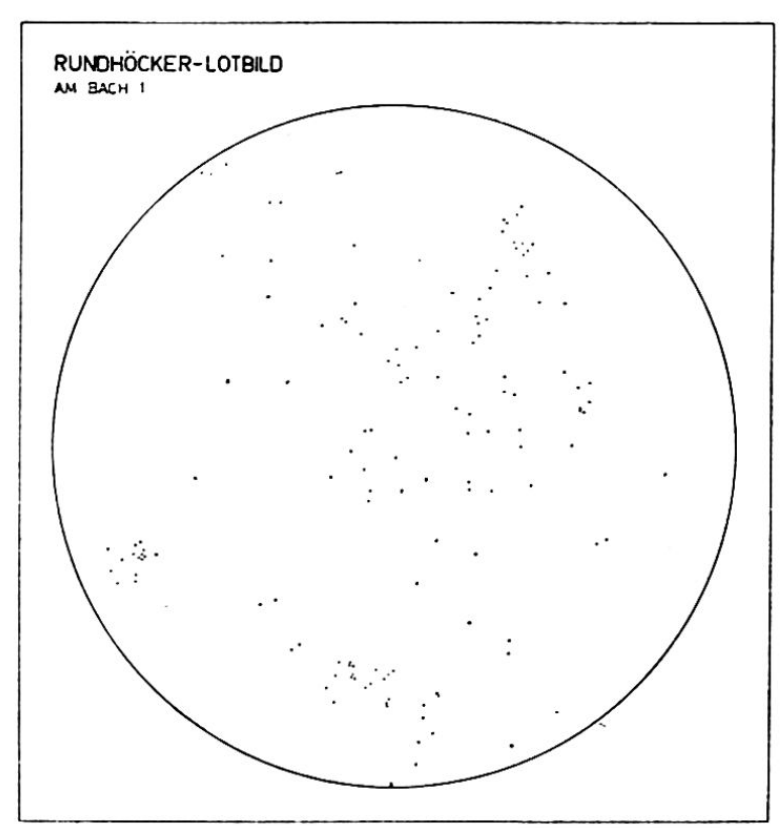

Das Lotbild zeigt deutlich, daß neben starken Häufungen (- am Rundhöcker: Zonen leichter Krümmung) auch große polfreie Gebiete (- am Rundhöcker: Zonen besonders starker Krümmung) vorkommen.

Die Lotbilder konnten natürlich auch zu Diagrammen umgearbeitet und in dieser Form für die graphische Auswertung gut verwendet werden. Für die mathematischen Betrachtungen eigneten sich indessen die Lotbilder besser.

Fig. 9: Oberfläche des Rundhöckers «Am Bach $1 \gg$. - Darstellung der Lage von Tangentialflächen als Lot-Bild.

24 Für sehr große Rundhöcker wurde manchmal der Abstand $1 \mathrm{~m}$ gewählt, bei solchen von mittlerer Größe auf dem Hauptspant $50 \mathrm{~cm}$, auf den Spanten $1 \mathrm{~m}$ mit seitlicher Verschiebung um $50 \mathrm{~cm}$ nach links oder rechts, was ein Diagonalnetz mit Maschenweite von $50 \sqrt{2} \mathrm{~cm}$ ergab.

25 Sie enthielt von links nach rechts:

Beschaffenheit der Fläche (rauh, poliert, rauh-poliert).

Ebenheit im Kleinen (eben, uneben).

Ebenheit im Großen (eben, uneben, gewölbt, leicht-gewölbt, konkav).

Besonderheiten (deutliche Kluft äche, Ausbruch).

Durch die Bildung des Quotienten aus Merkmalen der glazialen Bearbeitung und solchen glazialer oder postglazialer Zerstörung wurde ein Flächenindex

$$
\mathrm{f}=\frac{\mathrm{p}+\mathrm{rp}}{\mathrm{K}+\mathrm{A}}
$$

eingerichtet. Hohe f-Werte charakterisieren rundliche Rundhöcker, niedrige Werte hingegen eckige. In Gebieten, wo glaziale Politur nicht mehr zu finden war, wurde $p+r p$ durch $g+l g$ ersetzt. Im Gebiet des Grimselpasses fand ich folgende Beziehung:

$\mathrm{f}^{\prime}=\mathrm{C} \frac{\mathrm{g}+\mathrm{lg}}{\mathrm{K}+\mathrm{A}}$ Dabei ist für die Konstante $\mathrm{C}$ der Wert 1,82 zu setzen. 


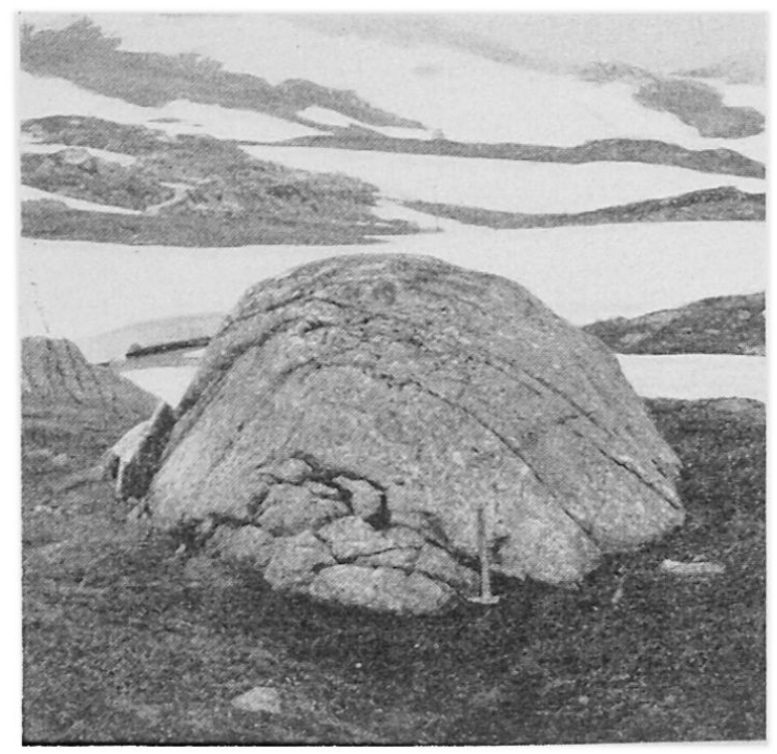

$A b b$. 12: Rundhöcker «Am Bach 1》. StoßSeite, Aufnahme gegen NW.

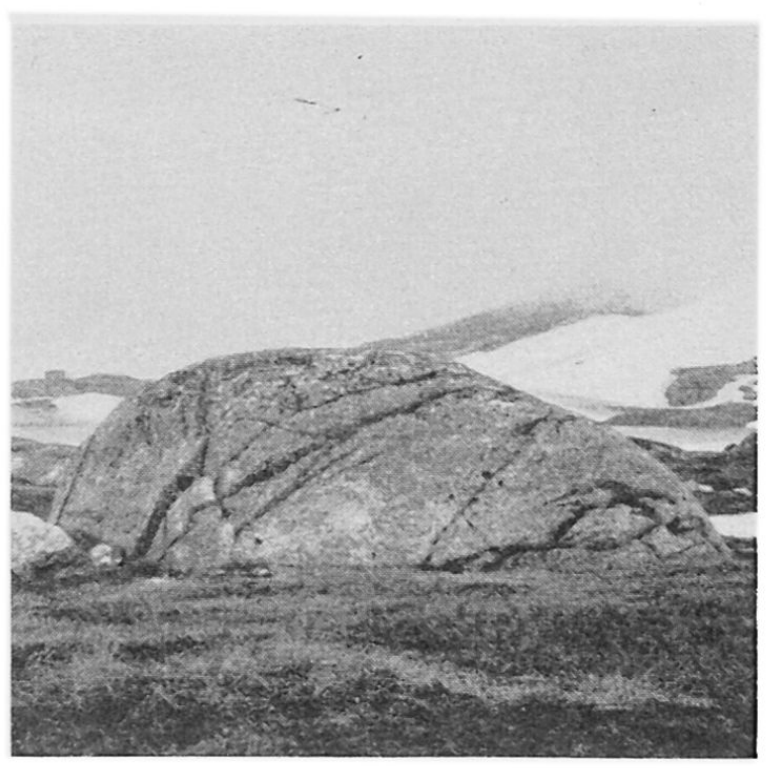

Abb. 13: Rundhöcker «Am Bach 1》. Linke Seite. Aufnahme gegen NE.

Bei der vorliegenden Untersuchung bestand von Anfang an die Gefahr, daß die gewonnenen quantitativen Resultate gar nicht hinreichend interpretiert werden könnten und daß zudem bei jeglichem Deutungsversuch keine entsprechende Sicherung gewährleistet wäre.

Ich definierte deshalb gleich zu Anfang zwei Vergleichskörper, sogenannte IdealRundhöcker mit geometrisch eindeutig bestimmten Formen. Es eigneten sich dazu besonders die Kugel (Ideal-Rundhöcker [K]) und das Rotationsellipsoid (Ideal-Rundhöcker $[E]$ ) mit dem im Feld gewonnenen Achsenverhältnis $c=1: 1,6$.

Alle an den Rundhöckern durchgeführten Verfahren wurden auch auf diese Ideal. Rundhöcker angewendet. Die Resultate der Arbeit erlaubten alsdann eine Abschätzung des praktischen Aussagewertes der ersteren.

Ich habe im letzten Abschnitt das Rundhöckernetz beschrieben. Es wäre nun noch zu untersuchen, ob die derart angeordneten Meßpunkte wirklich annähernd gleichmäßig über einen Rundhöcker verteilt sind, oder ob an irgend einer Stelle (Stoß-Seite/ Lee-Seite oder Seitenflächen) große Konzentrationen entstehen.

26 Betrachten wir einen Ideal-Rundhöcker, ausnahmsweise mit der bei der Erdkugel üblichen Gradeinteilung versehen. Bei horizontaler Lage der Erdachse würden dann die Parallelkreise der Kugel genau den Spanten am Rundhöcker entsprechen.

An Stelle der Punktdichte D (Punkte pro Flächeneinheit) kann für die Untersuchung der Quotient D' aus Länge des Mittelparallelkreises einer Zone, dividiert durch die Zonenfläche, treten.

Untersuchen wir den Wert D' für den Parallelkreis mit der geographischen Breite $q$ und die Zonenfläche zwischen den Parallelkreisen $\varphi+a$ und $q-a$, so erhalten wir:

$$
\begin{aligned}
& \mathrm{D}^{\prime}=\frac{\text { Länge des Kreises }}{\text { Fläche der Zone }}=\frac{\mathrm{r} \cdot \pi \cdot \cos \varphi}{\mathrm{r}^{2} \pi[\sin (q+a)-\sin (q-a)]}= \\
& =\frac{\cos \varphi}{\mathrm{r}(\sin \varphi \cdot \cos q+\cos \psi \cdot \sin \omega-\sin \psi \cdot \cos \alpha+\cos \varphi \cdot \sin \omega)}= \\
& =\frac{\cos \varphi}{2 \mathrm{r} \cos \varphi \cdot \sin \omega}=\underline{2 \mathrm{r} \cdot \sin \omega}=\mathrm{f}(\alpha)+\mathrm{f}(\varphi)
\end{aligned}
$$

Dieses Resultat besagt, daß die Punktdichte wirklich nur von der Zonenbreite, d. h. am Rundhöcker vom Spantenabstand (Maschenweite des Rundköckernetzes), aber nicht von der Lage auf dem Rundhöcker abhängig ist. 


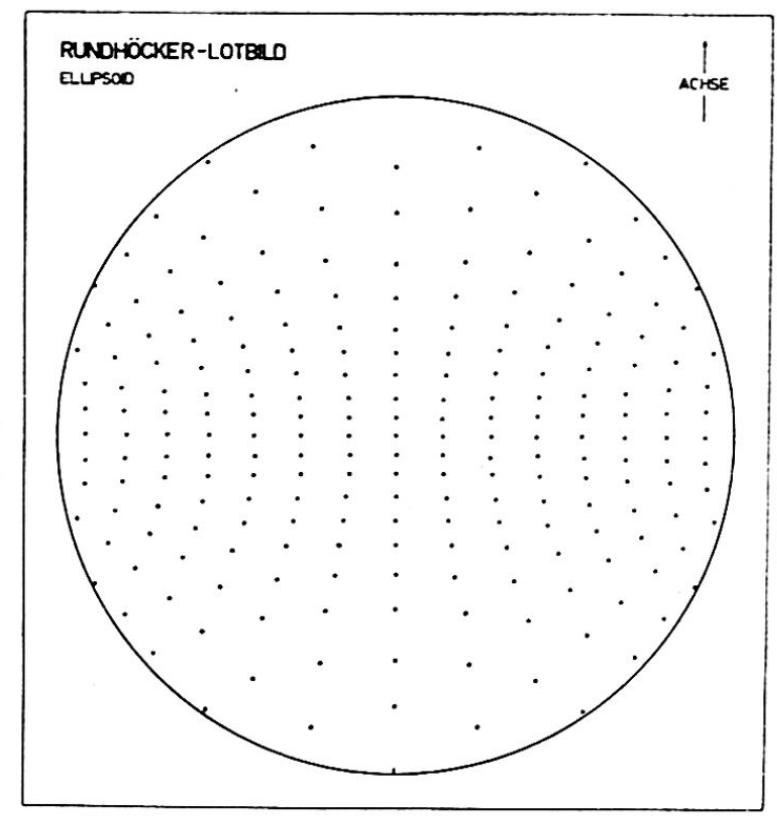

Fig. 1o: Oberfläche des Ideal-Rundhöckers (E).

- Darstellung der Lage von Tangentialflächen als Lot-Bild.

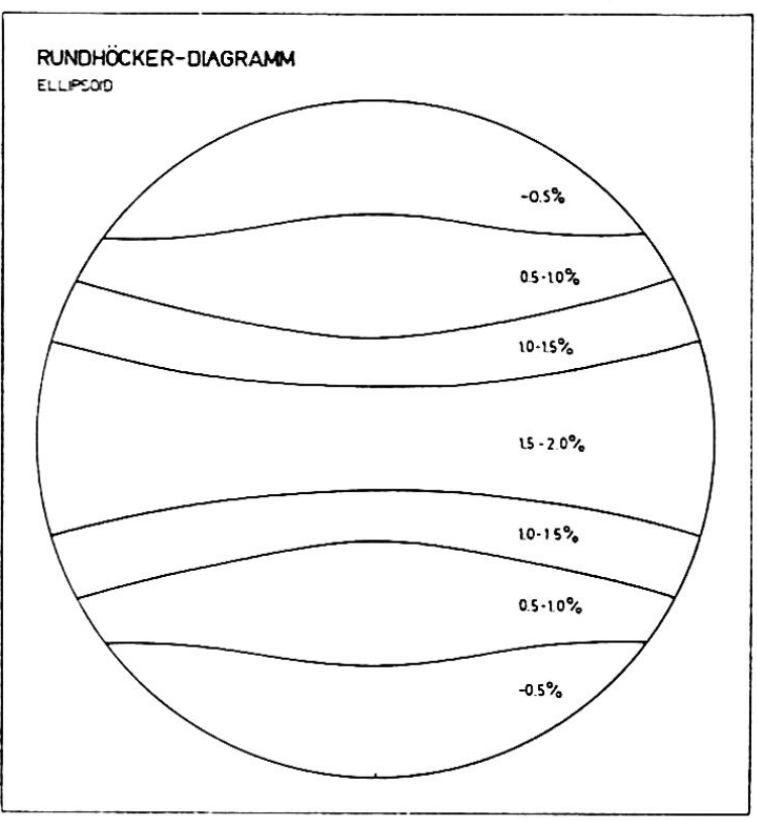

Fig. 11: Oberfläche des Ideal-Rundhöckers (E). - Darstellung der Lage von Tangentialflächen als Diagramm. Durch Reihenbildung erzeugte Unregelmäßigkeiten der Besetzungsdichte wurden ausgeglichen.

An den Idealrundhöckern (E) und (K) konnte diese Untersuchung gut durchgeführt werden. Für den Ideal-Rundhöcker $(K)$ ergibt die Rechnung eine vollständig gleichmäßige Verteilung der Meßpunkte über die ganze Oberfläche ${ }^{26}$. Auch das Lotbild dieses Rundhöckers (Kugel) müßte natürlich diese homogene Punktverteilung wieder zeigen (flächentreue Projektion). Für den Ideal-Rundhöcker (E) wurden die Lage der Meßpunkte und die Stellung der Lote mittels darstellender Geometrie konstruiert (Fig. 10).

Das Diagramm (Fig. 11) zeigt, daß die Werte für die Dichte der Pole von ungefähr $0,5 \%$ bis $2,0 \%$ variieren. Eine Zone dichterer Besetzung zieht quer über den Rundhöcker, während Stoß-Seite und Lee-Seite weniger dicht besetzt sind. Diese Werte liegen aber um ein Mehrfaches unter den im Feld gefundenen Dichtewerten für Rundhöcker.

\section{b) Nägelisgrätli}

Auf der Verebnung N Pt. 2395 im Aufstieg zum Nägelisgrätli wählte ich 3 Rundhöcker zur Bearbeitung aus. Sie liegen genau $200 \mathrm{~m}$ höher als jene um den Totensee und erscheinen dem Betrachter schon auf den ersten Blick sehr kluftbedingt, ja sogar nach einem sehr stark wirksamen Kluftsystem in Reihen geordnet. Ihre Glazialpolitur ist jedoch kaum mehr zu erraten. Durch die Verwitterung herausgearbeitete Mineralien 27 und harte Flechten erschwerten die Arbeit sehr.

c) Göschener Al.p

In diesem Gebiet wurden aus den Rundhöckern, welche die von Gwüest ( $N$ Jäntelboden) gegen $\mathrm{E}$ ansteigende Terrasse besetzen, drei zur Vermessung ausgewählt. Auch hier war die Oberfläche nicht annähernd so gut erhalten wie auf der Grimsel. Der Erhaltungszustand der Oberfläche entsprach etwa dem vom Nägelisgrätli ${ }^{27}$.

27 Siehe Abschnitt III B: Eisrichtung. 


\section{d) Gotthard}

Ich bearbeitete 3 Rundhöcker SW Pt. 2108,5 (Paßhöhe). Ihr Zustand war recht gut. Glazialpolitur bestand in der Umgebung in großen Flächen. Auch auf den betrachteten Rundhöckern waren Reste davon erhalten ${ }^{\mathbf{}} \mathbf{}$.

e) Bernina-Paß

SE der Paßhöhe wurden zwei Rundhöcker studiert. Einer der beiden wurde vermessen und konnte mit den hier üblichen Methoden dargestellt werden. Der zweite, von dem nur die Stoßseite einer Bearbeitung zugänglich war, diente zu einer Spezialstudie $\mathbf{2 8}$.

a) Grimsel

\section{Die Eisrichtung}

Um die Reaktion des geklüfteten Gesteins zu verstehen, ist es nötig, die Bewegungsrichtung des arbeitenden Eises möglichst genau zu kennen. Gletscherschliffe sind ja im Gebiet der Grimsel an vielen Stellen recht schön erhalten. Einzelne sind aber sehr unzuverlässig und je nach Lage der Gesteinsoberfläche zur Eisrichtung bedeutend abgelenkt. Vertrauenswürdig erscheinen demnach höchstens Schliffspuren auf ebenen, flachliegenden Felsplatten. EDELMANN (16) erwähnt für den ersten Fall Ablenkungen bis $50^{\circ}$. Er beschreibt aber auch Beispiele, wo der Eisstrom auf flachen Felsplatten durch Vorsprünge, die heute verschwunden sind, zerschert und abgelenkt wurde 29 .

Um solche Fehler zu vermeiden, zeichnete ich das Kärtchen der Gletscherschliffe (Fig. 12). Als Grundlage diente die Teilvergrößerung einer Luftaufnahme im Maßstab 1:5000. An 64 Orten fand ich insgesamt 200 Richtungen. Die Zahlen eines Meßortes wurden, allerdings unter Berücksichtigung ihrer Lage, gemittelt und in die Luftaufnahme (Pause) eingetragen. Meine Absicht bestand darin, der Karte später an jeder beliebigen Stelle, auch dort, wo keine Schliffe gefunden werden konnten, die wahrscheinlichste Eisrichtung entnehmen zu können.

Als meßbare Merkmale für die Richtung wurden verwendet:

$$
\text { Merkmale }
$$

Kratzer: Feinste Schliffspuren; einige $\mathrm{cm}$ bis dm lang; nur sichtbar, wenn Politur noch vorhanden (Kristalle flachgeschliffen; Abb. 14) und bei tiefstehender Sonne ${ }^{30}$.

Rillen: Fingerbreit, bis $3 \mathrm{~mm}$ tief und bis mehrere dm lang; mit und ohne Politur.

Rinnen: Bis mehrere $\mathrm{dm}$ breit, über $5 \mathrm{~cm}$ tief, bis einige $\mathrm{m}$ lang (Abb. 15).

Sichelbrüche, Parabelrisse und Rundhökkerform (siehe Anmerkung 32; p. 22).
Aussagewert

In der Richtung sehr zuverlässig, zeigen letztes Stadium, je nach Lage auch Plastizität des Eises (Eismächtigkeit).

Längere Eisarbeit ; gefährlich, da Gesteinstextur ähnliche Formen bilden kann.

Vorsichtig zu interpretieren; ev. teilweise Arbeit fließenden Wassers; ev. Richtung durch Ausriß längs Kluft angelegt.

Geben nur groben Hinweis auf die Hauptrichtung.

Kombinationen: Kratzer oder Rillen in Rinnen sind möglich.

28 Es wird hier auf die Darstellung dieser etwas vom Problem abweichenden und den Rahmen sprengenden Untersuchung verzichtet.

29 Klebelsberg (28) beobachtete auch starke Divergenzen der Gletscherschliffe in der Randzone des Gletschers.

30 Nach Heim (21) zerfallen zuerst Glimmer und Quarze, während die Feldspäte als Träger der Gletscherschliffe am längsten zurückbleiben. 


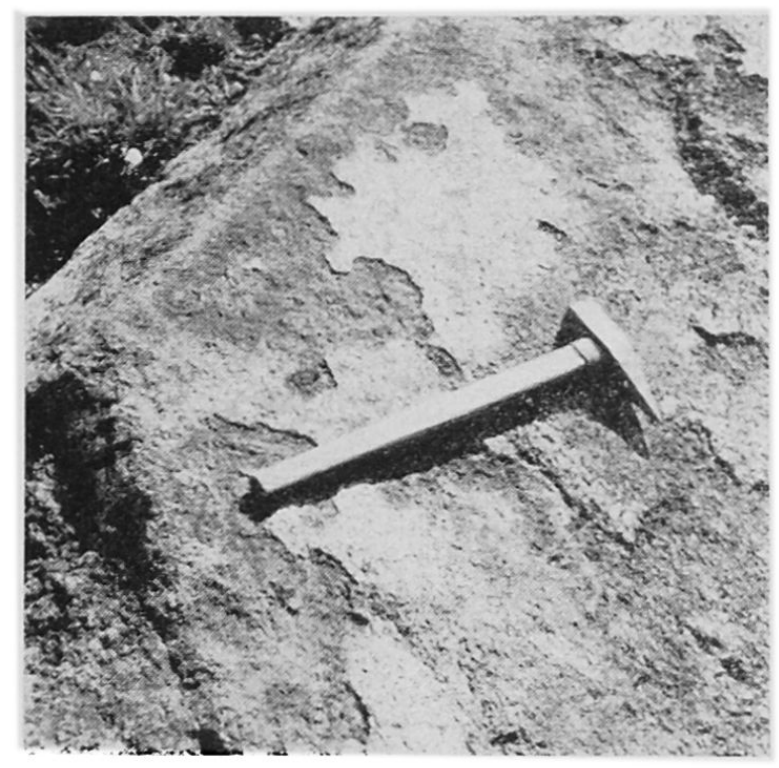

$A b b .14:$ Rundhöckeroberfläche mit Resten glazialer Politur. Daneben sog. rauhe Oberfläche. Die Feldspäte sind Hauptträger der Gletscherschliffe. Richtung des Hammers $=$ Schliffrichtung.

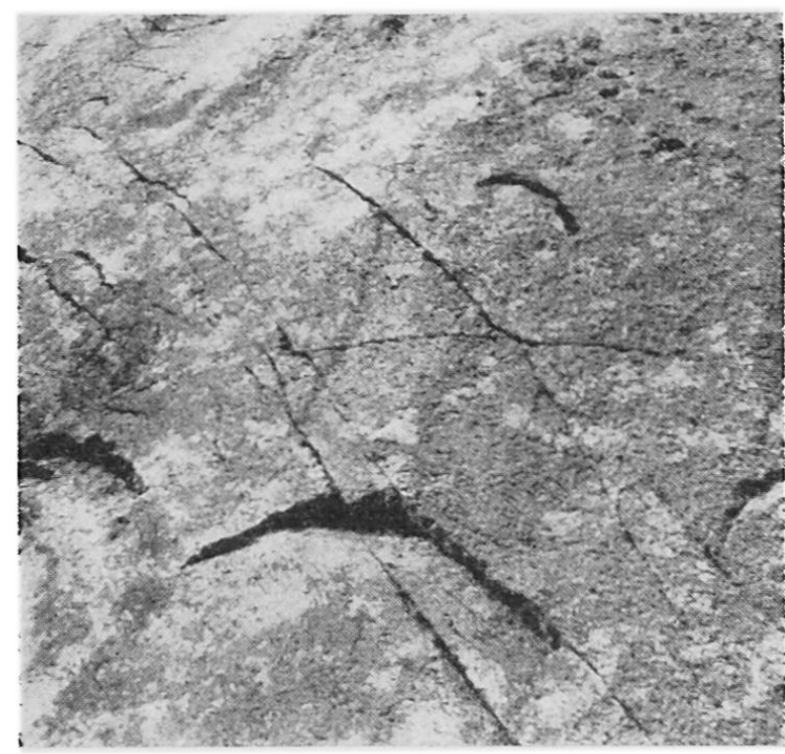

Abb. 16: Rundhöcker-Stoßseite mit Sichelbrüchen (siehe Anmerkung 32). Mittel der Symmetrieachsen $=94^{\circ}$.

Als Merkmale für den Richtungssinn des Eises wurden verwendet:

\section{Rundhöckerform}

Sichelbrüche und Parabelrisse (Abb. 15 und 16)

Abhebkanten des Eises (Abb. 19)

Topographische Verhältnisse

Die Karte (Fig. 12) zeigt folgendes:

Richtungen: Im Gebiet um den Totensee sind fast überall zwei Eisrichtungen festzustellen.

Eine erste Richtung zwischen $120^{\circ}$ und $160^{\circ}$ ist durchwegs deutlich zu erkennen (ältere Richtung). Sie scheint an der Prägung der Rundhöckerflur am stärksten verantwortlich $\mathrm{zu}$ sein. Die Schliffe dieser Richtung drehen von E-W-Streichen im Osten und SE-NW-Streichen im Süden der Karte allmählich auf SSE-NNW-Strei-

Abb. I5: Rundhöckeroberfläche mit Rinnen und Rillen (Parallel zum Bleistift, ca.153 ${ }^{\circ}$ ).

Kratzer (vor allem links im Bild) laufen vom Betrachter weg (ca. $96^{\circ}$ ).

Im Vordergrund sind Parabelrisse zu erkennen.

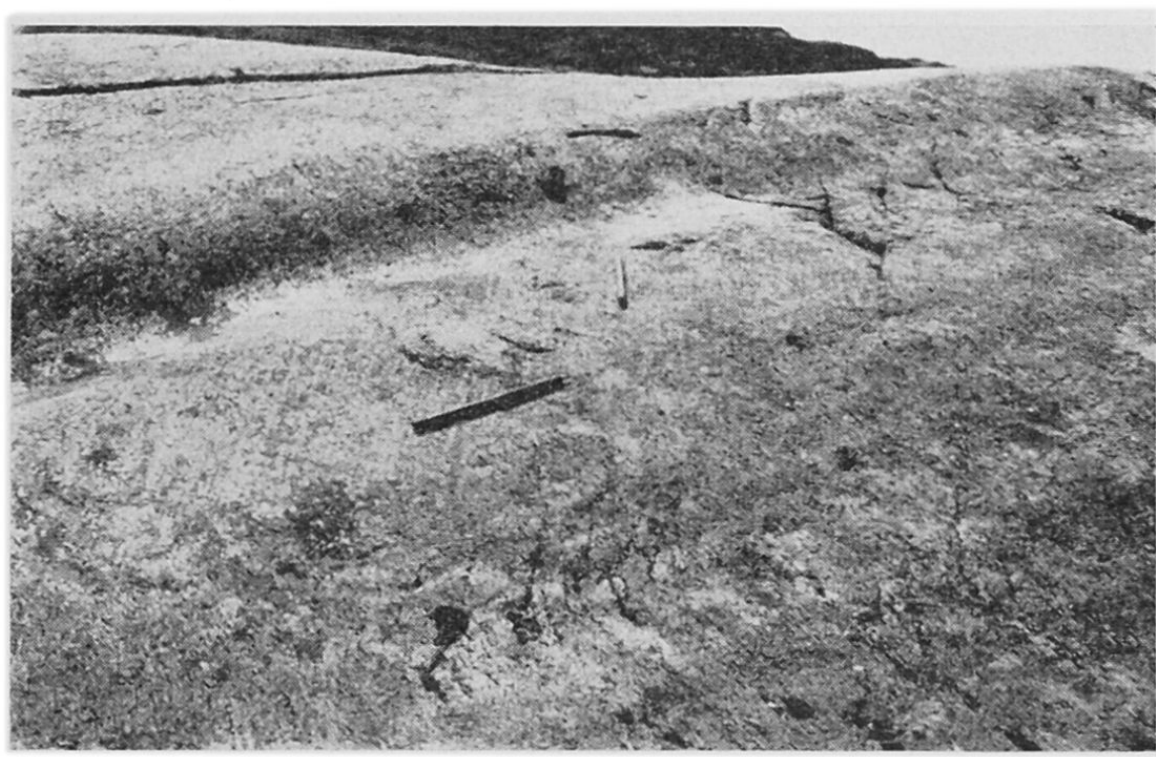




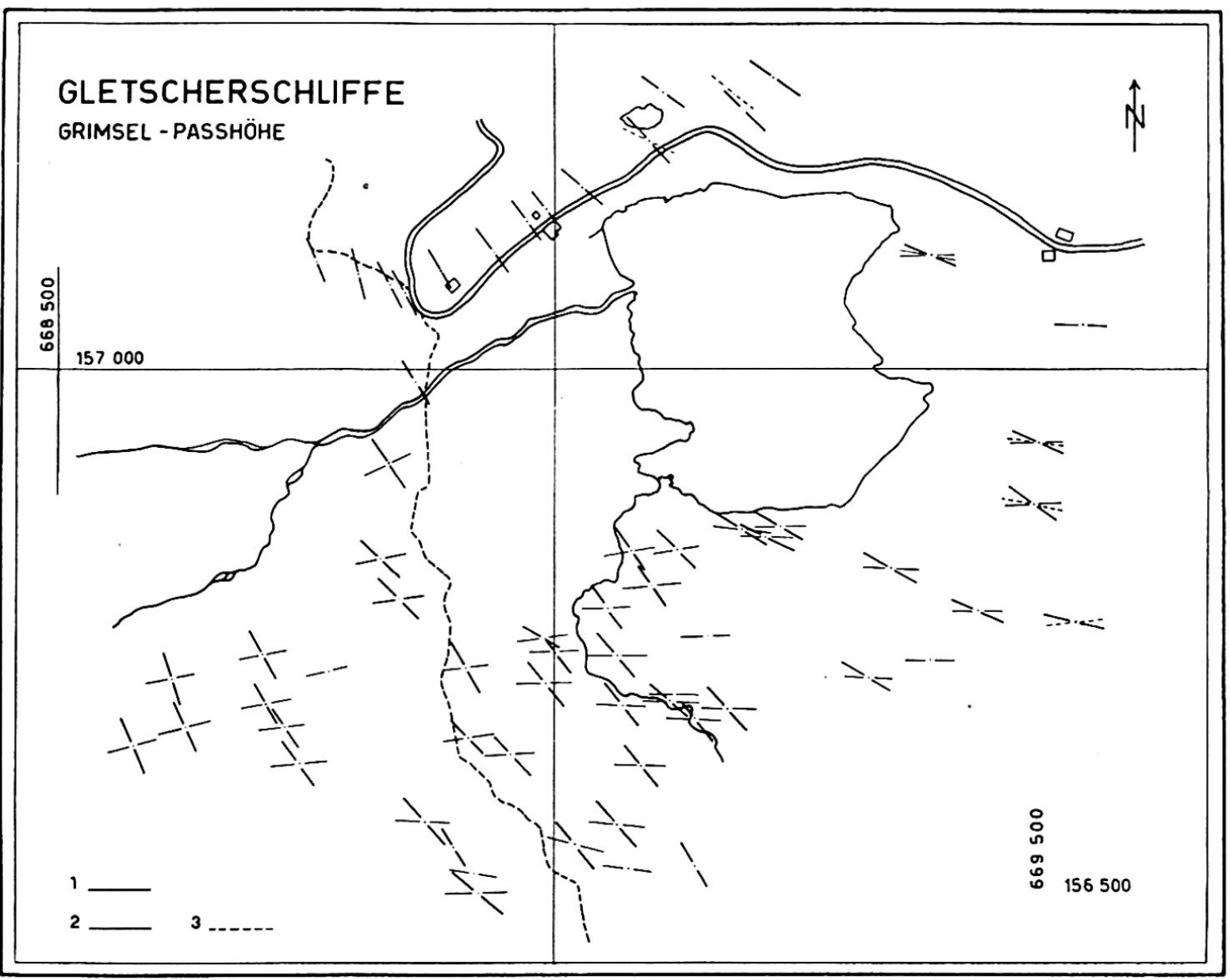

Fig.12: Richtung der Gletscherschliffe auf der Grimsel-Paßhöhe. - 1= ältere Richtung; 2 $=$ jüngere Richtung; $3=$ keiner Richtung eindeutig zuzuordnen.

Die topographischen Unterlagen wurden einer Flugaufnahme mit dem mittleren Maßstab von ca. 1:5000 entnommen.

chen im Norden. Eine Raffung der Schliffspuren beim Überfließen des Riegels $N$ Totensee tritt im Kartenbild deutlich hervor.

Eine zweite Richtung zwischen $80^{\circ}$ und $105^{\circ}$ (jüngere Richtung) weicht im westlichen Teil nur wenig von W-E gegen $\mathrm{N}$ ab, öffnet sich aber gegen $\mathrm{E}$ fächerförmig.

Die beiden Richtungen kreuzen sich im westlichen Teil fast rechtwinklig (Abb. 17). Der Schnittwinkel wird gegen $\mathrm{E}$ immer kleiner, bis die beiden Richtungen im östlichsten Abschnitt mehr oder weniger zusammenfallen ${ }^{31}$.

Richtungssinn: Auf Grund von Rundhöckerformen, Sichelbrüchen ${ }^{32}$, aus dem Verlauf der Schliffrichtung und nach dem Relief ist als Richtungssinn für die ältere

31 Nach Penck und Brückner (41) erkannte schon Agassiz (1842) das Abdrehen der Gletscherschliffe nach $\mathbf{N}$ und damit die Transfluenz ins Haslital. BALzER bezweifelte allerdings 1896 diese Tatsache nochmals. $\mathrm{Da} \beta$ die beobachteten Divergenzen in der Schliffrichtung aber z. T. auf die zwei verschiedenen Richtungssinne der Eisbewegung zurückzuführen sind, wird nicht erwähnt.

32 LJUngner (33) verknüpft Parabelrisse und Sichelbrüche in ihrer Entstehung. Der Eisdruck, durch einen Stein oder einen Block gesammelt und an einem bestimmten Punkt auf den Untergrund übertragen, erzeugt im Gestein das Spannungsbild eines Schlagkegels, der die Achse, durch die Eisbewegung verstärkt, nach vorn neigt. Seine proximale Seite erzeugt die senkrecht im Gestein eintauchenden Parabelrisse (konkave Seite in der Bewegungsrichtung), während auf der distalen Seite die flach einfallenden Risse als Anlage zu den herauszubrechenden Sicheln betrachtet werden können. (Konvexe Seite in der Bewegungsrichtung.) 
Abb. 17: Felsplatte mit Schliffen der ältern Richtung von links unten nach rechts oben (ca. $\left.144^{\circ}\right)$.Darüber, diese kreuzend,Schliffeder jüngern Richtung von vorn nach links oben $\left(\right.$ ca. $\left.84^{\circ}\right)$.

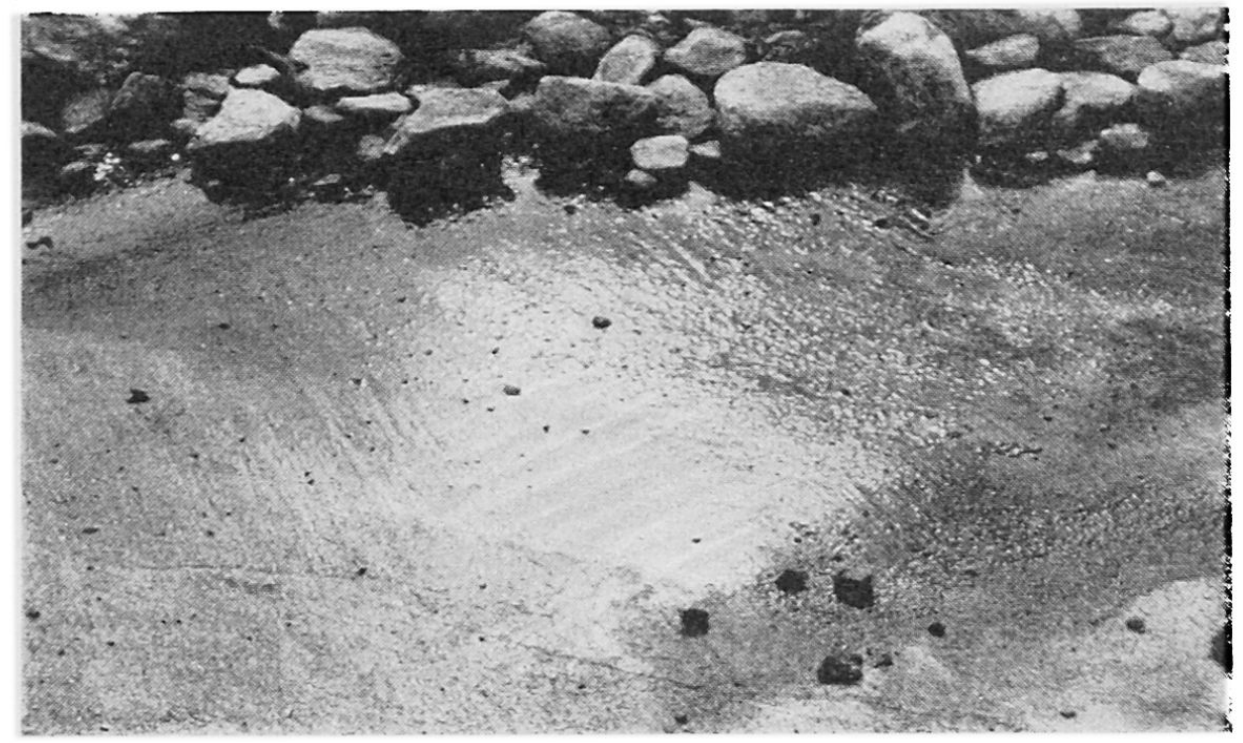

Richtung E-W-Bewegung mit langsamem Abdrehen nach $\mathrm{N}$ anzunehmen. Für die jüngere Richtung folgt aus den erwähnten Gründen W-E-Bewegung.

Wir hätten demzufolge ganz im $\mathrm{E}$ des Kärtchens in den zwei Phasen genau entgegengesetzt verlaufende Eisrichtungen. Einen Beweis für die Richtigkeit dieser Annahme fand ich in der entsprechenden Lage von Sichelbrüchen auf einer ca. einen Quadratmeter messenden polierten Felspartie (Abb. 18).

Dieser Fund illustriert zudem recht deutlich die geringe Wirksamkeit der zweiten Phase, da bei intensiverer Überarbeitung im letzten Stadium die Spuren früherer 'Tätigkeit stärker verwischt worden wären.

Zeitliche Folge: Ich habe die erstbeschriebene Richtung schon als die ältere benannt. Die Gletscherschliffe dieser Gruppe müssen dem Gestein von Eismassen mit sehr großer Plastizität aufgeprägt worden sein, denn das Eis muß die Rundhöcker fast allseitig umschlossen haben.

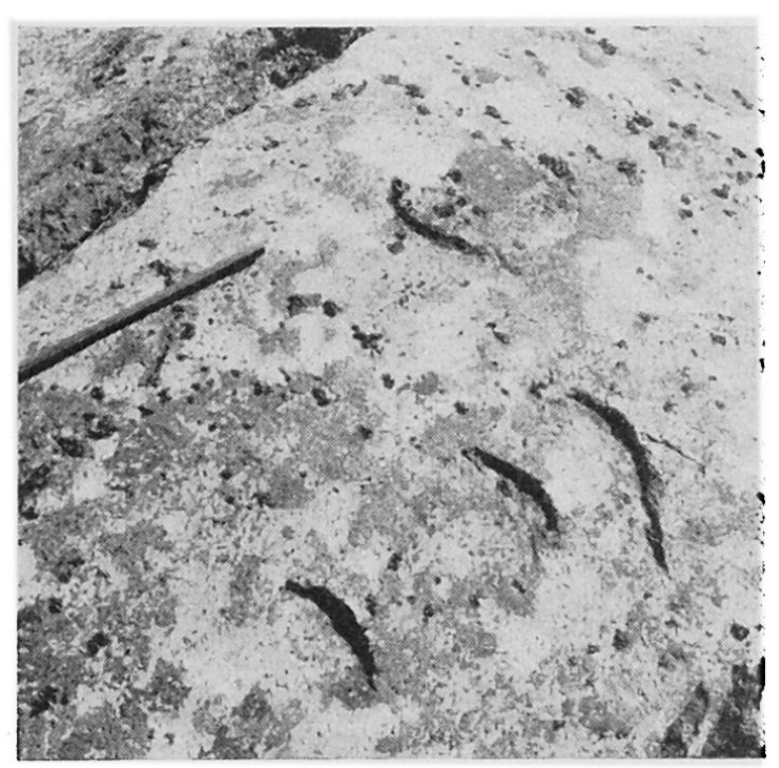

Abb.18: Rundhöcker mit Sichelbrüchen der jüngern Richtung vorn (ca. $90^{\circ}$; von $\mathrm{W}$ nach E) und der ältern Richtung hinten (ca. $85^{\circ} \pm 5^{\circ} ;$ von E nach $\mathrm{W}$ ).

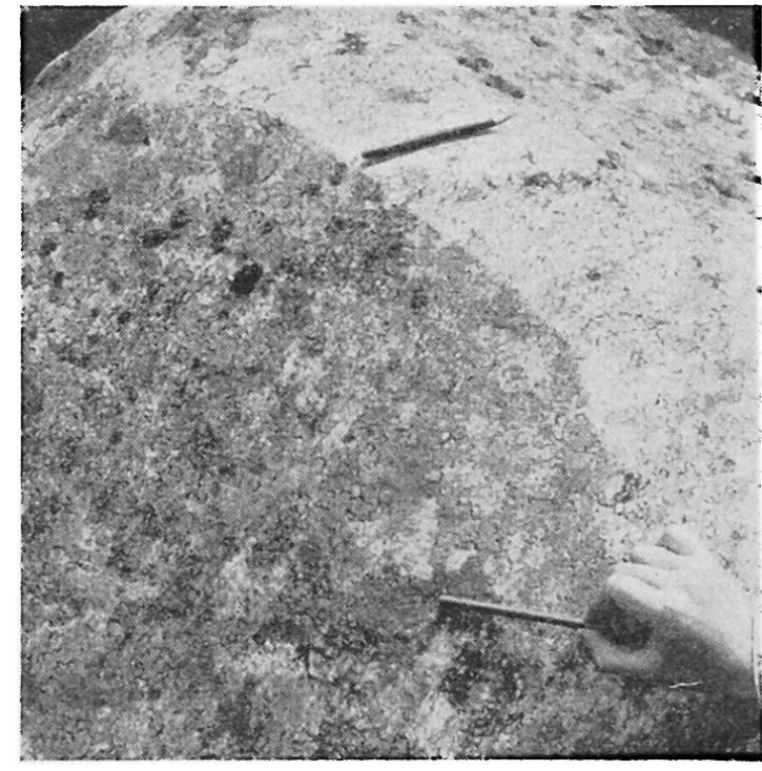

Abb.19: Abhebekante der Schliffe jüngerer Richtung (Bleistift; von rechts nach links) von den Schliffen der ältern Richtung (Hand mit Bleistift; gegen den Beschauer). 
In der zweiten Phase (als jüngere benannt) schliff das Eis oft nur die obersten Partien. Es war bedeutend weniger plastisch und bildete an der Politur der ersten Richtung N-S verlaufende Abhebekanten (Abb. 19).

Diese Schliffe ziehen deutlich über die ältern hinweg ${ }^{33}$. Ich ordne diese ältern Spuren deshalb einem Eishochstand zu, während ich für die jüngern nacheiszeitliche Lokalvergletscherung annehme.

b) Übrige Gebiete

Die bedeutend geringere Ausdehnung und die größere Einheitlichkeit der Eisrichtungen erlaubten es, die Bearbeitung dieses Elements hier bedeutend einzuschränken. Für alle 4 Gebiete wurden in nächster Nähe der Objekte Schliffspuren gemessen und gemittelt, extrem abweichende Werte aus den Protokollen gestrichen.

Tabelle 6 stellt die Mittelwerte, den Richtungssinn und die Anzahl der zur Mittelbildung verwendeten Messungen dar:

\section{Tabelle 6 - Gletscherschliffe}

$\begin{array}{lccc}\text { Ort der Messungen } & \text { Arithmet. Mittel } & \text { Richtungssinn } & \text { Anzahl } \\ \text { Nägelisgrätli . . } & .92^{\circ} & \text { E-W } & 16 \\ \text { Göschener } \mathrm{Alp} \text {. } & 85^{\circ} & \text { W-E } & 6 \\ \text { Gotthard-Paß } 34^{\circ} . & 122^{\circ} & \text { NW-SE } & 14 \\ \text { Bernina-Paß . . } & 130^{\circ} & \text { NW-SE } & 4^{*}\end{array}$

* Sehr fraglich, ev. nur lokale Richtung eines späten Stadiums.

\section{Korrelation der Beobachtungsergebnisse und Schluffolgerungen}

In diesem Abschnitt der Arbeit, der, wie schon erwähnt, eine Synthese der einleitenden Kapitel bilden soll, wähle ich folgendes Vorgehen:

Nach einer kurzen Erklärung der Methode im allgemeinen und ihrer Modifikation für meine besonderen $Z$ wecke werde ich am Beispiel eines Rundhöckers den Arbeitsgang vollständig darstellen. Gleich anschließend folgen dann Zusammenstellungen der entsprechenden Resultate für die andern Objekte, Diskussion derselben und mögliche Schlüsse.

\section{DISKUSSION DER METHODEN}

Durch die Auflösung der Rundhöckeroberfläche in eine Vielzahl von Flächenelementen mit zugeordneten Meßpunkten sind wir von einer Einzelerscheinung zu einer Massenerscheinung [vgl. WitzIG (61)] übergegangen. Es war deshalb naheliegend, die Beziehungen durch adäquate Methoden (z. B. durch statistische Maßzahlen wie die Korrelationsmasse) zu charakterisieren.

Aus der analytischen Betrachtung resultierten graphische Darstellungen der Klüfte und der Rundhöckeroberfächen und zwar für jedes Element in zwei Formen: Als Lot-Bilder oder als Diagramme. Es war deshalb möglich, eine oder sogar beide dieser Darstellungsformen für den Vergleich zwischen Klüften und Rundhöckern heranzuziehen. So entwickelten sich während der Bearbeitung dann auch zwei Korrelationsverfahren, ein graphisches und ein mathematisches.

Die graphische Korrelation vergleicht ein vollständiges Kluftdiagramm ${ }^{35}$ mit einem vollständigen Oberflächendiagramm. Diese Methode wurde vor allem zur

33 Viele Rundhöcker zeigen zudem der ältern Richtung zuzuschreibende Leeseiten, die deutliche Gletscherschliffe der jüngern Richtung aufweisen.

34 Nach PENCK und Brückner (41) handelt es sich auch hier um eine Transfluenz aus der Gegend des Lucendro-Sees über den Gotthardpaß nach Süden.

35 Es wurden immer Kluft-Sammeldiagramme verwendet. Darstellungen einer einzigen Meßstelle weisen zu wenig Punkte auf, enthalten zudem nur die örtlich durch den momentanen Verlauf der Oberfläche gerade sichtbar gemachten Kluftsysteme. 
Gesamtkorrelation, d. h. zur Korrelation von Oberflächen-Sammeldiagrammen eines ganzen Gebietes verwendet. Die graphische Methode erlaubt eine quantitativ nur sehr beschränkte Auswertung, sie hat aber den Vorteil, qualitative Aussagen zu gestatten, da im graphischen Bild natürlich Richtungen erhalten bleiben und gut zu erkennen sind.

Die mathematische Korrelation basiert auf der Darstellung der Elemente als Lot-Bilder. Sie wurde bei der Einzelkorrelation, d. h. bei der Korrelation mit Lotbildern einzelner Rundhöcker angewendet. Ihre Aussagen besitzen quantitativen Wert, sind aber für die qualitative Betrachtung unbedeutend. Die beiden Methoden ergänzen sich im besten Sinne.

\section{DIE MATHEMATISCHE PARTIALKORRELATION}

\section{Die Korrelationsmethode}

Die Statistik befaßt sich, wenn wir hier Fueter (19) folgen wollen, mit einer Eigenschaft von Repräsentanten eines Sammelbegriffs ${ }^{36}$ (Körpergröße von Rekruten eines Jahrgangs, Zahl der Kinder in den Familien eines Quartiers, Rechennoten der Schüler einer Klasse usw.). Da jedoch der Sammelbegriff oft zwei und mehr Eigenschaften besitzt, kann die Frage gestellt werden, ob diese in einer Wechselwirkung, d. h. Korrelation, zueinander stehen.

«Die Grundlage der Korrelation bilden daher zwei oder mehr Statistiken, von denen aber je eine $Z$ ahl der einen mit einer Zahl jeder andern dadurch verknüpft ist, daß sie demselben Repräsentanten angehören»(FUETER).

Das Maß der Korrelation wird durch den Korrelationskoeffizienten $r$ ausgedrückt, der sich aus den statistischen Maßzahlen wie arithmetischem Mittel und mittlerer quadratischer Abweichung berechnen läßt ${ }^{37}$.

Der Korrelationskoeffizient kann nur die Werte von -1 bis +1 annehmen ${ }^{38}$. Dabei bedeutet +1 vollständige lineare Abhängigkeit zwischen den beiden Merkmalen, -1 dagegen vollständige negative Abhängigkeit. Im ersten Fall nehmen beide Merkmale gleichsinnig zu oder $\mathrm{ab}$, im zweiten Fall verhalten sie sich entgegengesetzt. Der Wert $\mathrm{r}=\mathrm{O}$ zeigt an, daß keine Korrelation vorhanden ist.

Einige Beispiele solcher Korrelationskoeffizienten sollen das Theoretische veranschaulichen:

${ }^{36}$ Für Sammelbegriff wird nach FLECHNeR [siehe WITZIG (61)] häufiger der Begriff des Kollektivgegenstandes verwendet.

37 Siehe Linder $(32 ;$ p. 34$)$.

38 Nach Linder $(32 ;$ p. 33 ) berechnet sich der Korrelationskoeffizient nach der Formel

$$
r=\frac{\frac{1}{N \cdot 1} \sum_{i=1}^{N}\left(x_{i}-\bar{x}\right)\left(y_{i}-\bar{y}\right)}{\sqrt{\frac{1}{N-1} \sum_{i=1}^{N}\left(x_{i}-\bar{x}\right)^{2}} \cdot \sqrt{\frac{1}{N-1} \sum_{i=1}^{N}\left(y_{i}-\bar{y}\right)^{2}}}=\frac{S_{x y}}{S_{x} \cdot S_{y}},
$$

wobei den Zeichen der obigen Formel folgende Bedeutung zukommen:

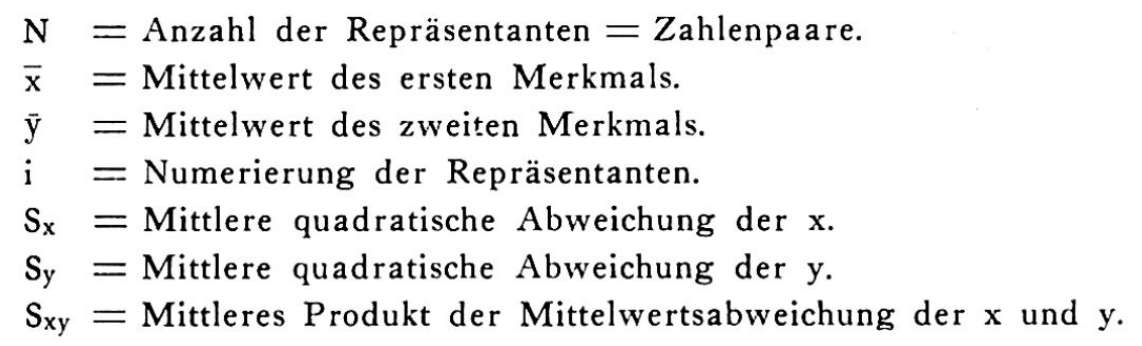


Tabelle 7 - Verschiedene Korrelationskoeffizienten

\begin{tabular}{lllcrl} 
Merkmal I & Merkmal II & Repräsentant & $\mathrm{r}$ & $\mathrm{N}$ & Autor \\
\hline Geschwindigkeit & Bremsweg & Testfahrten & $+0,806$ & 50 & Linder \\
Gewicht & Augenzahl & Kartoffeln & $+0,62$ & 99 & Hadorn \\
Alter des Mannes & Alter der Frau & Ehen & $+0,890$ & 528 & Fueter \\
Prüfungsnote & Übertrittsnote & Sekundarschüler & $+0,59$ & 237 & Witzig \\
Regenmenge & Luftruck & Zeitspanne & $-0,641$ & 10 & Fueter
\end{tabular}

\section{Die Anwendung der Korrelationsrechnung}

In meiner Arbeit waren von Anfang an zwei Statistiken vorhanden, die der Klüfte und die der Oberflächenmessung an den Rundhöckern.

Schwierigkeiten bereitete jedoch die Tatsache, daß sowohl die Kluftstatistik, als auch die der Oberflächen einen komplexen Charakter aufwies, weil ja jede Messung aus zwei Werten (Streichen und Fallen) zusammengesetzt war. Zudem waren Repräsentanten des Sammelbegriffs, die immer zwei Merkmale auf sich vereinigen sollten, gar nicht vorhanden. Sie mußten künstlich geschaffen werden. Nach verschiedenen Versuchen fand ich folgende Lösung als zweckmäßig:

Kluft-Lotbild und Oberflächen-Lotbild, beide auf Transparentpapier dargestellt, wurden in gleicher Orientierung übereinander gelegt, beide wiederum mit einem Hexagonalnetz überdeckt ${ }^{39}$.

Als Kollektivgegenstand konnte jetzt die Gesamtheit aller Sechsecke aufgefaßt werden. Das einzelne Sechseck stellte davon einen Repräsentanten dar, dem wirklich zwei Werte, nämlich die Zahl der darin liegenden Kluftpole bzw. Oberflächen-Pole, zuzuordnen waren ${ }^{40}$. Würden jetzt die Sechsecke nach ihren K-Werten geordnet, so müßte sich bei guter Korrelation auch unter den O-Werten eine entsprechende Ordnung einstellen.

Morphologische Gegebenheiten, nämlich die Tatsache, daß die meisten Rundhöcker im Schutt stecken, und die Beobachtung, daß ihre Lotbilder in der Regel auf jenen Seiten keine Oberflächen-Pole in den Randzonen aufweisen oder aufweisen können ${ }^{41}$, veranlaßten mich zu einer Korrektur des Verfahrens. Wenn das Lotbild an jenen Stellen keine Pole aufweisen kann, dürfen diese auch nicht in die Korrelationsrechnung einbezogen werden, da sonst das richtige Resultat durch einen nicht im morphologischen Problem eingeschlossenen Faktor unbegründet beeinflußt würde.

Die Verhältnisse der Vegetationsbedeckung konnten auf das Modell (E) des Rundhöckers übertragen werden. Durch Konstruktion war hierauf der Fallwinkel an einigen Stellen des Vegetationsrandes zu bestimmen. Im Netz wurden die so gefundenen Punkte mit Großkreisen verbunden und das außerhalb dieses Linienzuges liegende Gebiet der Lotbilder von der Korrelationsrechnung ausgeschlossen.

39 Beim Hexagonalnetz fällt die Orientierung der Achse bedeutend weniger ins Gewicht als beim Quadratnetz. Die Differenz der extremen Durchmesser ist weniger groß.

40 Die Maschenweite des Netzes wurde nach folgenden Überlegungen gewählt:

$$
\begin{aligned}
& \text { Radius des Innkreises } \mathrm{r}_{\mathrm{i}}= \\
& \text { Radius des Umkreises } \mathrm{r}_{\mathrm{u}}=\frac{2}{3} \mathrm{r} / 3=1,00 \mathrm{~cm} \\
& 1,15 \mathrm{~cm}
\end{aligned}
$$

Der Mittelwert der beiden Radien, nämlich $1,08 \mathrm{~cm}$, entspricht in den Randgebieten des Arbeitsnetzes einem Winkel von rund $6^{\circ}$, was dem doppelten Mittelwert für die Kluftschwankung bei jener Kluftstellung gleichkommt. Würde folglich das Zentrum eines Sechsecks mit dem einer Kluftschar zusammenfallen, so käme eine Kluft mit mittlerem Schwankungsbetrag selbst bei einer glazialbedingten Ablenkung, um nochmals den gleichen Betrag noch in dieses Sechseck zu liegen.

41 In die Randzonen fallen hier meist nur einzelne Oberflächen-Pole, die durch freigelegte Kluftflächen beim Zerfall des Rundhöckers erzeugt werden. Zahlenmäßig wirken sie sich kaum aus. 


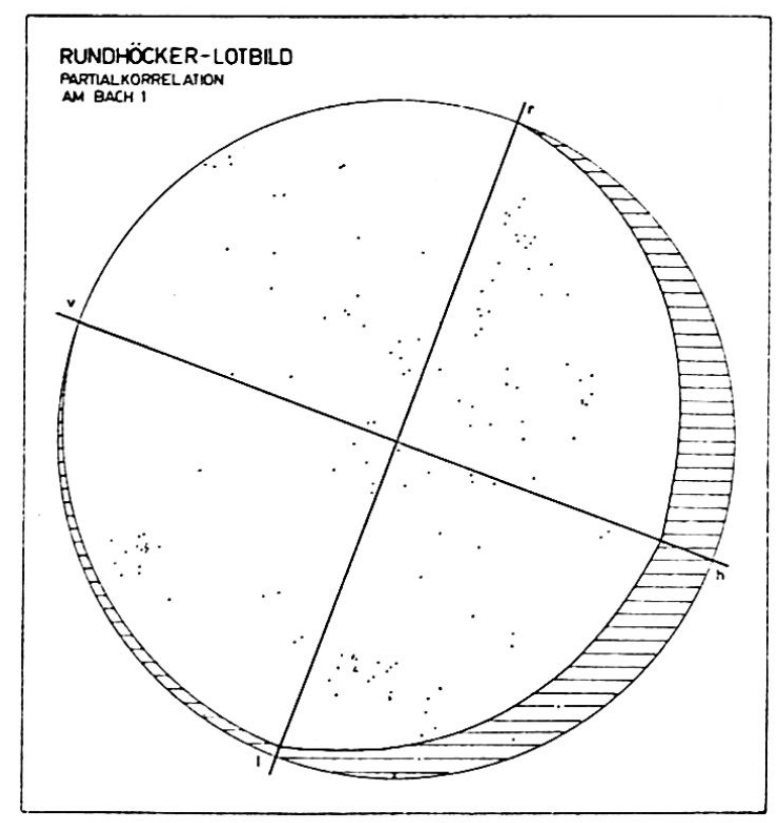

Fig. 13: Oberfläche des Rundhöckers «Am Bach 1 ». - Darstellung der Lage von Tangentialflächen als Lot-Bild. Durch Korrektur den morphologischen Gegebenheiten angepaßt. Die Bezeichnungen $\mathrm{v}=$ vorn, $\mathrm{h}=$ hinten, $\mathrm{l}=$ links und $\mathrm{r}=$ rechts, müssen auf die mittlere Eisrichtung bezogen werden.

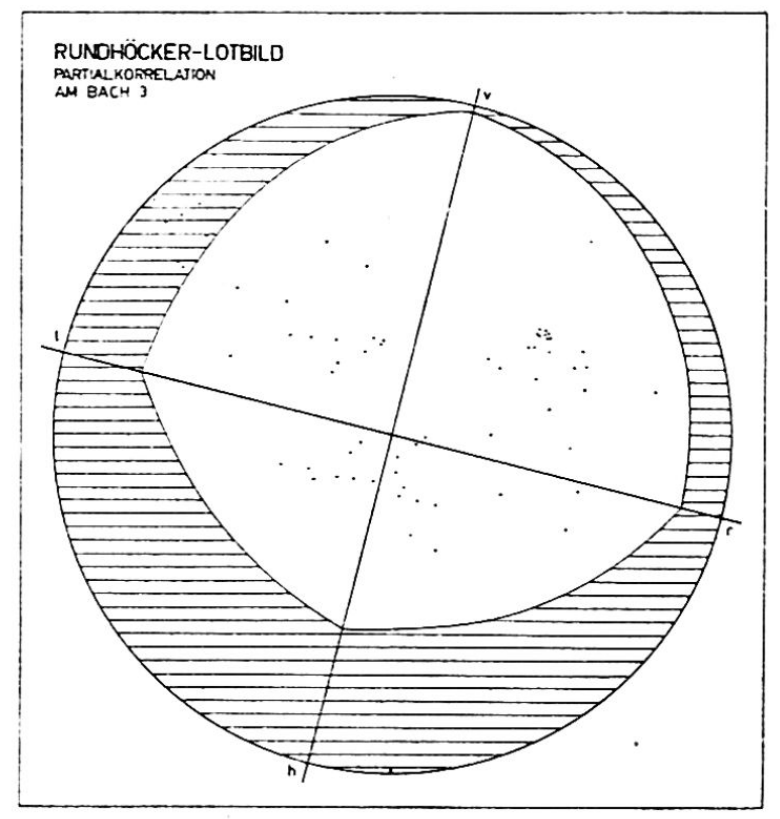

Fig. 14: Oberfläche des Rundhöckers «Am Bach 3 ». - Darstellung der Lage von Tangentialflächen als Lot-Bild. Durch Korrektur den morphologischen Gegebenheiten angepaßt. Bezeichnung wie Fig. 13.

Diese Methode ist allerdings nur ein Behelf, der immer noch gewisse Ungenauigkeiten in sich schließt. Ich bin jedoch überzeugt, hier in einer schwierigen Situation einen gangbaren Weg eingeschlagen zu haben.

Tabelle 8 zeigt das Schema der statistischen Verteilung, wie es für die Darstellung der Korrelationsrechnung üblich ist. Als Beispiel wurde wieder der Rundhöcker «Am Bach $1 \gg$ gewählt ${ }^{42}$ (vgl. Abb. 12 und 13, sowie Fig. 1 und 13).

Dieselben Korrelationen wurden auch für die Lot-Bilder des Ideal-Rundhöckers (E) durchgerechnet. Diese Resultate folgen später in der Tabelle der Korrelationskoeffizienten ${ }^{43}$.

42 Aus der Überlegung, da $\beta$ die $K$ - und $O$-Werte nur ganzzahlig auftreten und $\mathrm{da} B$ in sehr vielen Sechsecken einer der beiden Werte $O$ wird, benützte ich für die Berechnung der $r$ eine Formel, die mit praktischen (runden) Mittelwerten ( $D_{x}$ bzw. $D_{y}$ ) auskommt.

Es gilt wieder:

$$
r=\frac{S_{x y}}{S_{x} \cdot S_{y}}
$$

wobei aber jetzt

$$
\begin{aligned}
& \text { für } \left.S_{x y}=\frac{1}{N \cdot 1} \sum_{i=1}^{N}\left(x_{i}-D_{y}\right)\left(y_{i}-D_{y}\right)-\left(\bar{x}-D_{x}\right) \sum_{i=1}^{N}\left(y_{i}-D_{y}\right)\right], \\
& \text { für } S_{x}=\sqrt{\frac{1}{N \cdot 1}\left[\sum_{i=1}^{N}\left(x_{i}-D_{x}\right)^{2}-N\left(\bar{x}-D_{x}\right)^{2}\right]} \text { und } \\
& \text { für } S_{y}=\sqrt{\frac{1}{N \cdot 1}\left[\sum_{i=1}^{N}\left(y_{i}-D_{y}\right)^{2}-N\left(\bar{y}-D_{y}\right)^{2}\right]} \text { zu setzen war. }
\end{aligned}
$$

Als praktischer Mittelwert $\left(D_{x}\right.$ bzw. $\left.D_{y}\right)$ wählte ich $O$, wodurch erreicht wurde, daß viele der Doppelprodukte wegfielen. Die Rechenarbeit konnte so bedeutend reduziert werden.

43 Für zwei der Berechnungen wurde das Rundhöcker-Lotbild so gelegt, da $B$ ein möglichst hoher Korrelationskoeffizient zu erwarten war. (Achsenlgae $60^{\circ}=$ Max. I und Achsenlage $150^{\circ}=$ Max. II).

Für die dritte Berechnung hingegen wurde die ungünstigste Stellung ausgesucht (Achsenlage $120^{\circ}=$ Min. I). 
Oberfläche $\left(D_{\mathrm{x}}=0 ; \overline{\mathrm{x}}=1,3 ; S_{\mathrm{x}}= \pm 2,32\right)$

Klüfte $\left(D_{y}=0 ; \bar{y}=5,0 ; S_{y}= \pm 5,96\right)$

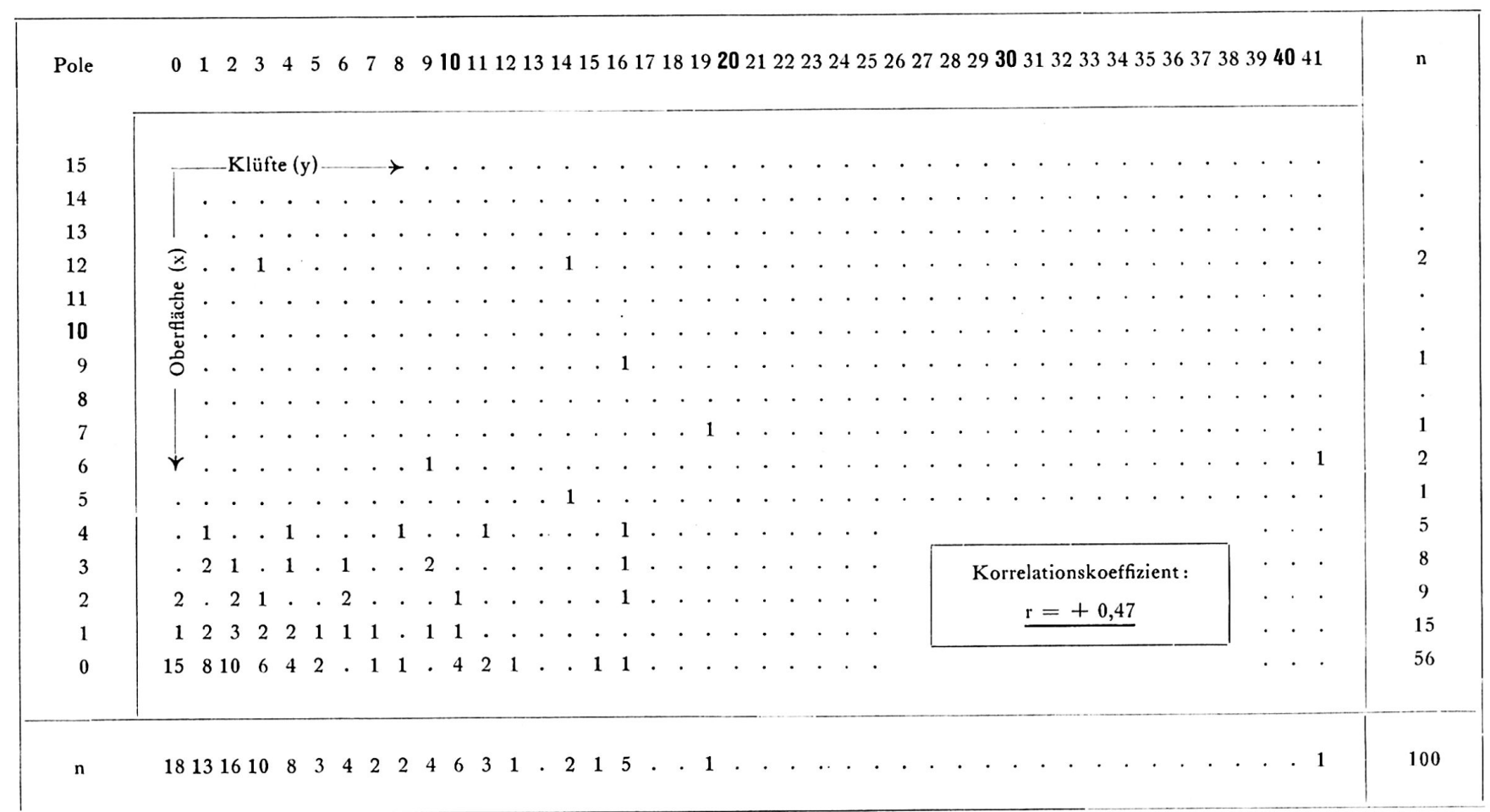




\section{Die Ergebnisse der mathematischen Partialkorrelation}

Für das Gebiet des Grimselpasses sind die Ergebnisse in der nachstehenden Tabelle 9 zusammengestellt:

Tabelle 9 - Statistische Maßzahlen der Rundhöcker (Grimselpaß)

\begin{tabular}{|c|c|c|c|c|c|c|}
\hline \multicolumn{3}{|l|}{ Runddhöcker ${ }^{4 t}$} & \multirow{2}{*}{$\begin{array}{c}\mathrm{n} \\
100\end{array}$} & r & $\left(r-Q_{g}\right)^{2}$ & $\mathrm{f}$ \\
\hline Am Bach 1 & . & . & & +0.47 & 0.0361 & 4.5 \\
\hline Am Bach 2 & . . & . & 50 & +0.11 & 0.0289 & 3.7 \\
\hline Am Bach 3 & . . & . & 60 & +0.35 & 0.0049 & 2.0 \\
\hline Pfeilstein 11 & . & . & 53 & +0.08 & 0.0400 & 4.4 \\
\hline Pfeilstein 14 & . . & . & 30 & +0.18 & 0.0100 & $-^{49}$ \\
\hline Pfeilstein 22 & . . & . & 58 & +0.41 & 0.0169 & 10.1 \\
\hline Kamel . . & . & . & 66 & +0.24 & 0.0016 & 5.8 \\
\hline Dach . . & . & . & 74 & +0.23 & 0.0025 & 2.9 \\
\hline Ideal $(\mathrm{K})$ & . . & . & 108 & $-{ }^{45}$ & - & - \\
\hline Ideal (E)/Max & & . & 108 & +0.04 & - & - \\
\hline Ideal (E)/Max & II . & . & 108 & +0.02 & - & - \\
\hline Ideal $(\mathrm{E}) / \mathrm{Min}$. & I. & . & 108 & -0.02 & - & - \\
\hline Mittelwert . &.. & . & $61^{46}$ & $+0.26^{4 i}$ & -48 & 4.8 \\
\hline
\end{tabular}

\section{Diskussion der Resultate}

a) Beim Betrachten der Rundhöcker-Lotbilder fällt auf, daß über Erwarten große Punkthäufungen vorkommen. Erstaunlich ist aber, daß diese sogar bei Rundhöckern auftreten, die nach einer abschätzenden Beurteilung kaum solche Bilder hätten erwarten lassen.

b) Alle Rundhöcker des Gebietes zeigen für $r$ bedeutend höhere Werte als die studierten Idealformen $(\mathrm{K})$ und $(\mathrm{E})$ in ihren besten Lagen. Ich erachte diese Vergleichsstudie als ebenso wichtigen Beitrag zur Sicherung der Ergebnisse wie die mathematischen Prüfverfahren. Sie betont recht eindrücklich das hohe Maß der Kluftbedingtheit dieser Rundhöcker. Man vergegenwärtige sich nur, wie klein die positiven oder negativen Veränderungen der entsprechenden $r$-Werte sind, wenn der Ideal-Rundhöcker (E) von seiner guten in eine bessere oder schlechtere Lage gedreht wird.

c) Die Ergebnisse der Korrelationsrechnung sind nach den Tabellen von FisHeR (17) 50 für einen P-Wert von 0,05 gesichert $^{51}$.

44 Als Bezeichnung der Rundhöcker wurden die während der Feldaufnahmen spontan eingeführten Namen beibehalten.

45 Sinngemäß keine Korrelation möglich, da ein Merkmal gleichmäßig verteilt ist. Der mathematische Wert wird unbestimmt.

46 Nur für wirkliche Rundhöcker (1-8).

$47=\varrho=$ arithmetisches Mittel der r. (mit $\mathrm{P}=0,05$ gesichert).

$\varrho_{\mathrm{g}}=$ gewogenes Mittel der $\mathrm{r}$; siehe unten.

48 Quadratische Abweichung vom gewogenen Mittel. Dienen der späteren Kontrolle der Ergebnisse.

49 Flächencharakteristik fehlt im Arbeitsprotokoll (erste Messungen an Rundhöckern).

50 Fisher, R. A.: «Values of the Correlation coefficient for different Level of Significance» [in Fisher (17)].

51 Der Wert $\mathrm{P}=0,05$ entspricht einer Wahrscheinlichkeit von $95 \%$ und ist nach der freundlichen Mitteilung von Herrn Prof. Dr. B. L. van der Waerden in den biologischen Wissenschaften der heute anerkannte Wert für statistische Prüfverfahren. 
d) Die Abweichungen der $r$ von ihrem Mittelwert wurden nach der bekannten $\chi^{2}$-Methode ${ }^{2}$ kontrolliert. Nach der Formel (c) erhält man für $\chi^{2}$ den Wert 10,61. Er liegt unter der in den Tabellen von Linder (32) für $\mathrm{N}=8-1=7$ Freiheitsgrade angegebenen Schranke von 14,0753.

Die Streuung der $r$-Werte ist folglich zufällig. - Dies bedeutet, daß für die untersuchte Beziehung zwischen Klüften und Rundhöckerform im Arbeitsgebiet ein und dasselbe Gesetz Geltung hat ${ }^{54}$.

e) Das Studium der Flächenindices $f$ ergibt deutlich, daß nicht die ausgesprochen eckigen und kantigen Rundhöcker hohe Korrelationskoeffizienten aufweisen. Wir finden den hohen $r$-Werten sogar meist mittlere bis hohe $f$-Werte zugeordnet (Pfeilstein 22, Am Bach 1, Kamel). Dies bedeutet, daß die Beziehungen zum Kluftbild auch dort nachgewiesen wurden, wo eine erste Beurteilung dies nicht hätte vermuten lassen.

f) Die zum Vergleich in andern Gebieten berechneten Korrelationskoeffizienten (sie folgen in Tabelle 10) ergaben etwa die gleichen Mittelwerte. Daß ihre Schwankungen etwas größer sind, hängt mit Besonderheiten der jeweiligen Kluftstatistik, sowie mit morphologischen und petrographischen Eigenheiten zusammen.

Einer besondern Bemerkung bedürfen noch die Verhältnisse auf dem Nägelisgrätli.

Die Rundhöcker erscheinen hier so stark kluftbedingt wie sonst nirgends (Abb. 6). Zwei der drei Koeffizienten fallen jedoch vollständig aus der Reihe der bisher errechneten, und nur der dritte Rundhöcker zeigt ein «normales» Verhalten. Die Abnormität ist zu verstehen, wenn man sich das Lotbild der beiden Rundhöcker vornimmt und mit den Verhältnissen in der Natur vergleicht. Ein bis zwei sonst kaum in Erscheinung tretende Klüfte haben hier die ganze Oberfächenbildung, ja sogar die Anordnung der Rundhöcker in

52 Anstelle der allgemein gebräuchlichen Formel

wobei hier

$$
\%^{2}=\frac{\sum_{i=1}^{N}\left(r_{i}-Q\right)^{2}}{\sigma^{2}}
$$

$$
\sigma=\frac{1-g^{2}}{V_{\mathrm{n}-1}}
$$

$\mathrm{N}=\operatorname{die}$ Anzahl der r, $\mathrm{n}=$ die Anzahl der Wertepaare der Korrelationsrechnung und $\varrho$ $=$ das a rithmetische Mittel der $\mathrm{r}$ darstellt, mußte, wegen der von Fall zu Fall verschiedenen Größe der $r, \chi^{2}$ nach der folgenden Formel berechnet werden :

$$
\chi^{2}=\frac{\left(r_{1}-\varrho_{g}\right)^{2}}{\sigma^{2}}+\frac{\left(r_{2}-\varrho_{g}\right)^{2}}{\sigma_{2}^{2}}+\ldots+\frac{\left(r_{s}-\varrho_{g}\right)^{2}}{\sigma^{2}}(c)
$$

Hier bedeuten $r_{1}, r_{2}, \ldots, \ldots, r_{8}$ die verschiedenen Korrelationskoeffizienten, $\varrho_{\mathrm{g}}$ das gewogene Mittel der gleichen Koeffizienten nach der Formel:

$$
\underline{g}_{\mathrm{g}}=\frac{\mathrm{g}_{1} \mathrm{r}_{1}+\mathrm{g}_{2} \mathrm{r}_{2}+\ldots \ldots+\mathrm{g}_{8} \mathrm{r}_{8}}{\mathrm{~g}_{1}+\mathrm{g}_{2}+\ldots+\mathrm{g}_{\mathrm{s}}}=0.28
$$

Die Werte $\mathrm{g}_{1}=\frac{\mathrm{c}}{\sigma_{1}^{2}}, \mathrm{~g}_{2}=\frac{\mathrm{c}}{\sigma_{2}^{2}}, \ldots$ usw. stellen die Gewichte der Korrelationskoeffizienten $r_{1}, r_{2}, \ldots$ usw. entsprechend der an ihrer Bildung beteiligten Zahl von Wertepaaren (n) dar.

Auf dieses Verfahren wurde ich freundlicherweise von Herrn Prof. Dr. B.L.van der Waerden aufmerksam gemacht.

53 Linder (32): Tabelle-Verteilung der $\chi^{2}$ (p. 224).

$54 \mathrm{Zu}$ Gesetz: Vgl. Јаков (26; p. 73/74). 
Reihen bestimmt. Ihr Anteil an der Oberfläche ist sehr groß. Wohl infolge ihrer höheren Lage sind die Rundhöcker zudem glazial weniger gerundet $\left(f^{\prime}=1,1-1,3\right)$. Diese starke Konzentration auf zwei Kluftsysteme läuft aber der allgemeinen Kluftverteilung zuwider und die r-Werte werden definitionsgemäß schlechter.

An diesen Beispielen wird sicher einer der Grenzen der Methode deutlich aufgezeigt. Der Korrelationswert muß bei der Interpretation stets mit den beiden LotBildern und mit den Verhältnissen in der Natur zusammen betrachtet werden.

\begin{tabular}{|c|c|c|c|c|c|c|}
\hline Rundhöcker & & & $\mathrm{n}$ & $\mathrm{r}$ & $\mathrm{f}^{\prime}$ & Arbeitsgebiet \\
\hline $\begin{array}{ll}\text { Coda } & \cdot \\
\text { Zahn } & \cdot \\
\text { Dreieck } & \cdot\end{array}$ & . & $\dot{.}$ & $\begin{array}{l}75 \\
75 \\
75\end{array}$ & $\begin{array}{l}+0,25 \\
-0,04 \\
-0,06\end{array}$ & $\begin{array}{l}1,3 \\
1,3 \\
1,1\end{array}$ & $\underset{\nu}{\text { Nägelisgrätli }}{ }^{55}$ \\
\hline $\begin{array}{l}\text { Gwüest I } \\
\text { Gwüest II } \\
\text { Gwüest III }\end{array}$ & . & . & $\begin{array}{l}90 \\
91 \\
98\end{array}$ & $\begin{array}{l}+0,02 \\
+0,10 \\
+0,22\end{array}$ & $\begin{array}{r}-57 \\
-\quad 5 i \\
0,36^{58}\end{array}$ & Göschener Alp \\
\hline $\begin{array}{l}\text { Rundling } \\
\text { Maximum } \\
\text { Blume }\end{array}$ & . & $\dot{.}$ & $\begin{array}{l}45 \\
78 \\
40\end{array}$ & $\begin{array}{l}+0,76^{56} \\
+0,05 \\
+0,52\end{array}$ & $\begin{array}{r}11,3 \\
5,8 \\
1,4\end{array}$ & Gotthard-Paß \\
\hline Bernina I & . & . & 45 & $+0,47$ & 3,3 & Bernina-Paß \\
\hline Mittelwert I & . & . & 71,2 & $+0,23$ & 3,2 & Mit $\backslash$ Nägel \\
\hline Mittelwert II & . & . & 66 & $+0,30$ & 3,7 & ohne / grätli \\
\hline
\end{tabular}

III. DIE GRAPHISCHE TOTALKORRELATION

Die hier darzustellende Arbeitsmethode ist in ihrem Wesen wohl mit den bisher gezeigten verwandt; die Resultate, die sie hervorbringt, liegen indessen, wenn wir wieder von der anfänglichen Problemstellung ausgehen wollen, nicht mehr im Zentrum der Betrachtung. Ihre Interpretation beantwortet z. T. Fragen dynamisch-genetischer Art. Diese sollen, als außerhalb liegend, nur kurz erwähnt werden.

\section{Die Auswertung der Sammeldiagramme}

Zur graphischen Totalkorrelation wurden für alle Arbeitsgebiete im Aarmassiv vorerst sog. Rundhöcker-Sammeldiagramme gezeichnet. In diesen gelangen alle Rundhöcker eines Arbeitsgebietes, im gleichen Diagramm summiert, zur Darstellung. Die Sammeldiagramme erwiesen sich für diese Korrelationsmethode als zuverlässiger. Die Zufälligkeiten der Einzeldiagramme wurden auf diese Art weitgehend ausgemerzt.

Für das Gebiet um den Totensee, mit 8 Rundhöckern, war es möglich, die 1\%Linien dieser 8 Einzel-Diagramme übereinander zu zeichnen und dann die Flächen von 1-8-maliger Besetzung darzustellen (Fig. 15). Dieses Diagramm ist besonders instruktiv.

In allen andern Gebieten brachte das entsprechende Verfahren, da nur je 3 Rundhöcker vermessen waren, schlechte, ungegliederte Bilder hervor. Bessere Darstellungen ergaben sich, als die Oberflächenmeßpunkte (bzw. ihre Pole) ganzer Gebiete zusammengetragen und zu Diagrammen ausgearbeitet wurden (Fig. 16-18). Auch für das Gebiet SW Totensee wurde zum Vergleich ein Sammeldiagramm dieser Art hergestellt (Fig. 16).

55 Partialkorrelation bis zur Neigung von $70^{\circ}$, da die Pyramidenform einen Vergleich mit dem Idealrundhöcker (E) nicht gut zuläßt.

56 Wegen starker Schuttbedeckung und Geländeanstieg wurde nur die linke Seite vermessen und korreliert.

57 Keine Flächencharakteristik, da eine der ersten Messungen.

58 Tiefer Wert, da Rundhöcker durch flache Klüfte fast horizontal abgeschnitten ist. 


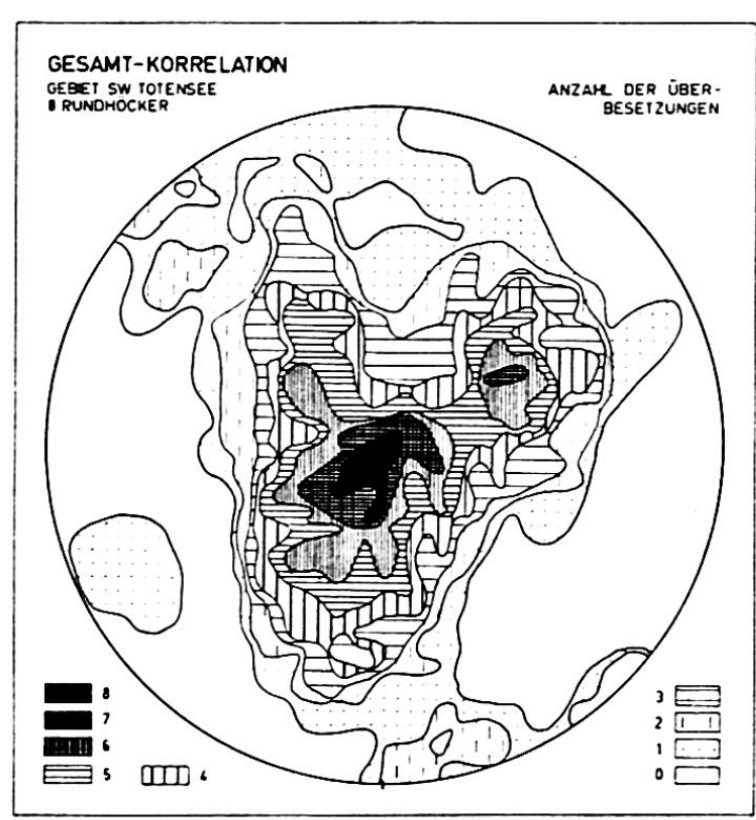

Fig. 15: Oberflächen von 8 Rundhöckern des Gebietes SW Totensee. - Dargestellt sind mit den Signaturen 1-8 die Anzahl der Übersetzungen (Punktdichten von über $1 \%$ in den betreffenden Flächen).

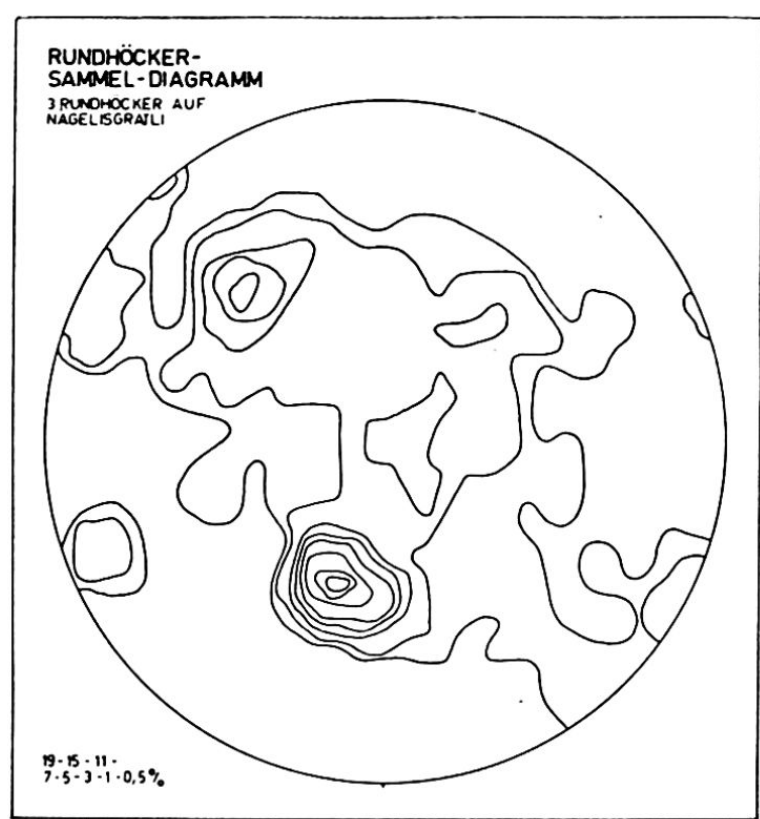

Fig. 17: Oberflächen von 3 Rundhöckern auf Nägelisgrätli. - Darstellung der Lage aller Tangentialflächen als Diagramm. Bezeichnung wie Fig. 16.

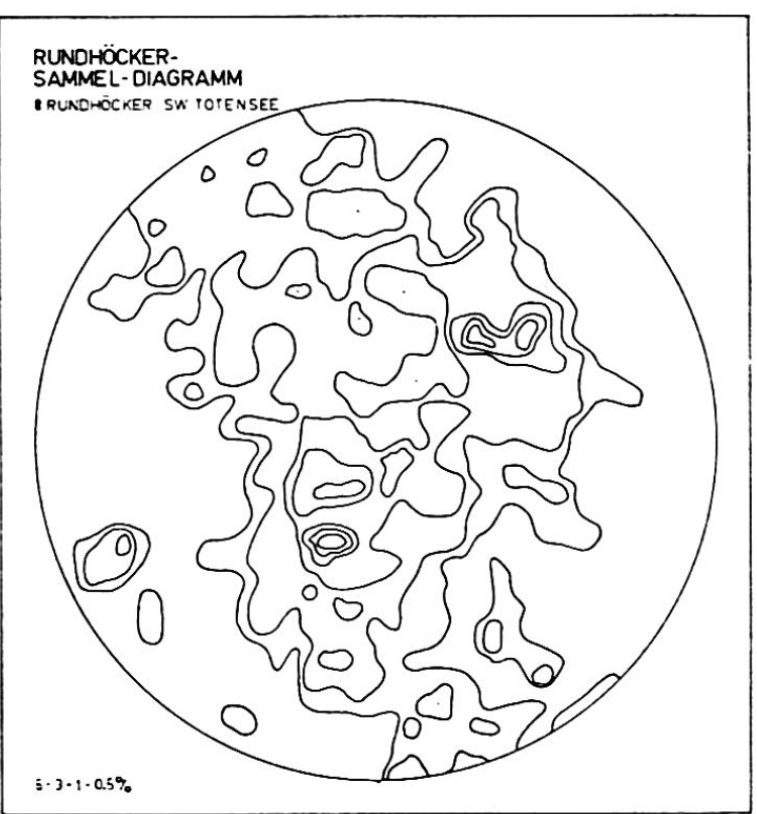

Fig. 16: Oberflächen von 8 Rundhöckern des Gebietes SW Totensee (wie Fig. 15). - Darstellung der Lage aller Tangentialfächen als Diagramm (Oberflächen-Pole in einer Darstellung zusammengetragen). Die Prozentwerte bezeichnen die Besetzungsdichten der verschiedenen Flächen.

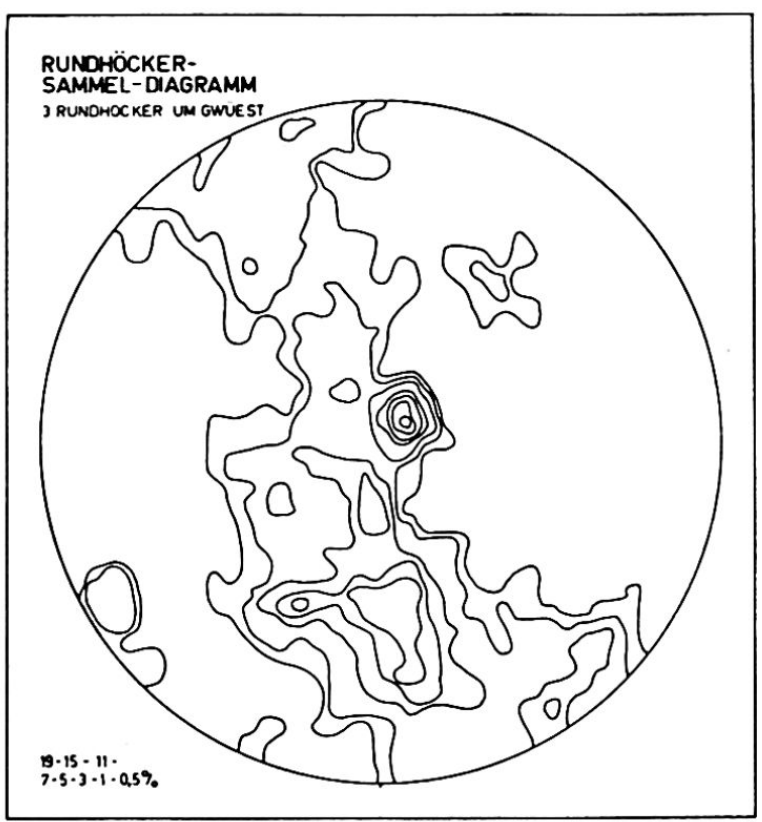

Fig. 18: Oberflächen von 3 Rundhöckern oberhalb Gwüest (Göschener Alp). - Darstellung der Lage aller Tangentialfächen als Diagramm. Bezeichnung wie Fig. 16.

Der Vergleich von Fig. 15 und den zugehörigen Klüften in Fig. 3 zeigt sofort die Ähnlichkeit der beiden Bilder. Die X-Form des Kluft-Diagramms tritt im Rundhökker-Oberflächendiagramm deutlich hervor. Etwas überbetont ist das ganze Gebiet SSW des Diagramm-Mittelpunktes, so daß an Stelle der bekanten X-Form eher eine V-Form entsteht ${ }^{59}$.

59 Siehe Anmerkung 61. 
Vergleichen wir die Sammeldiagramme von Totensee und Nägelisgrätli (Fig. 16 und 17)!

Die Ähnlichkeit der beiden Diagramme ist auffallend. Wenn wir uns erinnern, daß die mathematische Partialkorrelation für das Gebiet auf dem Nägelisgrätli schlechte Resultate hervorbrachte, muß uns diese Gegenüberstellung fast erstaunen.

Alle Merkmale treten in beiden Diagrammen in analoger Weise auf:

a) Die Groß-Verteilung in V-Form ist gut ausgebildet. Darin eingeschlossen liegen die 3 Maxima.

b) Längs einer NW-SE verlaufenden Grenze ist der SW-Teil frei von Oberflächen-Polen.

c) Eine kleine Oberflächenhäufung liegt im eben besprochenen freien Gebiet, um ein Kluftmaximum gruppiert.

d) Der NE- und z. T. der SE-Rand der Diagramme sind ebenfalls frei von Polen.

e) Die Grenzlinie verläuft im N-Teil gegen ESE und winkelt dann gegen SSW ab.

f) Das von Oberfächenpolen besetzte Gebiet schließt im NW und SE an den Rand des Diagramms an.

Das Diagramm für Gwüest (Fig. 18) ist auf den ersten Blick nicht so gut vergleichbar wie die eben besprochenen. Starke Analogien sind jedoch offensichtlich. Gehen wir die Punkte a-f wie oben durch:

a) Die V-Form wird nur noch angedeutet (2 Maxima sind schwach vorhanden).

b) Stimmt überein.

c) Stimmt überein.

d) Stimmt überein.

e) Stimmt nicht gut; der Knick ist in der NE liegenden isolierten Häufung zu ahnen.

f) Stimmt überein.

Dieses Ergebnis zeigt wiederum mit aller Deutlichkeit, daß unabhängig von den verschiedenen Eisrichtungen, vom Gelände und von kleineren petrographischen Abweichungen, für diese drei Arbeitsgebiete im Aarmassiv, die Rundhöcker-Oberflächen ähnliche, mit dem Kluftbild stark verwandte Züge aufweisen.

\section{Auswertung der Anomalenbilder}

Um über die Rolle der Eisrichtung bei der Rundhöckerbildung eine Auskunft zu erhalten, waren Oberflächen-Sammeldiagramme und Kluft-Diagramme nochmals näher $\mathrm{zu}$ betrachten. Aus beiden Darstellungen heraus wurden auf Grund der $1 / 2 \%$ Linien Anomalenbilder gezeichnet ${ }^{60}$.

Dargestellt wurden von den 4 Fällen, die für das qualitative Verhältnis von Oberflächenbild zu Kluftbild möglich sind $(+/+,-/-,-/+$ und $+/-)$ nur der letzte, d. h. Gebiete des Diagramms mit überbesetzten Oberflächendiagrammen $(+)$ und unterbesetzten Kluftdiagrammen (-).

Die ausgezogene Begrenzung der Anomalenfläche bedeutet Anschluß an ein Gebiet mit Überbesetzung durch Kluftpole, punktierte Begrenzung hingegen Anschluß an ein unterbesetztes Gebiet.

60 Wenn wir wie oben immer noch annehmen wollen, daß Flächen des Kluft-Diagramms mit hoher Punktbesetzung auch im Oberflächen-Diagramm wieder zu finden sein sollten, ist es begründet, Abweichungen von diesem Verteilungsgrundsatz durch Anomalen darzustellen. Untersucht wurde nicht quantitativ, nach verschiedenen Werten, sondern nur qualitativ, nach den Eigenschaften über- oder unterbesetzt. Als Grenze wäre die Wahl der $1 \%$-Linie sicher sinnvoll. Da diese jedoch, infolge Absorption vieler Punkte in den hohen Maxima, sehr unruhige Bilder ergab, wurde mit größerem Erfolg der Wert $1 / 2 \%$ als Grenzbildner verwendet. o- $1 / 2 \%$ gilt demzufolge als unterbesetzt $(-)$, über $1 / 2 \%$ als überbesetzt $(+)$. 


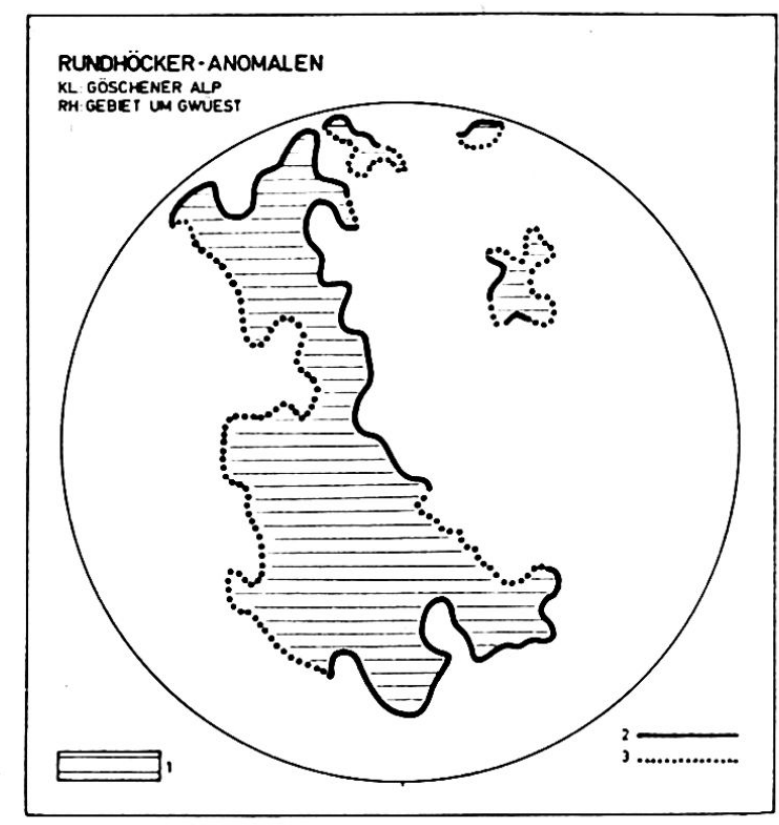

Fig. 19: Anomalen von 3 Rundhöckern oberhalb Gwüest (Göschener Alp). - Entsprechendes Kluft-Diagramm: Fig. 5. $1=+/-$ Anomalenflächen. $2=$ Anschluß der Anomalenfläche an überbesetztes Kluftgebiet. $3=\mathrm{An}$ schlu $B$ an unterbesetztes Kluftgebiet.

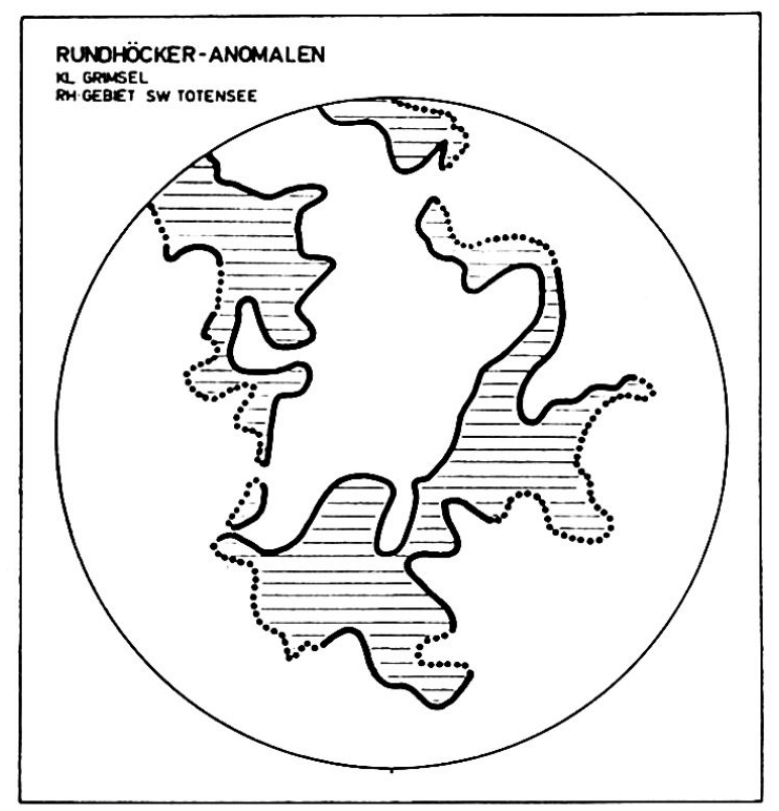

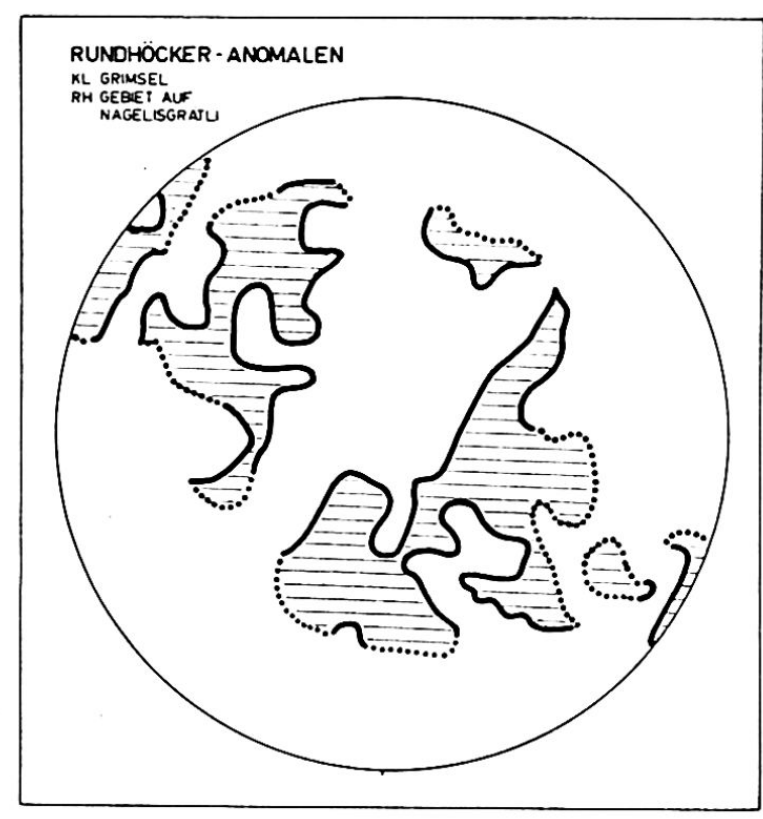

Fig. 2o: Anomalen von 3 Rundhöckern auf Nägelisgrätli. - Entsprechendes Kluft-Diagramm:

Fig. 3. - Bezeichnungen wie in Fig. 19.

Fig. 21: Anomalen von 8 Rundhöckern des Gebietes SW Totensee. - Entsprechendes KluftDiagramm: Fig. 3. - Bezeichnungen wie in Fig. 19.

Auf der Göschener Alp (Fig. 19), wo als mittlere Eisrichtung West-Ost $\left(85^{\circ}\right)$ festgestellt wurde, liegen fast die ganzen Anomalenflächen auf der Westseite, im Sektor zwischen NW und SSE. Das Hauptgewicht fällt eindeutig in den südlichen Teil, wo scheinbar das randliche Kluftmaximum der Schieferungskluft sehr stark wirksam ist (Ausgezogene Begrenzung der Anomalenfläche im Süden) ${ }^{61}$.

Interessant gestaltet sich der Vergleich zwischen Fig. 20 (Nägelisgrätli) und Fig. 21 (Totensee). Die beiden Darstellungen, dem gleichen Kluftdiagramm entspringend, zeigen keine allzu großen Verschiedenheiten.

Nägelisgrätli, mit Eisrichtung aus E $\left(92^{\circ}\right)$, weist im Sektor zwischen E und S den Hauptanteil der Flächen auf. Die dem Eis abgekehrte Seite im NW birgt zusätzliche Anomalenflächen, in kluftdurchsetzten Gebieten eingestreut.

Das eben besprochene Bild erfährt für Totensee eine merkliche Drehung im Uhrzeigersinn. Wiederum sind die Stoßseiten mit Anomalenflächen stark belegt. Diesmal

61 Nach DE QUERVAIN (42) sind glimmerreiche, gerichtete Gesteine bedeutend weniger widerstandsfähig. Wenn die Beanspruchungsrichtung mit der Schieferungsebene (bzw. Glimmerlagen) zusammenfällt, liegen die Werte für Druckfestigkeit bis zu $50 \%$ tiefer als bei Beanspruchung senkrecht dazu. 
sind jedoch zwei Eisrichtungen zu berücksichtigen $\left(135^{\circ}\right.$ aus $\mathrm{SE}$ und $85^{\circ}$ aus $\mathrm{W}$; Mittelwerte). Das Hauptgewicht der Anomalen liegt hier im ganzen Sektor, von SW über $\mathrm{S}$ bis nach $\mathrm{E}$ verteilt, eigentlich den Winkel zwischen den beiden Eisrichtungen ausfüllend. Auch hier findet sich eine Nebenhäufung im kluftdurchsetzten NW-Quadranten des Diagramms.

Richten wir das Augenmerk noch für einen Moment auf die Art der Begrenzung der Anomalenflächen. Diese grenzen meistens gegen das Zentrum hin an Kluftgebiete, während sie randwärts ins Leere hinauslaufen.

Steile Kluftgebiete werden von den Anomalen selten erreicht, es sei denn dort, wo stärkere Streuung der Klüfte zwischen Zentrum und Randzone schon vorhanden ist (NW und SE).

\section{Diskussion und Schlüsse aus der graphischen Totalkorrelation}

Wenn ich aus Kapitel 1 und 2, sowie aus weiteren Beobachtungen während meiner Feldarbeit ${ }^{62}$ eínige Schlüsse ziehen darf - sie liegen aber bereits außerhalb des mir zur Lösung aufgetragenen Problems — so sind es die folgenden:

Bei der Bildung der heutigen Rundhöckeroberfläche muß die Klüftung eine maßgebende Rolle gespielt haben.

Steile Klüfte mögen bei der Anlage und in der Anordnung der Rundhöcker besonders aktiv gewesen sein (Totensee, Nägelisgrätli, Gotthard).

Zur Gestaltung des Großteils der Oberflächen benützte die Erosion aber flache

Klüfte, die dann - vor allem auf den Stoßseiten - steilgeschliffen wurden.

Angesichts dieser Tatsachen zweifle ich an der Wirksamkeit einer Wellendynamik im Sinne Flückigers (18) bei der Bildung von Kleinformen. Wie StreiffBECKER anerkenne ich diese Theorie gerne als Erklärung für die Entstehung ähnlicher Großformen.

Die früher zusammengestellten Ansichten über die Rundhöcker-Genese scheinen mir gar nicht so weit auseinanderzulaufen. Der Grund ihrer Verschiedenheit liegt viel mehr in einer unterschiedlichen Beurteilung der Wirksamkeit der einzelnen Faktoren.

Die Ansichten von Davis (Abschleifen von Unebenheiten) sind sicher ganz zutreffend, wenn wir sie mit der PENCK'schen Auffassung vom weitmaschigen Kluftnetz (Kluftpolyeder) verbinden und stets daran festhalten, daß unter dem Gletscher fortwährend neue Klüfte freigelegt werden können (CAROL), so daß sich dadurch die Lage der Rundhöcker mit dem Tiefergreifen der Glazialerosion verändern kann.

Alle Versuche einer Erklärung in dieser Richtung, nur auf Grund des vorhandenen Beobachtungsmaterials, haben einen spekulativen Charakter. Sichere Schlüsse könnten nur zeitlich gestaffelte Aufnahmen des Gletscheruntergrundes liefern, doch zur Zeit fehlen uns dieselben leider noch. Ich kenne im Moment keine Methode, die uns solche mit der nötigen Genauigkeit liefern könnte ${ }^{63}$.

\section{Vergleichende Beurteilung der Untersuchungsmethode}

In der vorliegenden Arbeit wurden statistische Methoden zur quantitativen Untersuchung morphologischer Fragen verwendet. Klüfte und Rundhöcker, durch die Problemstellung herausgegriffen, sind Objekte mit dreidimensionalen Eigenschaften. Sollte die Statistik verwendet werden, mußte man beide in der gleichen Art darstellen. Die anzuwendende Methode hatte überdies dem dreidimensionalen Charakter der Objekte gerecht $\mathrm{zu}$ werden.

62 Studien über Pyramiden-Formen und Kluftsysteme SW der Gotthardpaßhöhe. Beobachtungen zu Rundhöckerreihen auf Nägelisgrätli und $S$ Totensee.

63 Vielleicht wäre es möglich, durch Echolotungen mit Ultraschall, ähnlich wie dies bei der topographischen Erforschung von See- und Meerbecken gemacht wird, weiterzukommen. 
Zwei Hauptmerkmale der Arbeit sind demzufolge in den Mittelpunkt dieser rückblickenden Schau zu stellen:

a) quantitativ-statistische Methoden.

b) graphische Darstellung räumlicher Eigenschaften.

Beide sind in geographischen Arbeiten schon öfters zur Anwendung gelangt:

a) Statistische Methoden sind sowohl in Klimatologie und Morphologie, als auch in der Anthropogeographie in einfacherem Rahmen wohlbekannt.

b) Die speziellen Darstellungsarten sind außerhalb ihres eigentlichen Anwendungsgebietes, der Mineralogie, in der Morphologie auch verschiedentlich verwendet worden ${ }^{64}$.

Neu war in meiner Arbeit folglich das Erfassen beider Elemente (vor allem des morphologischen) in der gleichen Darstellungsart, dann auch die Anwendung statistischer Methoden zur Verknüpfung der beiden Elemente.

Für eine Weiterführung dieser Untersuchungsmethoden sehe ich keine allzu groBen Möglichkeiten. Wohl könnten noch andere morphologische Erscheinungen mit den Kluftsystemen in Beziehung gebracht werden. Die günstigsten Studienobjekte dieser Art waren jedoch die Rundhöcker. Bei allen andern Formen, ich denke vor allem an Felswände, Talgehänge, Gräte, Gendarmen, Felsriegel usw., müßten - nach der Messung der Klüfte - zur Bestimmung der Oberfläche nochmals dieselben Flächen herangezogen werden. Zudem wird ein Übergang von der Kleinform, wie sie der Rundhöcker darstellt, zu den eben aufgezählten Großformen nicht leicht sein. In größern Bereichen wären bereits petrographische Differenzen (Gänge, Resorptionsschollen, Ruschelzonen) zu berücksichtigen.

Ich kann mir jedoch vorstellen, daß für ausgedehntere Studienobjekte, um der ersten Einschränkung zu begegnen, mit Erfolg großmaßstäbige Isohypsenkarten und morphometrische Arbeitsweisen die Feldaufnahmen weitgehend ersetzen könnten. Ein zweimaliges Vermessen der gleichen Flächen würde dadurch vermieden. Neben der Kluftmessung hätten statistische Aufnahmen über mittlere Kluftabstände, mittlere Größe der oberflächenbildenden Klüfte aller Systeme und andere Feldbeobachtungen die morphometrische Arbeitsweise selbstverständlich zu ergänzen.

\section{E. Anhang}

\section{ZUSAMMENSTELLUNG VON FACHAUSDRÜCKEN}

Um dem Leser ein mühsames Suchen wenig geläufiger Ausdrücke zu ersparen, wurde diese Zusammenstellung beigegeben. Sie enthält außer den für diese Arbeit neu geschaffenen Begriffen einige bekannte Fachwörter aus Geologie, Geomorphologie und Mathematik, die hier immer wieder gebraucht werden.

Die mit ${ }^{*}$ bezeichneten Ausdrücke sind in der Zusammenstellung selber erklärt. Achsen: Siehe Rundhöcker-Achsen*.

Achsenverhältnis: Quotient $\mathrm{c}$ aus den Rundhöckerachsen* a und b ( $\mathrm{c}=\mathrm{a}: \mathrm{b})$. Anomalen-Bild: Siehe Rundhöcker-Anomalen*.

Arbeitsnetz: Flächentreue, äquatorständige Azimutalprojektion der obern Hälfte der Lagekugel *.

64 Einige Arbeiten vergleichen die aus Petrographie und Gefügekunde gewonnenen und in dieser Art dargestellten Ergebnisse mit morphologischen Erscheinungen [BEHRENS (2); LARSSON (29) ]. Die morphologischen Eigenschaften werden in diesen Fällen durch eingehende Beobachtungen erfaßt, in Typen zusammengestellt und den oben gewonnenen Darstellungen zugeordnet.

Andere Arbeiten [Dylikowa (15); Jewtuchowicz (27)] stellen Eigenschaften glazialer Akkumulationsformen in der besprochenen Weise dar und ordnen sie den Richtungen der Bildungsvorgänge $\mathrm{zu}$. 
Diagramm: Nach Prozentwerten ausgezähltes und in Isolinien dargestelltes Lotbild* von Klüften oder Oberfächen-Polen*.

Einzel-Korrelation: Anwendung der Korrelationsrechnung* auf einen einzigen Rundhöcker.

Fallen: Winkel zwischen Horizontalebene und Fall-Linie einer zu beschreibenden Ebene (Kluftfläche, Schichtfläche, Tangentialfläche an Rundhöcker).

Flächen-Charakteristik: 4-stufige Angabe über die Beschaffenheit der Rundhöckeroberfläche (wurde jeder Oberflächen-Messung* beigegeben).

Flächen-Index: Mit $f$ bezeichnete Größe, die Rundung bzw. Politur und Bruchflächen (Klüfte/Ausbrüche) miteinander in Beziehung setzt. Große f: Rundliche, glatte Rundhöcker.

Gesamt-Korrelation: Anwendung der Korrelationsmethoden auf ein Rundhöcker-Sammeldiagramm*

Graphische Totalkorrelation: Vergleich von Konvergenzen und Divergenzen in 2 vollständigen Diagrammen* (Oberfläche + Klüfte).

Hauptspant: Scheitellinie eines Rundhöckers'(siehe Abb. 9).

Ideal-Rundhöcker: Fiktiver Rundhöcker in Form einer Halbkugel (K) oder eines Rotationsellipsoides (E) mit dem Achsenverhältnis 1:1,6 (= Mittelwert um Totensee).

Klüfte: Siehe Definition p. 1.

Kluft-Diagramm: Siehe Diagramm*.

Kluftrose, Kluftstern (auch Sprungrose): Nach Prozentwerten in Polarkoordinaten dargestellte Streichrichtungen* der Klüfte.

Korrelationskoeffizient: Mit $\mathrm{r}$ bezeichnete Größe zwisch -1 und +1 , die das Maß der Korrelation * angibt.

Korrelationsrechnung: Statistische Methode zur Untersuchung der Abhängigkeit in der Verteilung zweier Merkmale.

Lagekugel: Fiktive Kugel mit Gradnetz zur Darstellung der Kluftlage.

Lee-Seite: Dem Eisstrom abgekehrte Seite eines Rundhöckers.

Lot: Normale auf eine ins Zentrum der Lagekugel* verschobene Kluftfläche oder Tangentialfläche an einen Rundhöcker, errichtet im Zentrum der Kugel.

Lot-Bild: Darstellung der Polverteilung einer Kluftgesamtheit (bzw. Rundhöckeroberfläche) im Arbeitsnetz*.

Luv-Seite: Dem Eisstrom zugewandte Seite eines Rundhöckers.

Mathematische Partialkorrelation: Anwendung der Korrelationsrechnung* auf zwei den morphologischen Gegebenheiten angepaßte Lot-Bilder* (Oberfläche + Klüfte).

Oberfï̈chen-Diagramm: Siehe Diagramm*.

Oberflächen-Meßpunkt: Durch das Rundhöcker-Netz* auf dem Rundhöcker festgelegte Meß-Stelle ( $Z, \mathrm{~L}$ oder R).

Oberfächen-Messung: Bestimmung von Streichen* und Fallen* der Tangentialfläche der Rundhöcker in den Oberflächen-Meßpunkten*.

Pol: Durchstoßpunkte des Lotes* durch die obere Hälfte der Lagekugel *.

Regressionsgerade: Gerade, die in einem rechtwinkligen Koordinatennetz eine Punktverteilung möglichst genau wiedergibt.

Rundhöcker, Roches-moutonnées: Siehe Definition p. 15.

Rundhöcker-Achsen: Den Ellipsen-Hauptachsen a und b entsprechende Strecken des Rundhöcker-Grundrisses.

Rundhöcker-Anomalen: Darstellung bedeutungsvoller Divergenzen aus der graphischen Total-Korrelation*.

Rundhöcker-Flur: Von einer nach Genese und Lage zusammengehörenden Rundhökkergruppe besetztes Gebiet. 
Rundhöcker-Netz: Gesamtheit der zur Bestimmung der Oberflächen-Meßpunkte* eines Rundhöckers dienenden Strecken.

Rundhöcker-Sammeldiagramm: Lotbilder* mehrerer Rundhöcker in einem einzigen Diagramm* dargestellt.

Spanten: Schnittlinien der Rundhöcker-Oberfläche mit einer zur großen RundhöckerAchse* normalen Ebene (siehe Abb. 9).

Stoßseite: Siehe Luv-Seite*

Streichen: Winkel zwischen der Nordrichtung und einer horizontalen Geraden in einer zu bezeichnenden Ebene (Kluftfläche, Schichtfläche oder Tangentialebene an Rundhöcker).

\section{LITERATURVERZEICHNIS}

1. АмвӥнL, E.: Die Gotthardstraße. Schweizer Alnenposten, 1951.

2. Behrens, S. E.: Morphometrische, morphogenetische und tektonische Studien. Lund studies in Geography, Ser. A. Physical Geography, No. 5, 1953.

3. Beringer, C. Ch.: Geologisches Wörterbuch. Stuttgart 1951.

4. Billings, M. P.: Structural Geology. New York 1954.

5. BOESCH, H. H.: Roches moutonnées - Rundhöcker. Vierteljahresschrift der Naturforschenden Gesellschaft in Zürich, XCVI, 1951.

6. BubNoff von, S.: Methoden der Granitmessung und ihre bisherigen Ergebnisse. Geol. Rundschau, Bd. XIII, 1922.

7. Bubnoff von, S.: Über die Druckrichtung im Granit von Heidelberg. Jahresber. und Mitt. d. Oberrheinischen Geol. Vereins, Bd. XI, 1922.

8. BUCHER, H. W.: The mecanical interpretation of joints. The Journ. of Geol., XXVIII, 1920.

9. CADISCH, J.: Geologie der Schweizeralpen. Basel 1953.

10. Carol, H.: Beschreibung einer Gruppe von Gletscherrandklüften am Obern Grindelwaldgletscher. Mitt. d. Geographisch-Ethnographischen Gesellschaft in Zürich, Bd. XLII, 1943/45.

11. Carol, H.: Beobachtungen zur Entstehung der Rundhöcker. Die Alpen, Heft 6, 1943.

12. Cloos, H.: Einführung in die tektonische Behandlung magmatischer Erscheinungen. Berlin 1925.

13. Cloos, H.: Einführung in die Geologie. Berlin 1936.

14. Daubree, A.: Synthetische Studien zur Experimentalgeologie. Deutsche Übersetzung v. A. Gurtl. Braunschweig 1880 (nach Müller [36]).

15. Dylikowa, A.: De la méthode structurale dans la morphologie glaciaire. Bulletin de la Société des Sciences et des Lettres de Lodoz, 1952.

16. Edelmann, N.: Glacial abrasion and ice movement in the area of Rosala-Nötö, SW Finland. Bulletin de la Commission Géologique de Finlande, No. 154, 1951.

17. Fisher, R. A.: Statistical Methods for Research Workers. London 1948.

18. FlǘcKIGER, O.: Glaziale Felsformen. Ergänzungsheft zu Petermanns Mitteilungen, No. 218, 1924.

19. Fueter, R.: Das Mathematische Werkzeug des Chemikers, Biologen, Statistikers und Soziologen. Zürich 1947.

2o. Heim, A.: Handbuch der Gletscherkunde. Stuttgart 1885.

21. Heim, A.: Geologie der Schweiz. Leipzig 1919.

22. Hess, O.: Die Oberflächenformen des Trienttales (Wallis). Diss. Universität Zürich, 1935.

23. Hӧсвом, I.: Der Berg Luppio. Eine Studie über Klüftung und Glazialskulptur. Bulletin of the Geological Instit. of the University of Upsala, Vol. XIX, 1925.

24. HUGr, E.: Die Grimselstraße. Schweiz. Alpenposten, 1951.

25. HUGI, F. J.: Naturhistorische Alpenreise. Solothurn 183o (nach Boesch).

26. ЈАКов, J.: Die Grundlagen unserer naturwissenschaftlichen Erkenntnis. Zürich 1948.

27. Jewtuchowicz, S.: La structure du Sandre. Bulletin de la Société des Sciences et des Lettres de Lodoz, 1953.

28. Klebelsberg von, R.: Handbuch der Gletscherkunde. Bd. I, Wien 1948.

29. Larsson, I.: Structure and Landscape in Western Blekinge, southeast Sweden. Lund studies in Geography, Ser. A. Physical Geography, No. 7, 1954.

3o. Lehmann, H.: Die Gesteinsklüfte des östl. Harzvorlandes. Geol. Archiv., Bd. 1, Heft 1, 1923.

31. Liechti, H.: Recherches pétrographiques et tectoniques dans la vallée de Göschenen (Canton d'Uri). Diss. Universität Bern, 1933. 
32. Linder, A.: Statistische Methoden für Naturwissenschafter, Mediziner und Ingenieure. Basel 1951.

33. LJungner, E.: Spaltentektonik und Morphologie der schwedischen Skagerrak-Küste. Upsala 1927-3o.

34. Mead, W. J.: Notes of the Mechanics of Geologic Structures. Journ. Geol. Bd. 28, 192o (nach Müller).

35. Minder, W.: Beiträge zur Petrographie des mittleren Aarmassivs. Diss. Universität Bern, 1932.

36. Müller, L.: Untersuchungen über statistische Kluftmessungen. Geologie und Bauwesen, Jahrg. 5, Heft 4, 1933.

37. Müllerried, F.: Klüfte, Harnische und Tektonik des Dinkelberges und des Basler Tafeljuras. Verh. Naturh. mediz. Ver. Heidelberg. N. F. Bd 15, 1922.

38. Niggli, P.: Die Mineralien der Schweiz. Bd. II, Basel 1940.

39. Panzer, W.: Talrichtung und Gesteinsklüftung. Petermanns Mitt., Heft 7/8, 1923.

4o. Penck, A.: Morphologie der Erdoberfläche. Stuttgart 1894.

41. Penck, A. und Brückner, E.: Die Alpen im Eiszeitalter. Bd. II und III, Leipzig 1909.

42. Quervain de, F. und Moos von, A.: Technische Gesteinskunde. Basel 1948.

43. RÜGER, L.: Einige Bemerkungen zur Darstellung tektonischer Elemente, insbesonders von Klüften und Harnischen. Sitz. Ber. der Heidelberger Akad. d. Wissenschaften. Math.-Naturw. Klasse. 1. Abhandl. 1928.

44. Salomon, W.: Die Bedeutung der Messung und der Kartierung von gemeinen Klüften und Harnischen. Zeitschr. der Deutschen Geolog. Gesellschaft 1911.

45. Sander, B.: Einführung in die Gefügekunde der geologischen Körper. Wien und Innsbruck 1948.

46. Saussure DE, H. B.: Voyages dans les Alpes. Neuchâtel 1786 (nach Boesch).

47. Schmid, W.: Tektonik und Verformungslehre. Berlin 1932.

48. Sederholm, J.: Weitere Mitteilungen über Bruchspalten mit besonderer Beziehung zur Geomorphologie Fennoskandias. Bull. Comm. Geol. Finlande, 1913.

49. Stieler, C.: Ein Beitrag zum Kapitel «Klüfte». Centralblatt für Min. u. Geol., 1922.

5o. Stiny, J.: Technische Gesteinskunde. Wien 1929.

51. Stiny, J.: Gesteinsklüfte und alpine Aufnahmegeologie. Jahrb. der Geol. Bundesanstalt Wien, 1925.

52. Stiny, J.: Einiges über Gesteinsklüfte und Geländeformen in der Reisseckgruppe (Kärnten). Zeitschr. f. Geomorphologie Bd. I, 1926.

53. StREIfF-BECKer, R.: Glacialerosion und Eisbewegung. Vierteljahrsschrift der Naturforschenden Gesellschaft in Zürich, LXXIX, 1934.

54. Streiff-Becker, R.: Über die Entstehung glazialer Felsformen. Vierteljahrsschrift der Naturforschenden Gesellschaft in Zürich, LXXXVI, 1941.

55. Swanson, C. O.: Notes of strain, stress and joints. The Journal of Geology, XXXV, 1927.

56. Teichert, G.: Die Klufttektonik der cambro-silurischen Schichtentafel Estlands. Geol. Rundschau 18, 1927.

57. Thiele, S.: Die Scherflächen. Neues Jahrb. f. Mineralogie, Beil. Bd. 73, Abt. B, 1934.

58. Thiele, S.: Nochmals die Scherflächen. Zentralblatt f. Mineralogie, Abt. B, No. 12, 1935.

59. Thiele, S.: Die tektonische Stellung von Klüften in Sedimenten. Schriften aus dem Paläontolog. Institut d. Univ. Kiel, Heft 5, 1935.

6o. Tuominen, O.: Zur Geographie einer Rapikivilandschaft. Fennia 78, No. 4, 1954.

61. Witzıg, J.: Über Schülerleistungen in der Stadt Zürich. Statistik der Stadt Zürich, Heft 5, 1943.

62. Woldstedt, P.: Das Eiszeitalter. Bd. I, Stuttgart 1954.

\section{KARTEN UND FLUGAUFNAHMEN}

\section{Topographische Karten}

Landeskarte der Schweiz, $1: 50000$

63. Blatt 265, Nufenenpaß.

64. Blatt 255, Sustenpaß.

Topographischer Atlas der Schweiz, $1: 50000$

65. Blatt 522, Berninapaß.

\section{Geologische Karten}

66. LÜтнI, H.: Petrographische Übersichtsskizze des Exkursionsgebietes zwischen Innertkirchen und Oberwald. Schweiz. Alpenposten, Bern 1950. 
67. Амвӥнц, E.: Geologische Karte des Gotthardgebietes, 1:125 ooo. Schweiz. Alpenposten, Bern 1951.

68. StaUb, R.:Tektonische Skizze Oberengadin-Bergell. Schweiz. Alpenposten, Bern 1950.

\section{Flugaufnahmen}

69. Kartenskizzen für Gebiet um Totensee auf Grund von Flugb. No. 618, Platten No. 2/336 vom 10. 9.41. Eidg. Landestopographie, Wabern-Bern.

\section{JOINTS ET ROCHES MOUTONNÉES*}

Ce travail a été exécuté dans le massif cristallin de l'Aar et du Gothard dans les Alpes suisses. Son objet est l'étude de l'interdépendance entre les surfaces des roches moutonnées et les systèmes de joints de la roche sous-jacente.

Tout d'abord, on a mesuré et représenté tous les joints dans les trois dimensions (Kluftrosen, Kluft-Lotbild, Kluft-Diagramm).

Les surfaces des roches moutonnées, divisées en éléments de surface équivalents par un «réseau de roche moutonnée» défini spécialement (cf. fig. 9), ont pu être représentées de la même manière (Rundhöcker-Lotbild, Rundhöcker-Diagramm).

Les résultats de ces deux phases de travail ont été finalement mis en relation par une corrélation mathématique et graphique (Mathematische-Partialkorrelation, Graphische Totalkorrelation). Des études semblables faites sur des corps idéaux ont donné des valeurs de comparaison (Ideal-Rundhöcker $\mathrm{K}$ et $\mathrm{E}=$ Kugel et Rotationsellipsoid).

Le calcul de corrélation mathématique donne les coefficients de corrélation $(=r)$. Ils se trouvent dans les tabelles 9 et 1o. Ceux-ci montrent une dépendance étonnante entre les joints et les surfaces des roches moutonnées. Les valeurs varient entre ${ }_{0} \mathrm{o}, 76$ et $-0,04$. Les moyennes sont $+0,26$ et $+0,23$, respectivement $+0,30$. Toutes les valeurs sont assurées avec une probabilité de $P=0,05$. Une comparaison avec les indices des surfaces $(=f)$ montre que les grandes valeurs de $\mathrm{f}$ et de $\mathrm{r}$ coïncident toujours. Ce résultat un peu inattendu prouve que les roches moutonnées arrondies et bien polies sont conditionnées par la présence des systèmes de joints.

La corrélation graphique a dévoilé la grande parenté des roches moutonnées dans les roches faillées de facon semblable, même lorsque la direction de l'écoulement de la glace est très différente (Gesamt-Korrelation). Il s'ensuit en outre que les joints presque horizontaux contribuent fortement à la formation de la surface des roches moutonnées (Rundhöcker-Anomalen), tandis que les systèmes fortement inclinés déterminent plutôt leur position relative.

* J'emploierai dans ce résumé l'expression «joint»comme équivalent de «Kluft», 《faille» ou «diaclase».

\section{ROCK JOINTS AND ROCHES MOUTONNÉES}

This study has been carried out in the crystalline zone of the Aar and Gothard massifs of the Swiss Alps. It endeavours to show the dependance between the surfaces of the roches moutonnées and their respective joint systems.

To this purpose the joints have been measured and represented in their three-dimensional position (Kluftrosen, Kluft-Lotbild, Kluft-Diagramm).

In the same manner the surfaces of the roches moutonnées have been rendered (Rundhökker-Lotbild, Rundhöcker-Diagramm). To achieve this the surfaces were divided into equal elements by means of a specially defined «net of roches moutonnées» (see Abb. 9).

Through graphic and mathematic correlations the results of these two procedures were then checked with regard to their reciprocal relations. (Mathematische Partialkorrelation, Graphische Totalkorrelation). Comparative values have been obtained by investigations with ideal bodies (Kugel- and Rotationsellipsoid = Idealrundhöcker $\mathrm{K}$ and $\mathrm{R}$, respectively).

The mathematical correlation produced correlation coefficients $(=\mathrm{r})$. They are shown in Tables 9 and 10. From these coefficients follows a surprisingly great dependance between joints and surfaces of roches moutonnées. The values vary from $+0,76$ to $-0,04$. The arithmetic means are $+0,26$ and $+0,23$ or $+0,30$. All results are tested on ground of a probability of $\mathrm{P}=0,05$. A comparison with the areal indexes $(=\mathrm{f})$ reveals a practically complete coincidence of large $r$ and $f$ values. This result was not expected but it proves that particularly wellpolished, «rounded» roches moutonnées are greatly determined by joints.

The graphic correlation proved an eminent similarity of roches moutonnées in equally jointed rock, and this even with very different directions of ice flow (Gesamt-Korrelation). It is indicated that especially joints of low dip are responsible for the surface configuration of roches moutonnées (Rundhöcker-Anomalen). Systems of high dip rather seem to influence their relative location. 